\title{
A Review on Nanofluids: Fabrication, Stability, and Thermophysical Properties
}

\author{
Naser Ali $\mathbb{D}^{1},{ }^{1,2}$ Joao A. Teixeira, ${ }^{1}$ and Abdulmajid Addali ${ }^{1}$ \\ ${ }^{1}$ School of Water, Energy and Environment (SWEE), Cranfield University, Cranfield, Bedfordshire MK430AL, UK \\ ${ }^{2}$ Nanotechnology and Advanced Materials Program, Energy and Building Research Center, Kuwait Institute for Scientific Research, \\ Safat, Kuwait City 13109, Kuwait \\ Correspondence should be addressed to Naser Ali; nmali@kisr.edu.kw
}

Received 10 January 2018; Accepted 21 March 2018; Published 4 June 2018

Academic Editor: Shiyun Xiong

Copyright (c) 2018 Naser Ali et al. This is an open access article distributed under the Creative Commons Attribution License, which permits unrestricted use, distribution, and reproduction in any medium, provided the original work is properly cited.

\begin{abstract}
Nanofluids have been receiving great attention in recent years due to their potential usage, not only as an enhanced thermophysical heat transfer fluid but also because of their great importance in applications such as drug delivery and oil recovery. Nevertheless, there are some challenges that need to be solved before nanofluids can become commercially acceptable. The main challenges of nanofluids are their stability and operational performance. Nanofluids stability is significantly important in order to maintain their thermophysical properties after fabrication for a long period of time. Therefore, enhancing nanofluids stability and understanding nanofluid behaviour are part of the chain needed to commercialise such type of advanced fluids. In this context, the aim of this article is to summarise the current progress on the study of nanofluids, such as the fabrication procedures, stability evaluation mechanism, stability enhancement procedures, nanofluids thermophysical properties, and current commercialisation challenges. Finally, the article identifies some possible opportunities for future research that can bridge the gap between in-lab research and commercialisation of nanofluids.
\end{abstract}

\section{Introduction}

Fluids of different types are usually used as heat carriers in heat transfer applications. Such applications where heat transfer fluids (HTF) have an important role are heat exchanging systems in power stations [1], cooling and heating systems in buildings [2], vehicles air conditioning (AC) system in transportations [3], and cooling systems of most of the processing plants [4]. In all of the aforementioned applications, the HTF's thermal conductivity has a strong influence on the efficiency of the heat transfer process and with it the overall efficiency of the system. For such reason, researchers have continuously worked on developing advanced HTFs that have significantly higher thermal conductivities than conventionally used fluids [5].

Considerable efforts were made on heat transfer enhancement through geometrical modification up to now [6] but were all constrained by the low thermal conductivity of the heat transfer fluids used. However, in 1995, Choi developed a newly innovative class of heat transfer fluids that depends on suspending nanoscale particles of metallic origin with an average particle size of less than $100 \mathrm{~nm}$ into conventional heat transfer fluids and gave such type of fluids the term "nanofluids" [5]. In other words, the term nanofluid is used to describe a mixture containing nanoscale particles of average size less than $100 \mathrm{~nm}$ with any basefluid that does not dissolve the particles hosted by it.

The idea of dispersing solids in fluids was first proposed by Maxwell via his theoretical work more than 120 years ago [7]. It was later used to disperse $\mathrm{mm}$ and/or $\mu \mathrm{m}$ sized particles in fluids by Ahuja in 1975, Liu et al. in 1988, and researchers at Argonne National Laboratory (ANL) in 1992 [8-12]. Their work depended on the high thermal conductivity of metals at room temperature compared to fluids (i.e., order of magnitude higher in thermal conductivity). For instance, at room temperature, copper has a thermal conductivity 3000 and 700 times greater than that of an engine oil and water, respectively. The same difference in thermal conductivity cohabits between liquids, since metallic liquids have much higher thermal conductivity than nonmetallic ones. Figure 1 


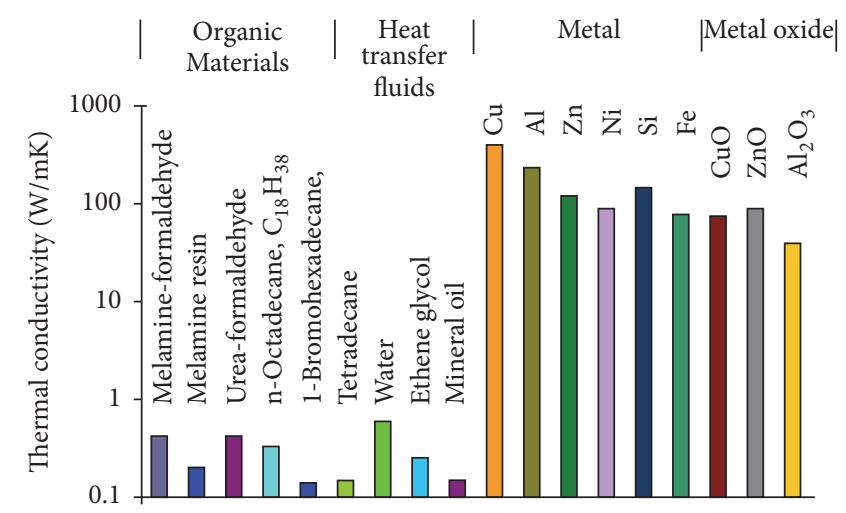

FIGURE 1: Thermal conductivity comparison of common polymers, liquids, and solids [64].

illustrates the thermal conductivities of different organic materials, heat transfer fluids, metals, and metal oxides. Therefore, by suspending metallic particles in a fluid, its thermal conductivity is expected to be enhanced.

One of the problems that arises from using fluids containing $\mu \mathrm{m}$ sized particles is the clogging of small passages caused from the large agglomeration of the solid particles, making it therefore hard to employ in heat transfer equipment fitted with small passages. On the other hand, nanofluids are believed to surpass such obstacle due to containing small enough particle size which can flow smoothly through such channels (i.e., they will not block flow passages). Another advantage of using nanoparticles is that they have an extremely large surface area over which the heat transfer mechanism between the particle and its surrounding takes place. For such reason, decreasing the size of particles from $\mathrm{mm}$ and $\mu \mathrm{m}$ down to $\mathrm{nm}$ would extremely largen the surface area and with it the enhancement in heat transfer. In the year 2000, Xuan and $\mathrm{Li}$ redefined the term nanofluids to include any nanoscaled particles of metallic, nonmetallic, and polymeric origin mixed with a noncarcinogenic basefluid [12]. They also stated that the effective thermal conductivity can be increased by more than $20 \%$ by adding concentration of nanoparticle as low as $1-5 \mathrm{vol} \%$ to the basefluid and that the enhancement gets affected strongly by the particles shape, particle dimensions, added volume fractions in the basefluid, particles thermophysical properties, and so forth. The term "effective" was introduced to describe the thermophysical property of nanofluids and to differ between the thermophysical properties of the basefluid itself and the newly formed fluid that consists of the basefluid and its dispersed nanoparticles [13]. Figure 2 highlights the main parameters that influence the effective thermal conductivity of any nanofluid.

Factors to be considered when selecting nanomaterials on preparing nanofluids for heat transfer applications are (i) chemical stability, (ii) thermophysical properties, (iii) toxicity, (iv) availability, (v) compatibility with the basefluid, and (vi) cost. The most commonly used nanoparticles for nanofluids formulation are aluminium $(\mathrm{Al})$, copper $(\mathrm{Cu})$, silver $(\mathrm{Ag})$, iron $(\mathrm{Fe})$, titanium $(\mathrm{Ti})$, silicon $(\mathrm{Si})$, zinc $(\mathrm{Zn})$, magnesium (Mg), carbon nanotubes (CNTs), graphene, graphene oxide, and diamond. Commonly used basefluids for nanofluid formulation are water, ethylene glycol (EG), EG $\mathrm{H}_{2} \mathrm{O}$ mixtures, and oils [63].

Several researchers have reported scale formation, also known as "fouling effect," on the surfaces when using nanofluids in applications at elevated temperature such as the inside of the annulus of heat exchangers [83-89]. This fouling effect acts similarly to surface nanocoating due to its nature of formation which is based on nanoparticles and can be effective in reducing the pressure losses caused by the high viscosity of nanofluids compared to their basefluid. This happens since the layer formed tends to smoothen the surface as illustrated in Figures 3(a) and 3(b).

Kang et al. demonstrated in their work how coating a riser surface with nanoparticles reduced the pumping power and improved the system efficiency by $25 \%$ [66]. This is because coating the riser surface has affected the contact angle between the fluid and the surface, making it more hydrophobic to the liquid in contact to it. Figure 4 demonstrates the relation between the surface contact angle and fluid. Ali et al. [65] also confirmed the changes in surface wettability behaviour caused from nanocoating, where they deposited $\mathrm{Al}$ particles on the surface of an $\mathrm{Al}$ substrate and then examined the film thickness, fluid $\mathrm{pH}$ value, and fluid temperature effects on the fluid-surface contact angle. Their findings showed that water of $\mathrm{pH}$ values above and below 7 tends to develop higher contact angles as the deposited layer thickness and fluid temperature increased, in contrast to water of neutral $\mathrm{pH}$ which showed the opposite behaviour.

Nanofluids fouling effect can also increase or decrease the nucleation boiling heat transfer depending on the surface/liquid contact angle as demonstrated by Phan et al., where they showed in their work that the highest heat transfer coefficient was obtained at a contact angle close to either $90^{\circ}$ or $0^{\circ}[90]$.

Besides to using nanofluid as a HTF in heat transfer applications, which was the main reason behind the development of such category of fluid, it is also used in, for example, sunscreen products [91], medicine [92, 93], reducing buildings pollution [94], magnetic sealing [95], microbial fuel cells [96], antibacterial activity, and many other applications [97]. 


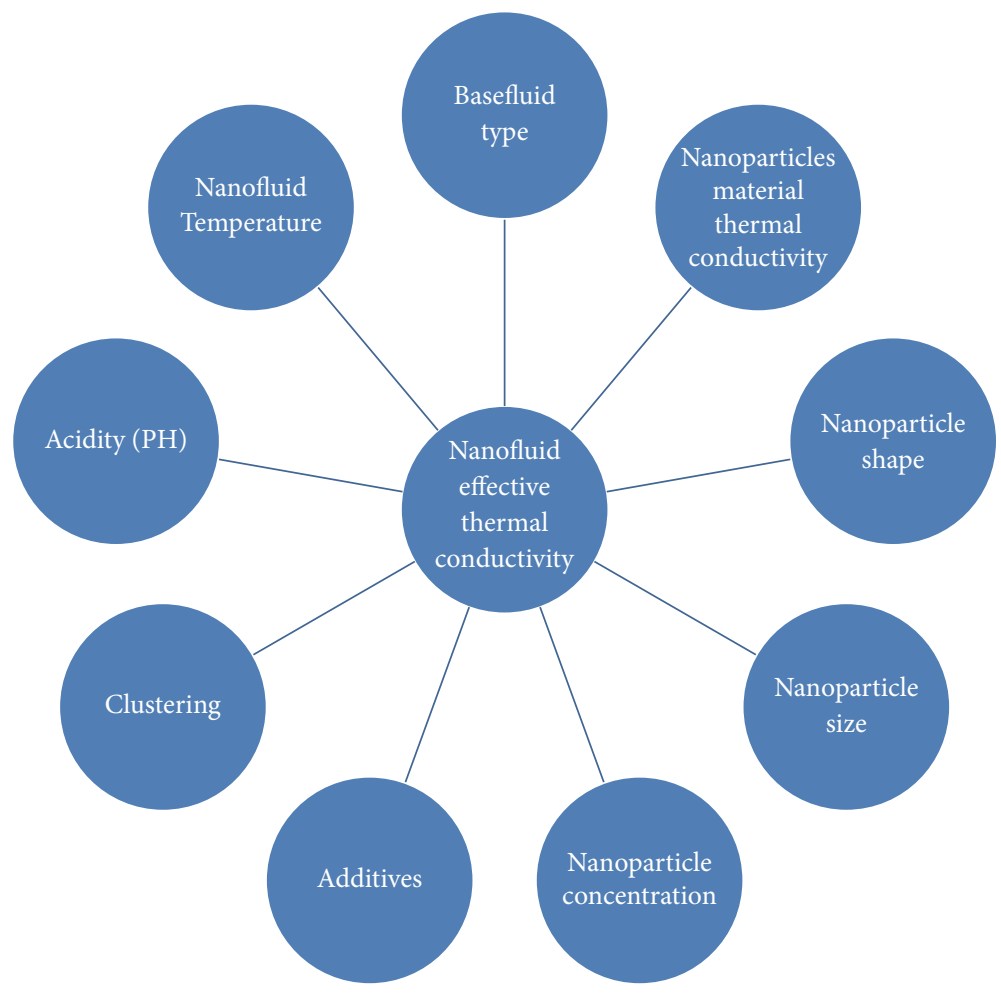

Figure 2: Parameters influencing nanofluids effective thermal conductivity.

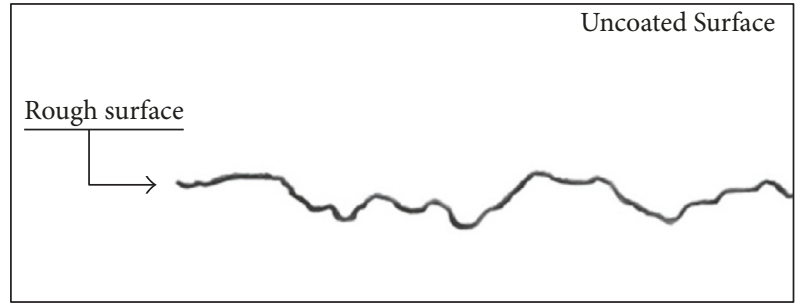

(a)

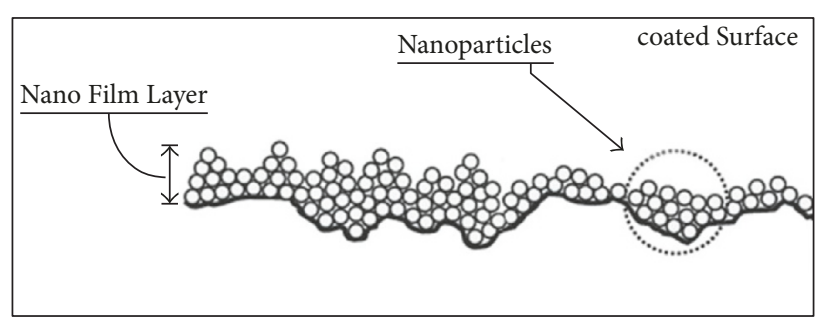

(b)

FIGURE 3: (a) Rough surface and (b) nanocoated surface or nanofouled surface [65].

Data obtained from the Scopus database from 1995 to 2018 showed an exponential increase in the number of documents with the word "nanofluids" as part of the title as seen in Figure 5, except for the year 2018 which is most likely to change with the upcoming data to the website [98]. Most of the documents reported are in the form of journal papers as shown in Figure 6.

\section{Types of Nanofluids}

Nanofluid, which is a term used to describe fluids containing dispersed particles of nanoscale, can be formed from nanoparticles of single element (e.g., $\mathrm{Cu}, \mathrm{Fe}$, and $\mathrm{Ag}$ ), single element oxide (e.g., $\mathrm{CuO}, \mathrm{Cu}_{2} \mathrm{O}, \mathrm{Al}_{2} \mathrm{O}_{3}$, and $\mathrm{TiO}_{2}$,), alloys (e.g., $\mathrm{Cu}-\mathrm{Zn}, \mathrm{Fe}-\mathrm{Ni}$, and $\mathrm{Ag}-\mathrm{Cu}$ ), multielement oxides (e.g., $\mathrm{CuZnFe}{ }_{4} \mathrm{O}_{4}, \mathrm{NiFe}_{2} \mathrm{O}_{4}$, and $\mathrm{ZnFe}_{2} \mathrm{O}_{4}$ ), metal carbides (e.g., $\mathrm{SiC}, \mathrm{B}_{4} \mathrm{C}$, and $\mathrm{ZrC}$ ), metal nitrides (e.g., $\mathrm{SiN}, \mathrm{TiN}$, and $\mathrm{AlN}$ ), and carbon materials (e.g., graphite, carbon nanotubes, and diamond) suspended in water, ethanol, EG, oil, and refrigerants $[82,99,100]$. They can be classified into two main categories: single material nanofluids and hybrid nanofluids.

2.1. Single Material Nanofluids. This category of nanofluid was first proposed by Choi, in 1995, and is considered as the conventional form of nanofluids used, where a single type of nanoparticles is used to produce the suspension via different preparation methods [5]. It was reported by many authors that nanofluids of such category are superior in performance, due to having much more favourable thermophysical properties than their basefluid [51, 101-104].

2.2. Hybrid Nanofluids. Hybrid nanofluids are an advanced category of nanofluids which are made of a combination of more than one type of nanoparticles suspended in a basefluid. This type of fluids was first studied experimentally by Jana et al., in 2007, in order to enhance the fluid thermal conductivity 
Based on the contact angle, the surface is called:

$(1) \Theta<90^{\circ}$ Hydrophilic;

(2) $\Theta>90^{\circ}$ Hydrophobic; and

(3) $\Theta>150^{\circ}$ Super-Hydrophobic

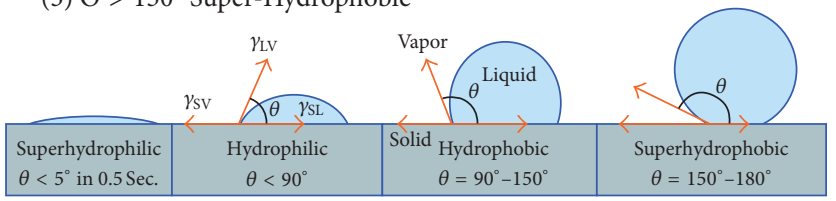

FIGURE 4: Relation between surface contact angle and fluids $[66,67]$.

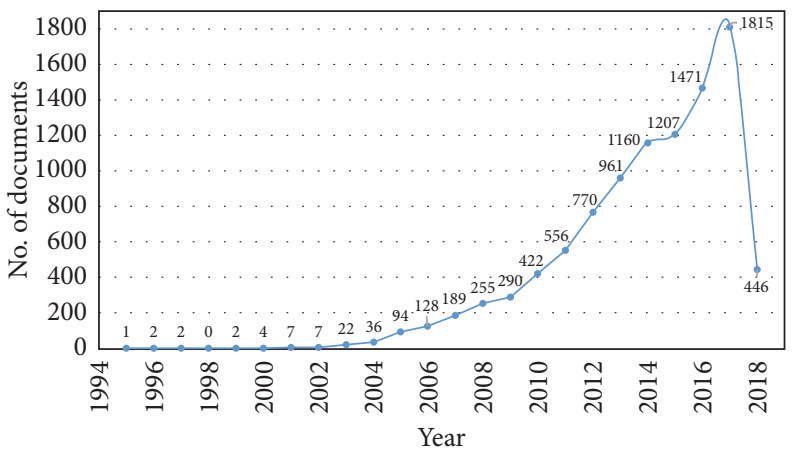

FIGURE 5: Number of documents with the word nanofluids in the title.

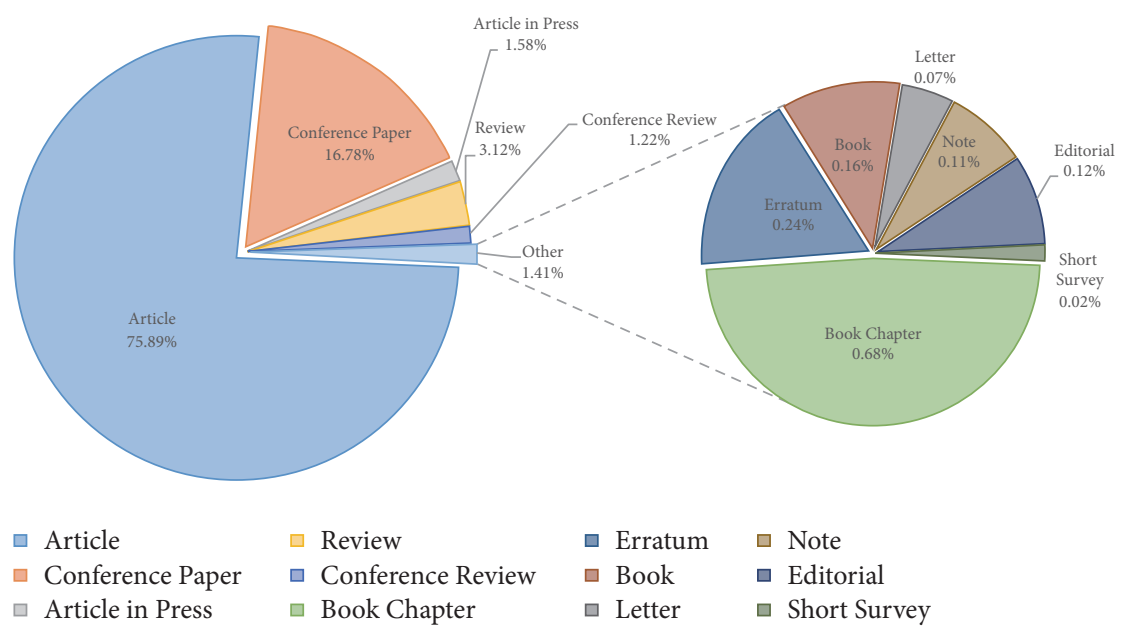

FIgURE 6: Percentage of available document types.

beyond that of a conventional single material type nanofluid [105]. In their study, $\mathrm{Cu}$ nanoparticles, carbon nanotubes (CNTs), and $\mathrm{Au}$ nanoparticles dispersed in water, as well as their hybrids $\left(\mathrm{CNT}-\mathrm{Cu} / \mathrm{H}_{2} \mathrm{O}\right.$ and $\left.\mathrm{CNT}-\mathrm{Au} / \mathrm{H}_{2} \mathrm{O}\right)$ were examined. The results showed that the thermal conductivity of $\mathrm{Cu} / \mathrm{H}_{2} \mathrm{O}$ nanofluid was the highest among the tested samples and increased linearly with the rise of particle concentration. Nevertheless, the stability of the $\mathrm{CNT}-\mathrm{Cu} / \mathrm{H}_{2} \mathrm{O}$ nanofluid achieved longer settling time than the other types of nanofluids. This enables the fluid to conserve its thermal conductivity much longer before degrading.

\section{Preparation of Nanofluids}

Uniformity of the particle dispersion depends mainly on the preparation method used and can have a significant effect on the thermophysical properties of the nanofluid. Meaning that if two similar nanofluids were to be prepared using different preparation methods, their thermophysical properties and tendency to agglomeration are most likely to vary from each other. This is because nanofluids are not simply formed from a solid-liquid mixture but requires special conditions to be present in the suspension such as homogeneity, physical and chemical stability, durability, and dispersibility. There are mainly two techniques used to fabricate nanofluids, namely, the bottom-up approach known as the one-step method and the top-down approach identified as the two-step method [106].

3.1. Single-Step Approach. The single-step approach relies on combining the production and dispersion processes of nanoparticles into the basefluid via a single step. There are 


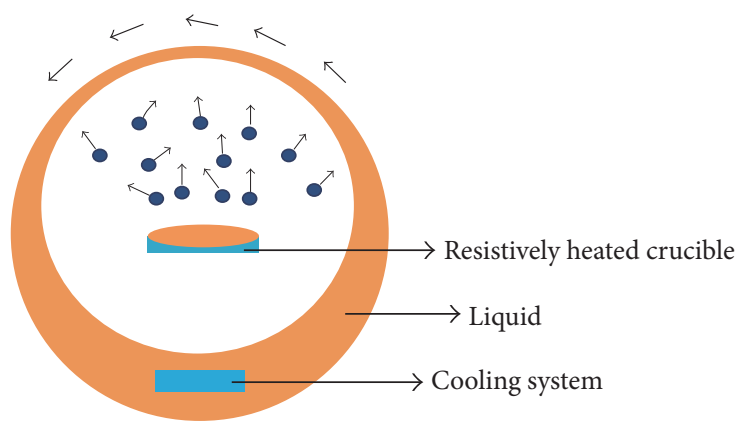

Figure 7: Preparation of nanofluid using one-step vapour deposition method [23].

some differences in this procedure. One of the commonly used methods for synthesising nanofluids, known as the direct evaporation one-step approach, depends on solidifying nanoparticles that are originally in gaseous phase inside the basefluid itself. The method was developed by Akoh et al. [107] and was named the Vacuum Evaporation onto a Running Oil Substrate (VEROS) method. The initial idea of this method was to produce nanoparticles but was found to be extremely difficult to obtain a dry form of nanoparticles from the produced fluid mixture. Wagener et al. [108] proposed a modified VEROS process, where they used high pressure magnetron sputtering to synthesis dispersions containing Fe and Ag nanoparticles. Eastman et al. [109] also developed a modified VEROS process, where they directly condensed $\mathrm{Cu}$ vapor with a flowing low-vapor-pressure EG to fabricate their $\mathrm{Cu} / \mathrm{EG}$ nanofluid. Zhu et al. [110] employed a one-step approach, through chemical reaction, to obtain $\mathrm{Cu}$ nanofluid. In their work $\mathrm{NaH}_{2} \mathrm{PO}_{2} \cdot \mathrm{H}_{2} \mathrm{O}$ with $\mathrm{CuSO}_{4} \cdot 5 \mathrm{H}_{2} \mathrm{O}$ in EG was irradiated to chemically react into producing the nanofluid. In addition, Tran and Soong [111] used a laser ablation onestep method to synthesise $\mathrm{Al}_{2} \mathrm{O}_{3}$ nanofluid. Another onestep approach also exists $[112,113]$, with all being favourable in minimizing the agglomeration of nanoparticles in the basefluid. However, the downside of using the one-step approach is the presence of contaminations that are difficult to dispose of [106]. Figure 7 shows a sample of the one-step approach used to prepare nanofluids by vapour deposition.

3.2. Two-Step Approach. In this approach, nanoparticles are initially produced or purchased in the form of dry powder and then dispersed in the basefluid. The commonly employed equipment for dispersing nanoparticles in the basefluid is magnetic stirrers, ultrasonic bath, homogenizers, high-shear mixers, and bead mills. Unlike the one-step approach, the two-step approach is more commonly used to fabricate nanofluids due to having a lower processing cost and a wide availability of commercially supplied nanoparticles by several companies. Figure 8 demonstrates an example of the schematic procedure of the two-step approach used for synthesising nanofluid.

Eastman et al. [109], Wang and Xu [114], and Lee et al. [115] adopted this approach to form their $\mathrm{Al}_{2} \mathrm{O}_{3}$ nanofluids. Murshed et al. [116] synthesised $\mathrm{TiO}_{2} / \mathrm{H}_{2} \mathrm{O}$ nanofluid via the same route. Xuan and $\mathrm{Li}$ [12] used as-received $\mathrm{Cu}$ nanoparticles to produce transformer oil based and water based nanofluids.
Single-walled and multiwalled carbon nanotubes were also reported to be used with or without adding surfactants for preparing nanofluids using the two-step method $[56,56,117-$ 120].

Some researchers claim that the two-step process is preferable for forming nanofluids containing oxide nanoparticles, while it is less effective toward nanoparticles of metallic origin [121]. The main disadvantage of the two-step approach is the large aggregation of particles that accompanies the process compared to the one-step method. Despite such disadvantages, this process is still the most popular route for producing nanofluids of large or small quantities and can be used to synthesise almost any kind of nanofluids [23].

\section{Stability of Nanofluids}

Part of the challenges that faces commercialising nanofluids is their poor stability due to the interaction between the particles themselves and between the particles and the surrounding liquid [26]. This kind of behaviour can be linked to two opposing forces: (1) the well-known Van der Waals attractive forces on the particles surface which causes the particles to be attracted to each other into forming clusters or agglomerations of particles and then separate from the basefluid and settle at the bottom due to gravitational force and (2) the electrical double layer repulsive force which tends to separate the particles from each other via steric and electrostatic repulsion mechanisms [122-124]. Figure 9 shows the steric and electrostatic repulsion mechanisms. Stability is a very important element in commercialising nanofluids as it extends the shelf-life of the product while conserving its thermophysical properties. To obtain a stable nanofluid the electrical double layer repulsive force should surpass the Van der Waals attractive forces.

4.1. Stability Evaluation Methods. As previously mentioned, stability of nanofluids has a vital role in extending its shelflife and preserving the thermophysical properties of the fluid. Different evaluation methods for the stability of nanofluids were discussed by different researchers [125, 126]. These techniques are discussed below.

4.1.1. Zeta Potential Analysis. The zeta potential analysis evaluates the stability of nanofluids through the observation of electrophoretic behaviour of the fluid [127]. This is because 


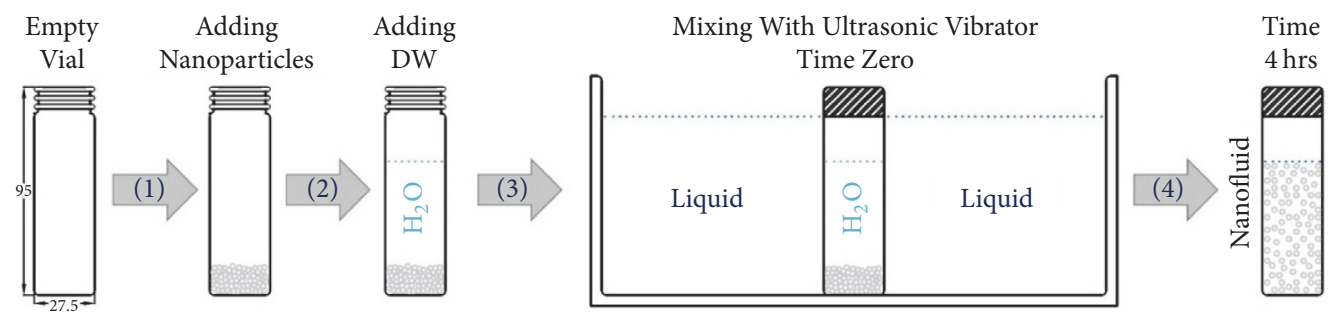

FIGURE 8: Schematic procedure of the two-step nanofluids preparation.

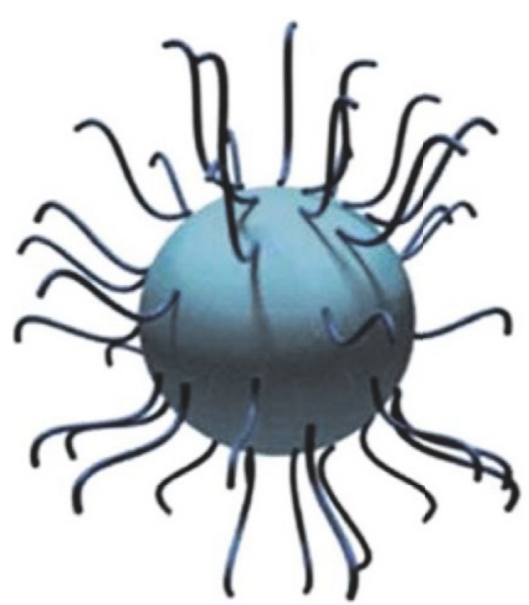

(a)

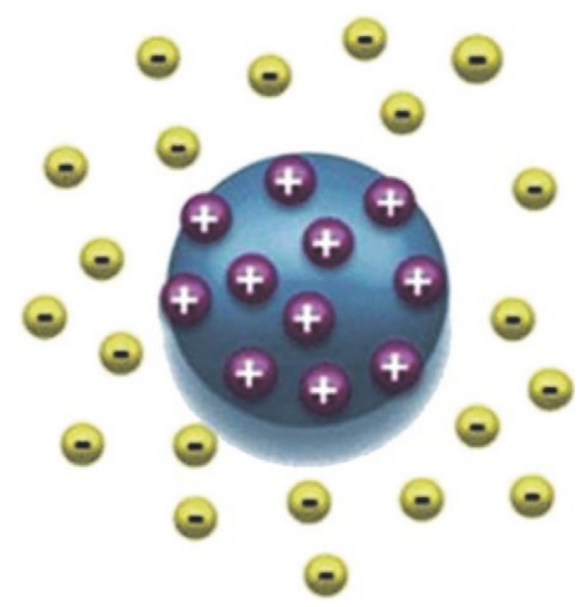

(b)

FIGURE 9: Repulsion mechanisms: (a) steric repulsion and (b) electrostatic repulsion [68].

the free charges in the basefluid get attracted to the opposite charges on the dispersed particles surface, causing the development of a layer of charged ions known as the stern layer. There is an additional layer that surrounds the formed stern layer, defined as the diffuse layer, which has its individual charges and is more diffusive. The zeta potential can be defined as the potential difference between the basefluid and the stern layer in contact to the dispersed particles as shown in Figure 10 and is measured in millivolts.

In any nanofluid, the zeta potential can be ranged from positive, at low $\mathrm{pH}$ values, to negative, at high $\mathrm{pH}$ values. In terms of nanofluid stability, zeta potential value $> \pm 60 \mathrm{mV}$ has excellent stability, \pm (40 to 60 ) $\mathrm{mV}$ has good stability, \pm (30 to 40 ) $\mathrm{mV}$ is considered stable, and $< \pm 30 \mathrm{mV}$ is highly agglomerative [125]. Measurement of the zeta potential value in a nanofluid can be performed using a Zeta Sizer Nano (ZSN) device [128].

Kim et al. [28] fabricated Au/water nanofluids, of particle size ranging from 7.1 to $12.11 \mathrm{~nm}$, without the addition of any dispersants and found out that the suspension remained outstandingly stable for up to 1 month. The stability of the nanofluids was characterised using the zeta potential analysis technique which showed a negative zeta potential values ranging from $-32.1 \pm 0.95(0.018 \mathrm{vol} \%)$ to $-38.5 \pm 1.84$ $(0.0025 \mathrm{vol} \%)$. Wang et al. [129] investigated the effect of different $\mathrm{pH}$ values and the variation of sodium dodecylbenzene sulfonate (SDBS) concentration on $\mathrm{Al}_{2} \mathrm{O}_{3} / \mathrm{H}_{2} \mathrm{O}$ and $\mathrm{Cu} / \mathrm{H}_{2} \mathrm{O}$ nanofluids stability. Nanoparticles of $0.05 \mathrm{wt} \%$ were employed in their zeta potential measurements of the two water based nanofluids. Their results indicated that in the region of $2.0<\mathrm{pH}<8.0$, the zeta potential value of alumina nanofluid was negatively higher than that of copper nanofluid sample at the same $\mathrm{pH}$ value, but in the region of $\mathrm{pH}>8.0$, $\mathrm{Cu} / \mathrm{H}_{2} \mathrm{O}$ nanofluid had shown better dispersion as the zeta potential value was higher than the $\mathrm{Al}_{2} \mathrm{O}_{3} / \mathrm{H}_{2} \mathrm{O}$ nanofluid at the same $\mathrm{pH}$ level. The maximum zeta potential values obtained were $-40.1 \mathrm{mV}$ for $\mathrm{Al}_{2} \mathrm{O}_{3} / \mathrm{H}_{2} \mathrm{O}$ and $-43.8 \mathrm{mV}$ for $\mathrm{Cu} / \mathrm{H}_{2} \mathrm{O}$. It was also reported that the addition of SDBS has improved the nanofluids dispersion, where the highest zeta potential value for alumina nanofluid, of $\mathrm{pH}=8.0$, was at SDBS $=0.1 \mathrm{wt} \%$ and the copper nanofluid, of $\mathrm{pH}=9.5$, was at SDBS $=0.07 \mathrm{wt} \%$. Mondragon et al. [70] examined the increase of silica nanoparticles mass fraction on the stability of silica-water nanofluids of different $\mathrm{pH}$ values. They concluded that raising the nanoparticles from $2 \%$ to $20 \%$ mass fraction has led to a reduction in the zeta potential value from $-48.63 \mathrm{mV}$ to $-16 \mathrm{mV}$ both at a $\mathrm{pH}$ of 10 , with a minimum achievable stability of $48 \mathrm{~h}$ for the $20 \%$ mass fraction. Researchers have reported the value of zeta potential of various types of nanofluids of water base, at different $\mathrm{pH}$ values and without the addition of any type of surfactant, as demonstrated in Figure 11.

4.1.2. Sedimentation Photograph Capturing Method. This method is considered to be one of the simplest approaches to measure the stability of nanofluids $[27,130]$. In this approach, 


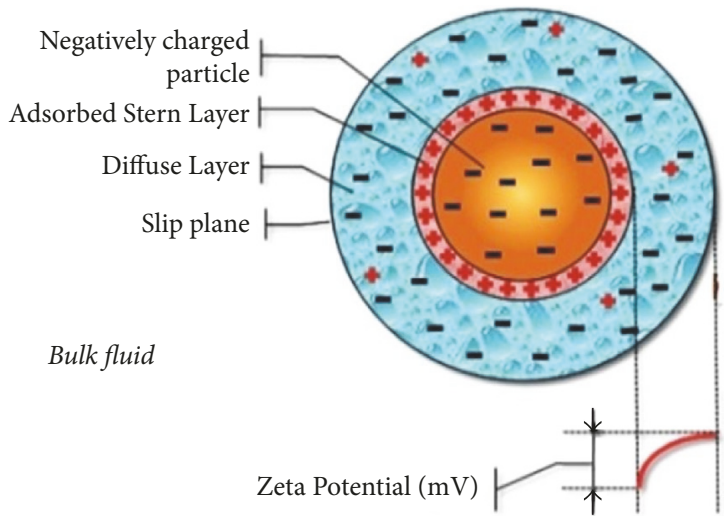

Figure 10: Zeta potential between the slip plane and stern layer of a nanoparticle [69].

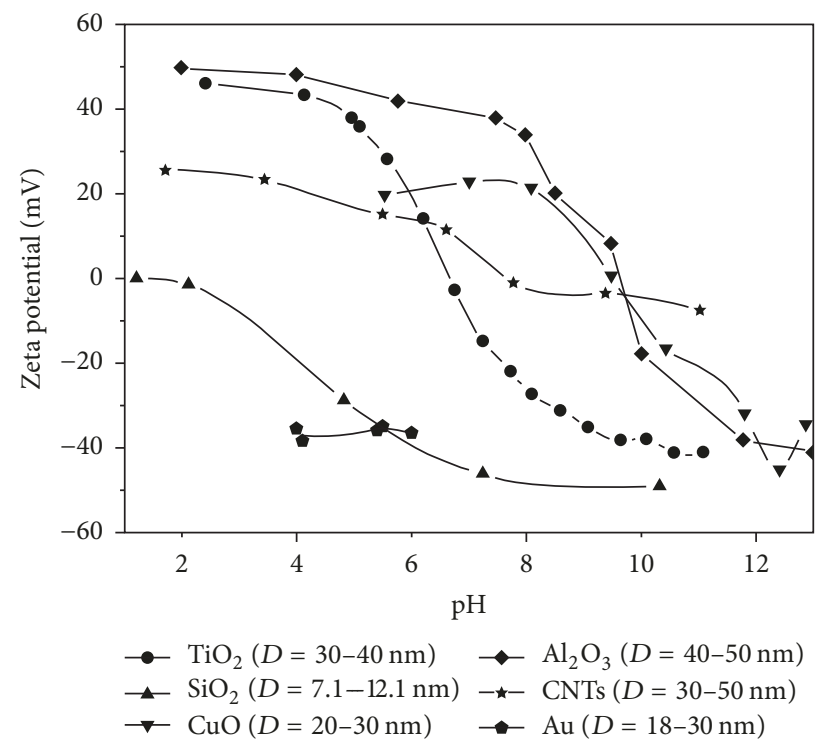

FIGURE 11: Zeta potential value as a function of $\mathrm{pH}$ for different nanoparticles dispersed in water [28, 33, 70-73].

the volume of the agglomerated nanoparticles in a nanofluid is monitored under an external force. This is done by placing a sample of the prepared nanofluid in a transparent glass vial; then the formation of sediments is observed via capturing photographs of the vial at equal intervals of time using a camera [131]. The captured images are then compared to each other to analyse the stability of the nanofluid. Thus, the characterised nanofluid is considered to be stable when the particles size and its dispersity remain constant with time (i.e., no sedimentation occurs).

Three behaviours of sedimentation can be observed in any unstable nanofluid: (1) dispersed sedimentation, where the sediment height is gradually increased from the bottom as the solution clarifies; (2) flocculated sedimentation, where the sediment height reduces with respect of time; and (3) mixed sedimentation, where both previous phenomena occur simultaneously in a nanofluid [132]. Figure 12 illustrates the three sedimentation behaviours.

Xian-Ju and Xin-Fang [133] investigated the $\mathrm{pH}$ value influence on alumina-water and copper-water nanofluids stability, at similar wt $\%$. Commercial $\mathrm{Al}_{2} \mathrm{O}_{3}$, of $15-50 \mathrm{~nm}$ particle size, and $\mathrm{Cu}$, of $25-60 \mathrm{~nm}$ particle size, nanoparticle were used at a wt $\%$ between $0.01 \%$ and $0.9 \%$ in their two-step fabrication process. Sedimentation photograph capturing method was adopted, for a period of 7 days, to determine the samples stability. Their results showed that the highest nanoparticles dispersion can be obtained at a $\mathrm{pH}$ of 8.0 and 9.5, for $\mathrm{Al}_{2} \mathrm{O}_{3} / \mathrm{H}_{2} \mathrm{O}$ and $\mathrm{Cu} / \mathrm{H}_{2} \mathrm{O}$ nanofluids, respectively. Angayarkanni and Philip [134] have studied the stability of $\gamma-\mathrm{Al}_{2} \mathrm{O}_{3}(13 \mathrm{~nm})$ and $\alpha-\mathrm{Al}_{2} \mathrm{O}_{3}(24.4 \mathrm{~nm})$ water based nanofluids at a vol\% ranging from 0.5 vol\% to 6.0 vol\%. Four time intervals were captured to analyse the stability of their nanofluids, specifically, at time of $0,3,30$, and $172 \mathrm{~h}$. From analysing the images, they noticed that up to $3 \mathrm{~h}$ there was minimum phase separation for both types of nanofluids, and at time $>3 \mathrm{~h}$, the $\alpha-\mathrm{Al}_{2} \mathrm{O}_{3}$ particles started settling, with a complete phase separation being reached after $172 \mathrm{~h}$. On the other hand, $\gamma-\mathrm{Al}_{2} \mathrm{O}_{3}$ nanofluids have maintained their stability throughout the time period. Witharana et al. [75] also used the same approach as part of their investigation of 


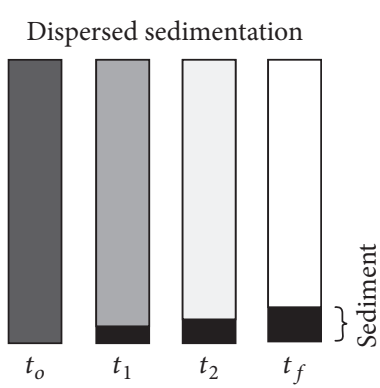

Flocculated sedimentation

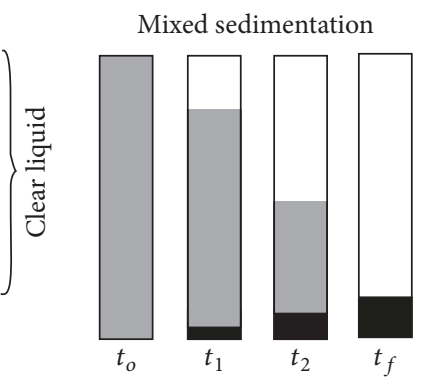

FIgURE 12: Types of sedimentation behaviours in nanofluids, where $t$ indicates time and $t_{o}<t_{1}<t_{2}<t_{f}$ [74].

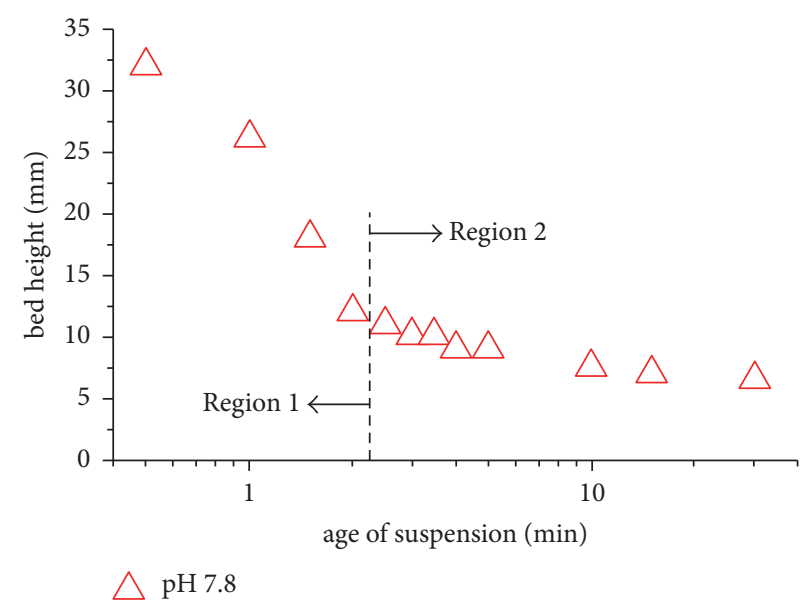

FIgURE 13: Instable $\mathrm{Al}_{2} \mathrm{O}_{3}$ nanofluid phase separation speed regions [75].

$\mathrm{Al}_{2} \mathrm{O}_{3}$ /deionised water (DIW) nanofluid, of spherical shape and particles size in the range of $10-100 \mathrm{~nm}$, aggregation and settling behaviour. For the suspensions preparation, they used 0.5 wt $\%$ of alumina nanopowder and then dispersed it with the basefluid for $4 \mathrm{~h}$ using an ultrasound device. The $\mathrm{pH}$ of the produced suspensions was afterward adjusted to a $\mathrm{pH}$ of 6.3 and $\mathrm{pH}$ of 7.8 . Their results have illustrated that the as-prepared nanofluid of $\mathrm{pH} 6.3$ was stable for more than $30 \mathrm{~min}$, and the nanofluid of $\mathrm{pH} 7.8$ was rapidly settling (i.e., highly unstable). They also concluded, from their findings, that within the unstable nanofluid there exist two main regions, which reflects the phase separation speed. The first region is called the rapid settling region (up to $2 \mathrm{~min}$ ), where the settling speed was $\sim 46 \mathrm{~mm} / \mathrm{min}$, and the second is called the slow settling region (beyond $2 \mathrm{~min}$ ), where the settling was at $4 \mathrm{~mm} / \mathrm{min}$. Figure 13 demonstrates the unstable nanofluid phase separation speed regions. Ilyas et al. [135] tested the stability of as-received alumina nanoparticles, of 40,50 , and $100 \mathrm{~nm}$ average diameter, dispersed in waterethanol (0-100 wt\%) using the same method. They divided their samples between a low particles concentration group (nanoparticles: $0.1,0.3$, and $0.5 \mathrm{wt} \%$ and ethanol: 0-50 wt\%) and a high particles concentration group (nanoparticles: 1.0, 3.0, and $5.0 \mathrm{wt} \%$ and ethanol: $60-100 \mathrm{wt} \%$ ). Observing the sediment formation, with and without sonication, they found out that the low concentration samples have followed a dispersed sedimentation mechanism, with complete settling after $16 \mathrm{~h}$. On the contrary, the high concentration group showed a flocculated sedimentation behaviour where nanofluids fully settled after $16 \mathrm{~h}$, with an exception to the $100 \mathrm{wt} \%$ of ethanol samples, where the settling exhibited a mixed sedimentation behaviour.

All of the aforementioned researchers have confirmed that the stability of nanofluid can be indicated using the sedimentation photograph capturing method. Despite the fact that this approach represents a high-performance analysis of nanofluid stability with low cost, very few papers were published using this method [136]. One of the reasons that can be linked to the limited adaptation of such stability evaluation approach is its requirement of a long period of observation which is very time consuming [69].

4.1.3. Centrifugation Method. Nanofluid centrifugation is a much faster method for determining the stability of the prepared fluid compared to the sedimentation photograph capturing approach. It has been employed in a variety of stability studies, in which a visual examination of the nanofluid sedimentation is performed using a dispersion analyser centrifuge.

Singh and Raykar [137] confirmed the stability of the as-prepared silver/ethanol nanofluids, of 30-60 nm particle size and $0.0112-0.0114$ vol\%, with added polyvinylpyrrolidone surfactant and centrifuging the samples for $10 \mathrm{~h}$ at $3000 \mathrm{rpm}$. The outcome of their experiment showed excellent stability with no signs of sedimentation. Li and Kaner [138] also evaluated the instability of an aqueous polyaniline colloids via 
TABLE 1: Examples of nanofluids absorption wavelength peaks reported using an UV-Vis spectral analyser.

\begin{tabular}{lccc}
\hline Investigators & Nanoparticle & Basefluid & Peak wavelength (nm) \\
\hline Liu et al. [14] & Aligned CNTs & DW & 210 \\
Jiang et al. [15] & $\mathrm{CNTs}$ & $\mathrm{DW}$ & 253 \\
Chang et al. [16] & $\mathrm{Cu}$ & $\mathrm{DW}$ & 270 \\
Chang et al. [16] & $\mathrm{CuO}$ & $\mathrm{DW}$ & 268 \\
Sato et al. [17] & $\mathrm{Ag}$ & $\mathrm{DW}$ & 410 \\
Hwang et al. [18] & Fullerene & Paraffin oil & 397 \\
\hline
\end{tabular}

manipulating its $\mathrm{pH}$ value and employing the same stability technique. He found out that the electrostatic repulsive force surrounded by the nanofibers helped in providing the longest stability to the colloids, with an optimum stability reached at a $\mathrm{pH}$ value of 2.6. Mehrali et al. [139] observed the instability via centrifuging their graphene/distilled water (DW) suspension, of $2 \mu \mathrm{m}$ diameter and $2 \mathrm{~nm}$ thickness, from 5 to $20 \mathrm{~min}$ at $6000 \mathrm{rpm}$. Four mass concentrations $(0.025,0.05,0.075$, and $0.1 \mathrm{wt} \%$ ) were used in their research and all have shown good stability with the presence of few sedimentation at the bottom of the test tubes at the end of each centrifugation process.

4.1.4. Spectral Analysis Method. This method was firstly proposed, in 2003, by Jiang et al. [15] and can be implemented only if the dispersed nanoparticles have an absorption to wavelength between 190 to $1100 \mathrm{~nm}$ [68]. The nanoparticle size distribution in nanofluid is characterised via the absorbed spectrum due to the optical properties of the particles, which depend on their morphology (i.e., shape and size). In general, the absorption intensity and the concentration of nanoparticles in a nanofluid cohabit a linear relationship [68]. A UV-Vis spectral analyser may be used in such process to determine the variation in sedimentation time with the supernatant particle concentration via measuring the absorption of the nanofluid. The main advantage of this method is its capability of presenting a quantitative concentration from analysing the nanofluid. Hwang et al. [18] estimated the stability of multiwalled carbon nanotube (MWCNTs) dispersed in paraffin oil nanofluids at different sedimentation time for $800 \mathrm{~h}$ using this technique. The MWCNTs used into fabricating the nanofluids had an average length of $10-50 \mu \mathrm{m}$ and average diameter of $10-30 \mathrm{~nm}$. Their results showed that the MWCNTs nanofluids had a low spectrum absorption throughout their wavelength (between 360 and $700 \mathrm{~nm}$ ), with the highest spectrum absorption being at a wavelength of $397 \mathrm{~nm}$, revealing the poor stability and large agglomeration of their nanofluids. Souza et al. [140] examined the uniformity distribution of $\mathrm{TiO}_{2} / \mathrm{DW}$, of $40.7 \mathrm{~nm}$ average particles size and nanofluids of $\mathrm{pH} 7.5$, via a UV-Vis absorption spectrum analysis. According to their results, the nanofluids wavelength peaked with absorbency $>1$ between 280 and $400 \mathrm{~nm}$, which demonstrated high stability. Some of the nanofluids absorption wavelength peaks reported by different researchers, measured by UV-Vis method, can be seen in Table 1.

4.1.5. 3w-Method. Evaluation of the thermal conductivity changes in nanofluids, caused by the sedimentation of nanoparticles, was also proposed as a stability measuring approach known as the $3 \omega$-method [69]. Three articles were found using this method [76, 141, 142]. Oh et al. [76] work consisted of examining the stability of the asprepared $\mathrm{Al}_{2} \mathrm{O}_{3} / \mathrm{DIW}$ and $\mathrm{Al}_{2} \mathrm{O}_{3} / \mathrm{EG}$ nanofluids, where the nanoparticles were of $45 \mathrm{~nm}$ diameter and $0-4 \mathrm{vol} \%$. The nanofluids effective thermal conductivity was measured for one hour, which showed an increase in its value with time. This was believed to be caused from the aggregation of the nanoparticles within the basefluids. On the other hand, Martínez et al. [141] investigated the same effect on $\mathrm{TiO}_{2} / \mathrm{H}_{2} \mathrm{O}$ nanofluids that were constructed at $5^{\circ} \mathrm{C}$ and $15^{\circ} \mathrm{C}$, using $5 \mathrm{wt} \%$ as-received $\mathrm{TiO}_{2}$ of $6 \mathrm{~nm}$ average particles size. It was found that nanofluids fabricated at $5^{\circ} \mathrm{C}$ lost its stability after $5.55 \mathrm{~min}$ but had maintained its form for $7.53 \mathrm{~min}$ when applying a $1000 \mathrm{kPa}$ inert pressure to the samples. Moreover, the $15^{\circ} \mathrm{C}$ samples had achieved a $7.18 \mathrm{~min}$ and $6.77 \mathrm{~min}$ stability, with and without added pressure, respectively. Figure 14 shows the experimental configuration of the $3 \omega$-method.

4.1.6. Electron Microscopy Methods. Particles size distribution can be measured to determine the nanofluid stability using a transmission electron microscopy (TEM) or scanning electron microscopy (SEM) devices. These very highresolution microscopes tend to capture the digital image, known as the electron micrograph, of approximately $0.1 \mathrm{~nm}$ in size $[23,69]$. If clusters of nanoparticles are found within the obtained images, then sedimentation mechanism is most likely to occur (i.e., the nanofluid is considered unstable).

The usual practice reported for inspecting the sample stability using a TEM device is by placing a drop of the asprepared nanofluid on a carbon coated copper grid and then monitoring the distribution of the nanoparticles on top of the copper grid when the basefluid is completely evaporated [23]. Total evaporation of the basefluid always results in aggregation of the nanoparticles. For such reason, the TEM characterisation approach is only applicable for nanofluids of low particles concentration. On the other hand, SEM inspection of the sample is performed by placing a drop of the nanofluid on a sticky tape, which is fixed on top of the specimen holder, then heated in a vacuum oven, and dried naturally with air. Finally, the dried sample is placed in the SEM vacuumed chamber to capture the particles images [26]. Figures 15(a) and 15(b) demonstrate the $\mathrm{CuO}$ nanoparticles images taken by TEM and SEM, respectively.

Das et al. [143] used TEM images to determine the stability of $99.7 \%$ pure alumina $(50 \mathrm{~nm}$ average particles diameter) dispersed in DW, with and without surfactant, at 


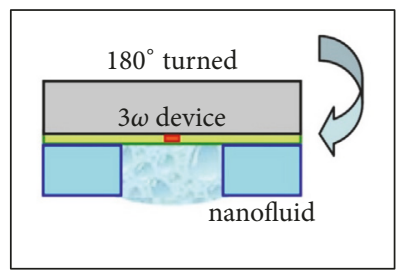

Figure 14: Experimental configuration of the $3 \omega$-method used by Oh et al. [76].

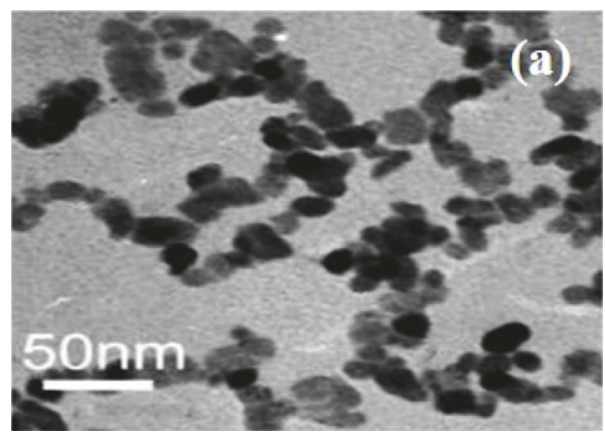

(a)

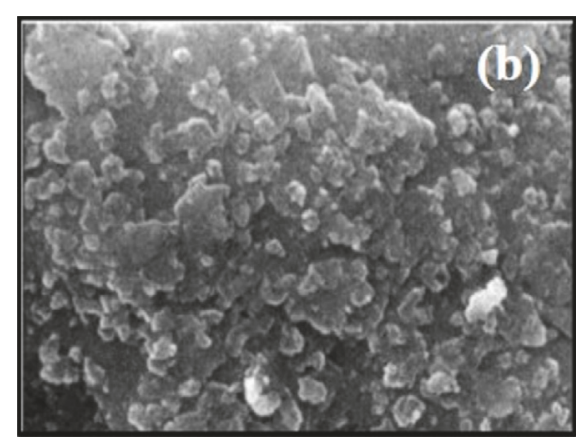

(b)

FIGURE 15: Electron micrograph of CuO nanoparticles using (a) TEM [77] and (b) SEM [78].

0.1-2.0 vol\%. Sodium dodecyl sulphate (SDS), cetyl trimethyl ammonium bromide (CTAB), and SDBS surfactants were used separately in the fabrication process to form $\left(\mathrm{Al}_{2} \mathrm{O}_{3}-\right.$ SDS - DW), $\left(\mathrm{Al}_{2} \mathrm{O}_{3}-\mathrm{CTAB}-\mathrm{DW}\right)$, and $\left(\mathrm{Al}_{2} \mathrm{O}_{3}-\mathrm{SDBS}\right.$ - DW) nanofluids, which were compared to pure $\mathrm{Al}_{2} \mathrm{O}_{3}$ / DW samples. In all the examined cases, the nanofluids containing surfactant have illustrated less agglomeration than the pure $\mathrm{Al}_{2} \mathrm{O}_{3} / \mathrm{DW}$ nanofluids, with the highest stability being achieved from the SDBS surfactant of $2: 1$ particle to surfactant mass ratio. Kim et al. [144] studied the dispersion of one-step fabricated $\mathrm{Cu}$ /ethanol, Ni/ethanol, $\mathrm{Cu} / \mathrm{EG}$, and $\mathrm{Ni} / \mathrm{EG}$ nanofluids, of spherical shape and average particles size $<100 \mathrm{~nm}$, by analysing their TEM images. The high magnified images revealed that EG, as a basefluid, had better dispersibility effect on the nanoparticle than ethanol, with $\mathrm{Cu} / \mathrm{EG}$ nanofluid showing finer particle size and better dispersibility behaviour than the other three cases. SEM technique was adopted by Rubalya Valantina et al. [145] to determine the $0.03 \mathrm{vol} \%$ dispersed $\mathrm{ZnO}(69 \mathrm{~nm})$ and $\mathrm{ZnZrO}(23.9 \mathrm{~nm})$ nanoparticles in rice bran oil with/without tert-butylhydroquinone (TBHQ) antioxidant. Their results showed that $\mathrm{ZnO}$ particles were homogeneously distributed, with or without TBHQ, in the sample and that the $\mathrm{ZnZrO}$ nanofluid had noticeable particle agglomerations.

In addition to the TEM and SEM devices used to characterise the nanofluids stability, cryogenic electron microscopy (Cryo-EM) can also analyse the stability of nanofluids, if the microstructure of the nanofluid is unchangeable throughout the examination process [146].

4.2. Stability Enhancement Procedures. Several literatures have reported diverse ways of improving the stability of nanofluids, which are discussed in the following section.
4.2.1. Addition of Surfactants. Adding surfactants, also referred to as dispersant, is an effective stability enhancement method that prevents the agglomeration of nanoparticles within the nanofluid [147]. It is considered as a simple and economical chemical method, which reduces the surface tension of the basefluid and improves the immersion of nanoparticles. This is because surfactants consist of hydrophobic tail portion (e.g., long-chain hydrocarbons) and hydrophilic polar head group that tends to increase the hydrophilic behaviour between the basefluid and the nanoparticles.

Based on the head composition, dispersant can be divided into four classes: (1) ionic surfactants with head groups of negative charge (e.g., alkyl sulphates, long-chain fatty acids, phosphates, sulfosuccinates, and sulfonates), (2) nonionic surfactants with neutral head groups (e.g., alcohols, polyethylene oxide, and other polar groups), (3) cationic surfactants with head groups of positive charge (e.g., longchain quaternary ammonium compounds and long-chain amines), and (4) amphoteric surfactants of zwitterionic head groups (charge is a pH depended) [68].

Commonly used surfactants are listed in Table 2. Selecting a suitable surfactant is determined by the basefluid used in preparing the nanofluids. In general, if the basefluid is a polar solvent, then a water-soluble surfactant should be used; otherwise, an oil-soluble is used instead. The solubility of nonionic dispersant can be estimated through the hydrophilic/lipophilic balance (HLB) value. The higher the HLB value, the more water-soluble the surfactant, while the lower the HLB value, the more oil-soluble the surfactant. HLB values can be found in many handbooks [68].

The disadvantage of using dispersant as a nanofluid stabilizer is its sensitivity to hot temperature. This is because the rise in temperature causes the bounds between the 
TABLE 2: Commonly used surfactants and their structure formulas.

Surfactant
Polyvinylpyrrolidone
(PVP) [19]

(PVP) [19]

Structure formula

Sodium dodecyl sulphate
$(\mathrm{SDS})[20]$

Oleic acid (OA) [21]

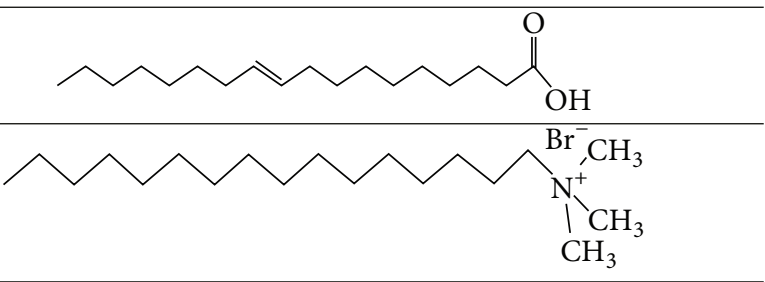

Hexadecyl trimethyl ammonium

bromide (HCTAB) [22]

Poly(acrylic acid sodium salt) [23]

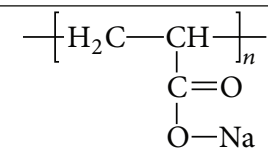

Sodium dodecyl benzene sulfonate

(SDBS) [23]

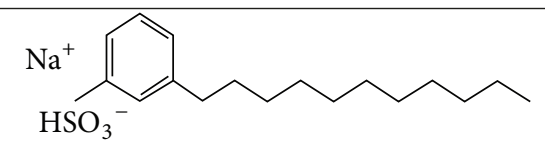

Dodecyltrimethylammonium bromide

(DTAB) [24]

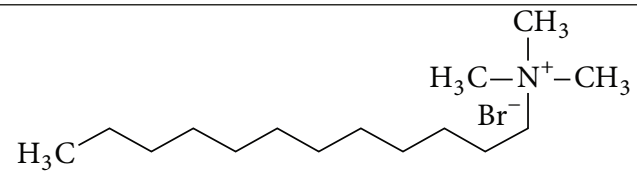

Gum Arabic [25]
$\begin{aligned} & \text { Sodium octanoate } \\ & \text { (SOCT) [26] }\end{aligned}$

nanoparticles and the surfactant to be damaged and in some cases, it can chemically react into producing foams [148]. Additionally, excessive amount of surfactant affects the thermophysical properties of the nanofluid, where it increases the viscosity of the nanofluid and reduces its thermal conductivity $[23,149]$.

Timofeeva et al. [150] dispersed $15 \mathrm{~nm}$ silicon dioxide nanoparticles in synthetic oil, Therminol 66 (TH66), to improve the basefluid heat transfer efficiency. Benzethonium chloride (BZC), benzalkonium chloride (BAC), and CTAB were used as surfactants, at $5 \mathrm{wt} \%$, to examine their influence on the nanoparticles dispersion behaviour. The $\mathrm{SiO}_{2}$ nanopowder, of 1 vol\%, and TH66 basefluid were sonicated with/without surfactant for 50 min to prepare the nanofluids. Visual appearance of the samples, for $24 \mathrm{~h}$, indicated that the surfactants had improved the stability of the nanofluids, with BAC showing the highest dispersion condition. However, pure $\mathrm{SiO}_{2} / \mathrm{TH} 66$ nanofluid had illustrated large particles agglomeration which was linked to the strong attraction force between the nanoparticles. The findings were also confirmed through SEM and spectral analysis. Rohini Priya et al. [32] fabricated $40-60 \mathrm{~nm}$ particle size $\mathrm{CuO}$ with $\mathrm{H}_{2} \mathrm{O}$ and tiron (surfactant) nanofluids via $6 \mathrm{~h}$ sonication. It was reported that the ideal $\mathrm{CuO}$ : tiron ratio that could ensure colloidal stability corresponded to $2.5: 1$. This was also confirmed from the zeta potential measurements, where the nanofluids were found to possess an absolute value of $30 \mathrm{mV}$, which was sufficient to preserve the stability of the colloidal. Furthermore, the authors have stated that the stability of their nanofluids was also confirmed through visual observation but gave no 


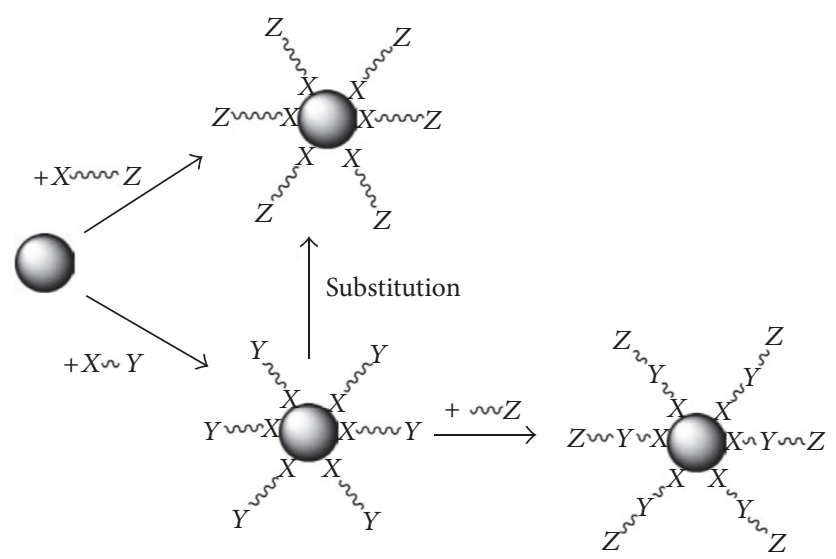

Figure 16: The two functionalized nanoparticles approaches. Method 1 (top): $Z$ functionality with the ligands reacts directly with the nanoparticle; method 2 (bottom): $Y$ functionality with the ligand reacts directly with the nanoparticle and is then converted into another functionality $Z$ [79].

data on the manner. Byrne et al. [151] prepared $\mathrm{CuO} / \mathrm{DW}$ nanofluids with and without CTAB. Three concentrations of the $\mathrm{CuO}$ nanopowder were used, $0.005 \mathrm{vol} \%, 0.01 \mathrm{vol} \%$, and 0.1 vol\%, with and without surfactant, of $1: 1$ vol\% ratio, to produce the suspensions. Dynamic light scattering (DLS) measurements indicated an increase in agglomeration with the rise in particles concentration, where the 0.1 vol\% sample containing no surfactant showed a rapid decrease in particle size from about $3000 \mathrm{~nm}$ at time zero to $300 \mathrm{~nm}$ after $4 \mathrm{~h}$. This reduction in particle size was explained by the researchers to be caused from the settling of heavier agglomerates of particles, leaving the smaller particles freely detected. On the other hand, the samples that contained surfactant had an average particle size of $200 \mathrm{~nm}$ with no variation for a period of 7 days.

4.2.2. Surface Modification Techniques. One of the methods used to achieve long-term stability of nanofluids, without the need of surfactants, is by modifying the nanoparticles surface via functionalization. This is done by introducing functionalized nanoparticles into the basefluid in order to obtain a self-stabilized nanofluid. Usually, suitable functional organic groups are selected as they tend to attach to the atoms surface, enabling the nanoparticles to self-organize and avoid agglomeration [79].

There are two approaches where functional groups can be introduced. The first method is by introducing all the functional ligand in one step, which requires bifunctional organic compounds. A single functionality $(X)$ is employed to be attached to the nanoparticle surface and an additional group $(Z)$ is where the nanoparticles are functionalized. The second method relies on the reaction between the bifunctional compounds $X-Y$, where group $Y$ acts as a coupling location and can convert afterwards to a final functionality $Z$ [79]. Figure 16 shows the two functionalized nanoparticles approaches.

Kayhani et al. [152] functionalized spherical $\mathrm{TiO}_{2}$ nanoparticles, of $15 \mathrm{~nm}$ particles size, by chemical treatment to achieve stabilized $\mathrm{TiO}_{2} / \mathrm{DW}$ nanofluids. Titanium dioxide powder was mixed with $1,1,1,3,3,3$, hexamethyldisilazane
(C6H19NSi2), at a mass fraction ratio of $2: 1$, and then sonicated for $1 \mathrm{~h}$ under $30^{\circ} \mathrm{C}$ to obtain soaked nanoparticles. Using a rotary evaporation device, the soaked nanoparticles were dried and then dispersed by ultrasonic vibration, for 3-5h, with DW. The fabricated nanofluids were stable for several days without any visible signs of agglomerations. This stability behaviour was linked to the hydrophilic ammonium groups placed on the $\mathrm{TiO}_{2}$ nanoparticles surface. Yang and Liu [35] were able to maintain the dispersion of $\mathrm{SiO}_{2} / \mathrm{DIW}$ nanofluids, of $30 \mathrm{~nm}$ size and $10 \%$ mass concentration, for 12 months by functionalizing the nanoparticles with silanes of (3-glycidoxylpropyl) trimethoxysilane. The term "functionalized nanofluid" was also proposed to describe any nanofluid that uses functionalizing in its fabrication process. Chen et al. [148] compared the stability of pristine CNTs (PCNTs) and chemically treated CNTs (TCNTs) dispersed in DW, EG, and glycerol. The average length and diameter of the CNTs used were about $30 \mu \mathrm{m}$ and $15 \mathrm{~nm}$, respectively. Potassium hydroxide was used, via a mechanochemical reactor, to introduce hydrophilic functional groups to the CNTs surface and hence produce TCNTs. Through TEM images and visual evaluation, it was revealed that the PCNTs nanofluids were rapidly aggregating and completely sedimented after 5 min from preparing the nanofluids of 0.1 vol\% PCNT. On the other hand, the TCNTs nanofluids, of similar vol\%, maintained a long-term stability (many months) with no visible precipitation at the bottom of the test vial. It is worth mentioning that surface modification technique via functionalization is not a special method used only for nanofluid but can also be employed in other applications (e.g., functionalizing graphene oxide bonded to a graphene-based film to improve thermal management) [153].

4.2.3. Ultrasonic Agitation. Sonication, which is a physical method that depends on employing ultrasonic waves through the fluid, can be used to enhance the stability of the nanofluid by rupturing the nanoparticles attractional force within the sediments [154]. There are two types of ultrasonicators available, the probe type and the bath type. Both types can be seen in Figure 17. 

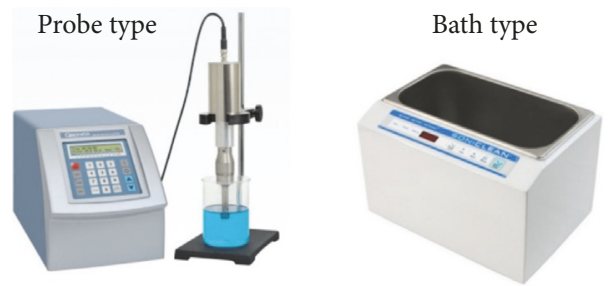

FIgURE 17: Probe type and bath type ultrasonicators [80, 81].

Many researchers have used ultrasonication in preparing and stabilizing their nanofluids. It was also reported that the probe type sonicator gave a better improvement to the nanofluid than the bath type [26]. Chung et al. [155] demonstrated this through their research work, where they examined the as-prepared $\mathrm{ZnO} / \mathrm{H}_{2} \mathrm{O}$ nanofluid, of $20 \mathrm{~nm}$ average particle size, in terms of rate of sedimentation, rate of size reduction, and minimum size achieved. They found out that the probe type sonicator was more effective than the bath type sonicator, where the particles within the nanofluid were of 50-300 $\mathrm{nm}$ in size. Petzold et al. [156] investigated the distribution of $1.0 \mathrm{~g}$ of fumed silica (aerosol) particles, of 7-40 $\mathrm{nm}$ size, dispersed in $100 \mathrm{ml}$ of water samples. Particles scattering, within the basefluid, was performed using a magnetic stirrer, high intensity ultrasonic probe, and an ultraturrax, each for $10 \mathrm{~min}$. The zeta sizer analysis results have shown that, unlike the magnetic stirrer and ultraturrax samples, the nanofluids prepared using ultrasonic probe had a uniform particles dispersion along the 30 min examination period.

Although sonication technique is widely used, particularly in the nanofluid two-step preparation method, the optimum sonication time, wave, and pulse mode are still unknown. It was also pointed out that increasing sonication time does not necessarily improve the reduction in particle size, as it can largen rather than reduce the particle size as illustrated by Kole and Dey [157]. In their work, $\mathrm{ZnO} / \mathrm{EG}$ nanofluid, of 1.0 vol\%, showed a rapid decrease in particles size (from $459 \mathrm{~nm}$ to $91 \mathrm{~nm}$ ) between 40 and $60 \mathrm{~h}$ of sonication and then an increase in size that reached to $220 \mathrm{~nm}$ after $100 \mathrm{~h}$.

4.2.4. $p H$ Control of Nanofluids. Manipulating the $\mathrm{pH}$ value of nanofluids changes the nanoparticles surface and can strongly improve the stability of the dispersed nanoparticles $[158,159]$. This is because the stability of a nanofluid is directly related to its electrokinetic properties. Therefore, the zeta potential can be increased/decreased by changing the $\mathrm{pH}$ value of the nanofluid and as mentioned previously, zeta potential values of nanofluids above $+30 \mathrm{mV}$ or below $-30 \mathrm{mV}$ are considered to be more stable because of the high repulsive force generated between the charged nanoparticles. The $\mathrm{pH}$ value of a nanofluid can be increased or decreased by adding an appropriate nonreactive alkaline or acidic solution, respectively [160].

Many studies were carried out to demonstrate the effect of $\mathrm{pH}$ level on the stability of nanofluids [161-166]. Witharana et al. [75] examined the settling and aggregation behaviour of alumina $\left(\mathrm{Al}_{2} \mathrm{O}_{3}\right) / \mathrm{H}_{2} \mathrm{O}$ nanofluid of $0.5 \mathrm{wt} \%, 46 \mathrm{~nm}$ particle size, and of spherical particle shape at $\mathrm{pH}$ values of 6.3 and 7.8. They discovered that the suspensions were stable at a $\mathrm{pH}$ value of 6.3 for more than $30 \mathrm{~min}$ compared with the $\mathrm{pH}$ value of 7.8 which had endured a complete particle separation and settlement after $30 \mathrm{~min}$. Manjula et al. [167] studied in their work the effect of added surfactants and $\mathrm{pH}$ level on the dispersion behaviour of water based alumina nanofluid through its sedimentations. Their results showed that adding surfactant and optimising the $\mathrm{pH}$ level maximized the stability of the nanosuspension. Zhu et al. [168] investigated the influence of different concentrations of SDBS and $\mathrm{pH}$ values on the behaviour of $\mathrm{Al}_{2} \mathrm{O}_{3} / \mathrm{H}_{2} \mathrm{O}$ suspension. They found out that the effective thermal conductivity and stability of their nanofluid were significantly dependent on the SDBS concentration and $\mathrm{pH}$ value of the fluid, where the effective thermal conductivity was increased by $10.1 \%$ at a $\mathrm{pH}$ value of 8 and particle concentration of $0.15 \mathrm{wt} \%$.

Modak et al. [101] experimentally investigated the heat transfer characteristics of copper oxide $(\mathrm{CuO}) / \mathrm{H}_{2} \mathrm{O}$ nanosuspension impingement on a hot surface. During the preparational phase of the nanofluid, they found out that the optimum stability for the $0.15 \%$ and $0.60 \%$ volume concentration dispersion, at stationary condition, can be achieved for a period of $60 \mathrm{~h}$ at a $\mathrm{pH}$ value of 10.1 with a $0.2 \mathrm{wt} \%$ added sodium dodecyl sulfonate (SDS) surfactant. Lee et al. [169] evaluated the thermal conductivity and stability of $\mathrm{CuO}$ nanoparticles, of $25 \mathrm{~nm}$ mean diameter, dispersed in DIW. Their particle size measurements revealed that the formed agglomeration of particles sized from $160 \mathrm{~nm}$ to $280 \mathrm{~nm}$ at a $\mathrm{pH}$ range of 3 to 11 . They concluded that the stability of the suspension was influenced by the hydrodynamic size of the embedded particles and the $\mathrm{pH}$ value. It was also reported that the effective thermal conductivity enhanced by about $11 \%$ over that of the basefluid at a $\mathrm{pH}$ value of 11 . Chang et al. [170] studied the sterical and electrostatic stability of a high suspension self-prepared $\mathrm{CuO}$ nanofluid, of an average particle size of $60 \mathrm{~nm}$ and $0.01 \mathrm{wt} \%$ nanoparticle concentration, without the addition of any dispersant. The suspensions were prepared using a vacuum arc spray nanofluid synthesis system (ASNSS) combined with an ultrasonic vibrator. The prepared nanofluids $\mathrm{pH}$ were adjusted to a range of values between 4 and 13 by adding $\mathrm{NaOH}$ or $\mathrm{HCl}$ to the solutions. Different lengths of settling time, average particle size, and zeta potential of the nanofluids were observed for $7,30,90$, and 180 days. They concluded that their nanofluid can maintain its stability for more than 6 months once it achieved a zeta potential value above $30 \mathrm{mV}$. Song et al. [171] 


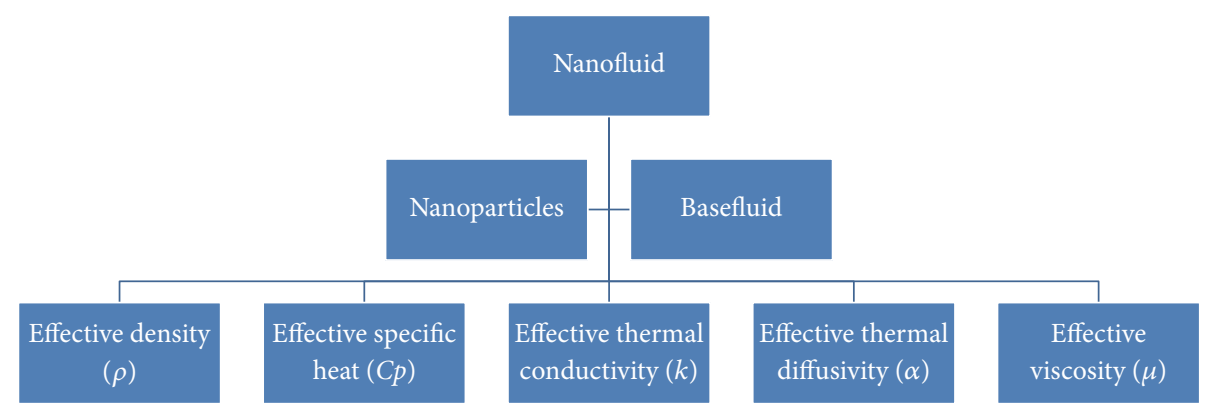

FIGURE 18: Nanofluid thermophysical properties.

explored the possibility of stabilizing stainless steel (SS) 316L, of $70 \mathrm{~nm}$ particle size, dispersed in water with SDS and SDBS surfactants. The $\mathrm{pH}$ values used in their experiment were 8.0, 9.0, 10.0, 11.0, and 12.6. They used five methods to determine the stability and durability of their prepared nanofluids, namely, (1) transmission electron microscope (TEM) observation, (2) sedimentation observation, (3) zeta potential measurement, (4) particle size distribution measurement, and (5) absorbance measurement. The results of the long-term stability showed that the prepared nanofluids of $\mathrm{pH} 11$ lasted for 10 days, $\mathrm{pH} 10$ lasted for 3 days, and those of lower $\mathrm{pH}$ value completely settled in less than a day. As for the sample of $\mathrm{pH} 12.6$, it experienced an excess amount of $\mathrm{OH}^{-}$ions which caused the electrostatic stability of the fluid to be disrupted and settle rapidly.

Our review of the available literature quoted above shows that the $\mathrm{pH}$ value of nanofluids has a strong effect on their stability and that the optimum $\mathrm{pH}$ value varies between samples. It also revealed that the $\mathrm{pH}$ value is influenced by the nanofluid temperature.

Table 3 summarises some of the available studies, on water base nanofluids stability measurements and dispersion improvement, conducted by different researchers. The types of nanofluids, parameters used, characterisation technique, and main findings are also shown.

\section{Nanofluids Thermophysical Properties}

Nanofluids are considered superior to their basefluid, because a new type of fluid has been formed with a completely different thermophysical properties such as density, specific heat capacity, thermal conductivity, convective heat transfer, thermal diffusivity, and viscosity [13]. The word "effective" is commonly used to describe the thermophysical properties of nanofluids (e.g., effective viscosity and effective density). This is done to differ between the thermophysical properties of the basefluid and the fabricated nanofluid. Figure 18 demonstrates the thermophysical properties of nanofluids which are discussed in more detail below.

5.1. Effective Density. The effective density of a nanofluid can be theoretically calculated through its basefluid density $\left(\rho_{\mathrm{bf}}\right)$ and nanoparticle density $\left(\rho_{\mathrm{np}}\right)$ as it is assumed to be a mixed property of both, basefluid and nanoparticles [13]. To determine the nanofluid effective density $\left(\rho_{\mathrm{nf}}\right)$, the mixing theory (1) and (2) is employed [172].

$$
\begin{aligned}
& f_{V}=\frac{V_{\mathrm{np}}}{V_{\mathrm{np}}+V_{\mathrm{bf}}} \approx \frac{V_{\mathrm{np}}}{V_{\mathrm{bf}}} \\
& \rho_{\mathrm{nf}}=f_{V} \cdot \rho_{\mathrm{np}}+\left(1-f_{V}\right) \cdot \rho_{\mathrm{bf}},
\end{aligned}
$$

where $V_{\mathrm{np}}, V_{\mathrm{bf}}$, and $f_{V}$ are the nanoparticles volume, basefluid volume, and particle volumetric fraction, respectively.

The only constraint to the aforementioned equation (2) is that it is generally limited to a low $f_{V}$ as illustrated in Vajhha et al. [173] research findings, where they compared between the theoretical and experimental effective density of alumina, antimony-tin oxide, and zinc oxide nanoparticles dispersed in $60: 40 \mathrm{EG} / \mathrm{H}_{2} \mathrm{O}$ basefluid at a temperature range of $0^{\circ} \mathrm{C}$ to $50^{\circ} \mathrm{C}$. A digital density meter and a circulating fluid temperature bath were used to experimentally measure effective density of the $1,2,4,6,8$, and 10 vol\% alumina nanofluids; 1,2 , 4 , and 5.88 vol\% antimony-tin oxide nanofluids; and 1, 2, 3, 4, 5,6 , and 7 vol $\%$ zinc oxide nanofluids. The ranges of deviation percentage between the measurements and (2) were found to be -0.7897-1.1854 (alumina nanofluids), 0.1116-1.2073 (antimony-tin oxide nanofluids), and -7.0736--1.3591 (zinc oxide nanofluids). From the previous comparison, it can be concluded that (2) has a good prediction of effective density for some types of nanofluids with different particle concentrations but is more accurately used toward nanofluids of low vol\%.

There were few attempts undertaken to measure the density of nanofluids experimentally, as the majority of researchers tend to use the mixing theory in order to predict its value [152, 174-210]. Sommers and Yerkes [211] measured the effective density of alumina/propanol nanofluid, of $10 \pm$ $5 \mathrm{~nm}$ average particles size and $0-4 \mathrm{wt} \%$ concentration, at room temperature using two ways: (1) hydrometer and (2) weighting a sample, of known volume, with a high precision balance $( \pm 0.001 \mathrm{~g})$. The two measuring methods, at nanoparticles concentrations $\leq 4 \mathrm{wt} \%$, were found to be 98.2\% agreeable to each other. Ho et al. [212] used a density meter, of $5 \pm 10^{-5} \mathrm{~g} / \mathrm{cm}^{3}$ accuracy, to measure the effective density of alumina nanofluids at a temperature range between $10^{\circ} \mathrm{C}$ and $40^{\circ} \mathrm{C}$ with $0,0.1,0.3,1.0,2.0,3.0$, and 4 vol $\%$ nanofluids samples. It was reported that the experimental results compiled well with (2) and that the density of alumina 


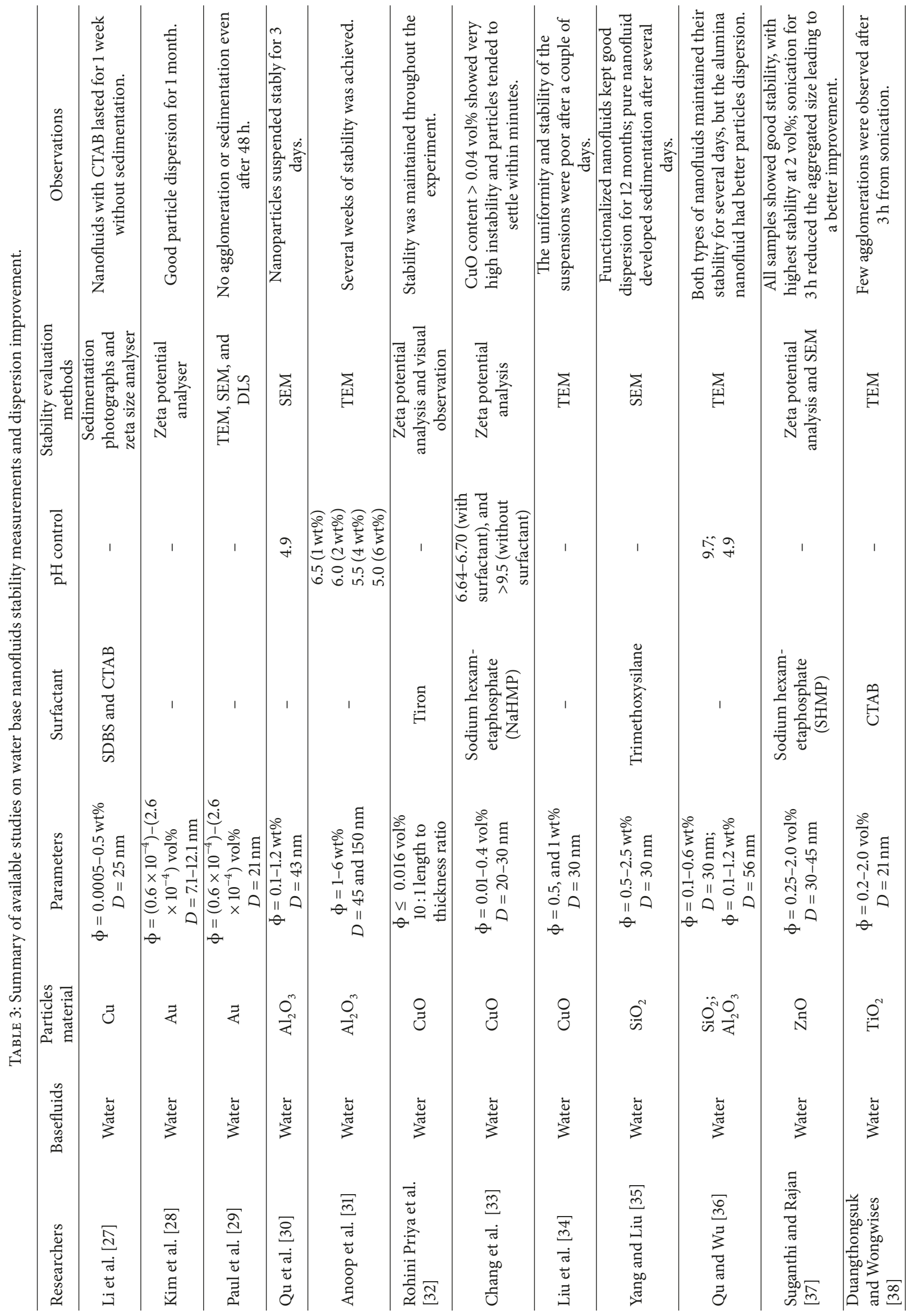




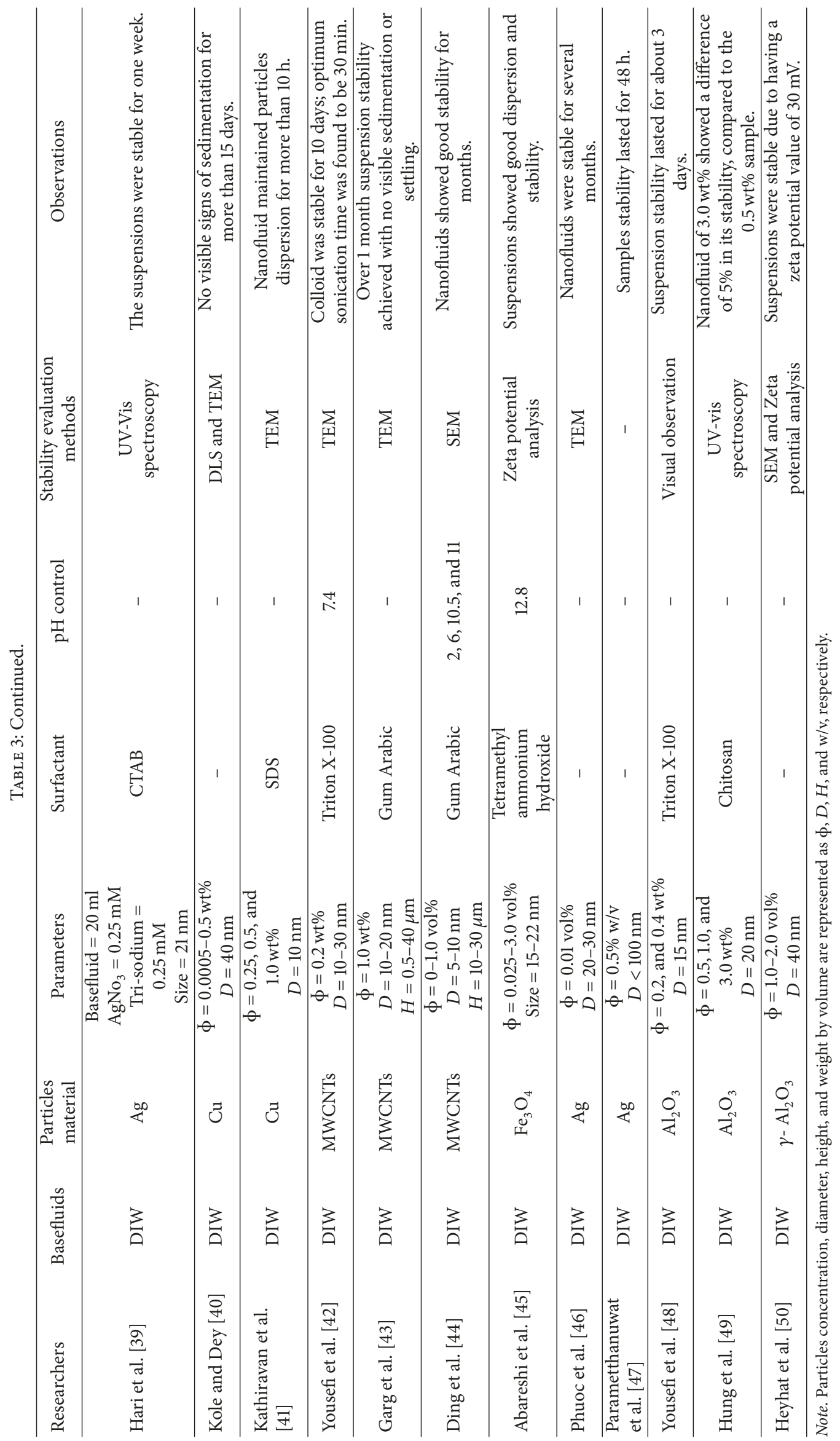




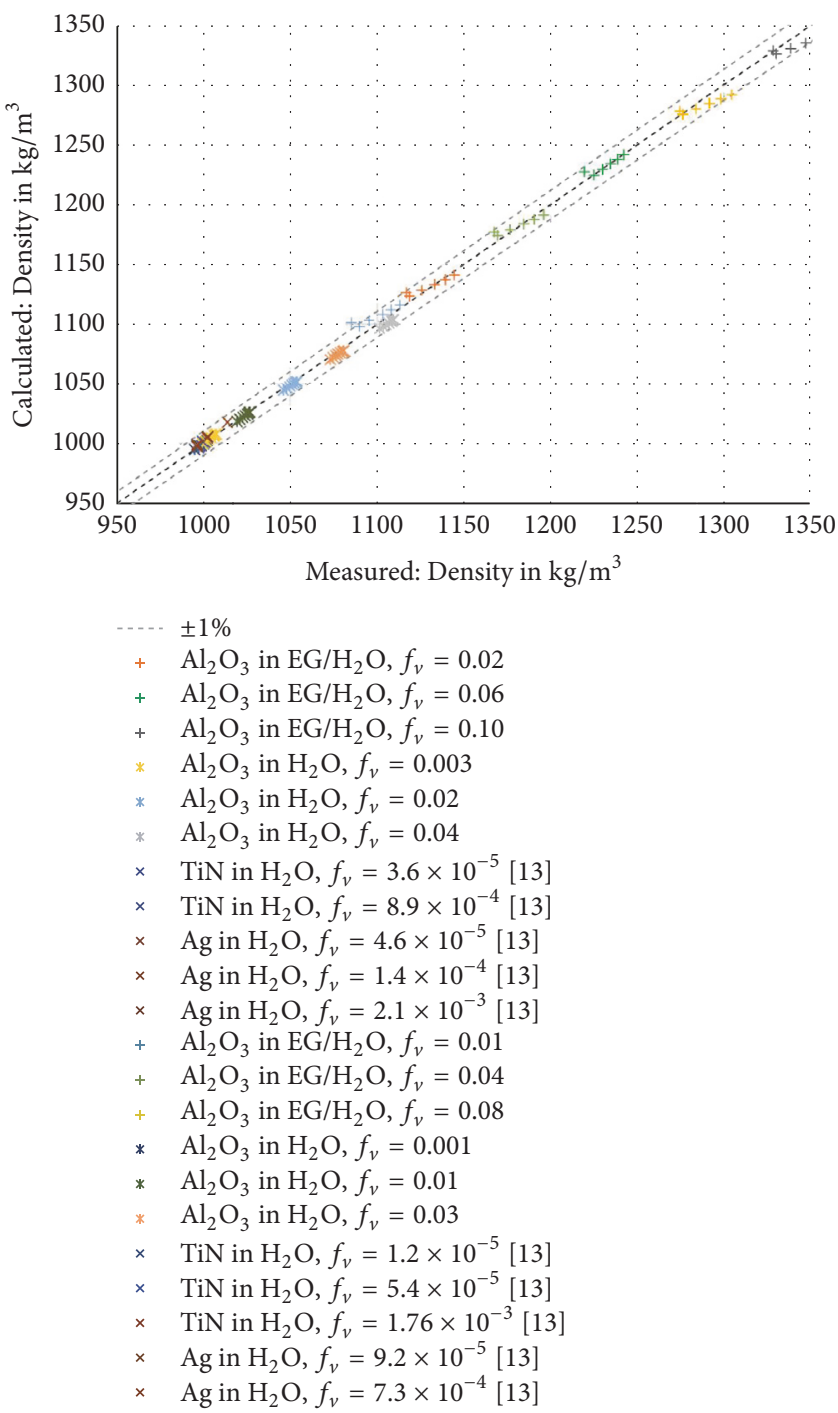

FIGURE 19: Comparison between theoretically calculated effective density (2) and measured data [13]. The dashed line refers to the margin of error $( \pm 1 \%$ margin of error).

particles was less sensitive to the temperature variation in comparison with the basefluid. Eggers and Kabelac [13] measured the effective density of $\mathrm{Ag} / \mathrm{H} 2 \mathrm{O}$ and $\mathrm{Ti} / \mathrm{H} 2 \mathrm{O}$ nanofluids, by a pycnometer, and used (2) to compare its outcomes with their measurements and other published experimental data as seen in Figure 19. The dashed line in the figure represents a perfect fit to (2) and the two parallel lines show a $\pm 1 \%$ deviation to its value. It can be concluded that the mixing theory complied very well with the published data, indicating a reliable prediction to the effective density value within the margin of error.

There are limited number of correlations available, for the effective density of nanofluid, that takes into account the particle size and shape, nanofluid temperature, added surfactant, and the nanolayer between the particles and the basefluid effect $[213,214]$. Hence more work is needed in this area to insure a much accurate prediction of the effective density at higher particles concentrations.
5.2. Effective Specific Heat. The effective specific heat of a nanofluid $\left(C_{p_{\mathrm{nf}}}\right)$ is the amount of heat needed to increase the temperature of one gram of nanofluid by one degree Celsius. It is a very important property that affects the heat transfer rate of a nanofluid. There are two main effective specific heat models that were suggested to calculate the effective specific heat of nanofluids. The first model was proposed by Pak and Cho [172], based on the volume concentration of nanoparticles and the liquid-particle mixture formula.

$$
C_{p_{\mathrm{nf}}}=f_{V} \cdot\left(C_{p}\right)_{\mathrm{np}}+\left(1-f_{V}\right) \cdot\left(C_{p}\right)_{\mathrm{bf}} \cdot
$$

The second model is the commonly accepted correlation, which was presented by Xuan and Roetzel [215].

$$
C_{p_{\mathrm{nf}}}=\frac{\left(1-f_{V}\right) \cdot\left(\rho C_{p}\right)_{\mathrm{bf}}+f_{V} \cdot\left(\rho C_{p}\right)_{\mathrm{np}}}{f_{V} \cdot \rho_{\mathrm{np}}+\left(1-f_{V}\right) \cdot \rho_{\mathrm{bf}}},
$$


where $C_{p_{\mathrm{bf}}}$ and $C_{p_{\mathrm{np}}}$ are the specific heat capacity of the basefluid and the specific heat capacity of the nanoparticles, correspondingly.

Zhou and Ni [216] experimentally investigated the effective specific heat of $\mathrm{Al}_{2} \mathrm{O}_{3} / \mathrm{DIW}$ suspension, of $45 \mathrm{~nm}$ average particles diameter and $0-21.7 \mathrm{vol} \%$, at a temperature range between $25^{\circ} \mathrm{C}$ and $40^{\circ} \mathrm{C}$. It was found that the prediction of (4) collapsed well with the experimental data obtained from the differential scanning calorimeter (DSC) and that (3) had shifted largely from these data. For example, at $21.7 \mathrm{vol} \%$, the effective specific heat was $1.3 \%$ and $3.8 \%$ higher when using (4) and (3), respectively, than the measured values. Teng and Hung [217] examined the deviation between the experimental and calculated effective specific heat of $20 \mathrm{~nm}$ $\mathrm{Al}_{2} \mathrm{O}_{3}$ nanoparticle dispersed in $\mathrm{H}_{2} \mathrm{O}$. The nanofluids were fabricated at $0.5,1.0$, and $1.5 \mathrm{wt} \%$ of nanoparticles and $0.2 \mathrm{wt} \%$ added chitosan as surfactant using the single-step approach. A DSC device was used, at a temperature range of $25^{\circ} \mathrm{C}$ to $65^{\circ} \mathrm{C}$, to measure the effective specific heat of the samples and then compare them to the calculated results from (3) and (4). It was found that the theoretical calculation using (3) was able to predict the effective specific heat of the $0.5 \mathrm{wt} \%$ samples but had a large overestimation in its value with the $1.0 \mathrm{wt} \%$ and $1.5 \mathrm{wt} \%$ nanofluids, which suggest that (3) is more suitable to be employed toward suspensions of low concentrations. Moreover, (4) had underestimated the effective specific heat value of the $0.5 \mathrm{wt} \%$ suspension and overpredicted it with the $1.0 \mathrm{wt} \%$ and $1.5 \mathrm{wt} \%$ samples. The reported deviations between the experimental data and the two equations were in the range of $-0.07 \%$ to $5.88 \%$ and $-0.35 \%$ to $4.94 \%$ for (3) and (4), respectively. Kulkarni et al. [218] used a self-designed specific heat measuring device to obtain the effective specific heat of $45 \mathrm{~nm}$ alumina particles dispersed as 2,4 , and $6 \mathrm{vol} \%$ into an equal quantity of EG/DIW mixture. Comparing (3) and (4) to their experimental data, obtained at a temperature range of $25^{\circ} \mathrm{C}$ to $70^{\circ} \mathrm{C}$, they discovered that both equations have failed to predict the effective specific heat, with (4) having less deviation to the measured data than (3). In addition, it was concluded that (1) the effective specific heat of the dispersion decreases as the concentration of nanoparticles increases and (2) the effective specific heat of nanofluids increases with the rise in temperature. Eggers and Kabelac [13] evaluated (4) performance with their DSC measured effective specific heat of $\mathrm{TiN} / \mathrm{H}_{2} \mathrm{O}$ and $\mathrm{Ag} / \mathrm{H}_{2} \mathrm{O}$ nanofluids and other published data. Figure 20 illustrates the theoretical and experimental comparison, where the dashed line shows a perfect fit to (4) and the two parallel lines indicate a $\pm 5 \%$ deviation from it. One can conclude from Figure 20 that the model can predict the effective specific heat value of nanofluids well within the $\pm 5 \%$ margin.

From the previous studies, it can be noticed that there are few published works on effective specific heat of nanofluids; hence more work is needed to narrow the gap of knowledge in this area. In addition, nanoparticles size and concentration, nanofluid temperature, and basefluid type have been shown to strongly influence the effective specific heat of nanofluids which was also pointed out by Sekhar and Sharma [219]. Other effective specific heat models that contain correction
TABLE 4: Commonly used nanoparticles thermal conductivities [51].

\begin{tabular}{lc}
\hline Material & Thermal conductivity $(\mathrm{W} / \mathrm{mK})$ \\
\hline $\mathrm{Al}_{2} \mathrm{O}_{3}$ & 40 \\
$\mathrm{CuO}$ & 76.5 \\
$\mathrm{Fe}_{2} \mathrm{O}_{3}$ & 6 \\
$\mathrm{MgO}$ & 54.9 \\
$\mathrm{SiO}_{2}$ & $1.34-1.38$ \\
$\mathrm{TiO}_{2}$ & 8.4 \\
$\mathrm{ZnO}$ & 29 \\
$\mathrm{Ag}$ & 429 \\
$\mathrm{Al}$ & $238-273$ \\
$\mathrm{Au}$ & 310 \\
$\mathrm{Cu}$ & 401 \\
$\mathrm{Fe}$ & $75-80$ \\
$\mathrm{MWCNTs}$ & $2000-3000$ \\
\hline
\end{tabular}

TABLE 5: Commonly used basefluids thermal conductivities [51].

\begin{tabular}{lc}
\hline Fluid & Thermal conductivity $(\mathrm{W} / \mathrm{mK})$ \\
\hline EG & 40 \\
Ethylene oxide & 76.5 \\
Ethanol & 6 \\
Glycerol & 54.9 \\
Kerosene & $1.34-1.38$ \\
Toluene & 8.4 \\
Water & 29 \\
\hline
\end{tabular}

factors to compensate for the over/underestimation of the results or were designed for certain testing conditions can be found in the following literatures [219-225].

5.3. Effective Thermal Conductivity. One of the main driving forces behind the concept of nanofluids is the enhancement of the thermal conductivity compared to conventional fluids, which has a positive effect on the fluid convective heat transfer. Adding nanoparticles to a conventional fluid improves its thermal conductivity, if the added nanoparticles had a higher thermal conductivity than its basefluid. Some of the most common nanoparticles and basefluids thermal conductivities are shown in Tables 4 and 5 , respectively.

This increase in effective thermal conductivity can be linked to different factors such as the Brownian motion (Figure 21(a)) which is the core mechanism controlling the thermal behaviour of fluid-nanoparticles dispersion. Another reason is the liquid molecules surrounding the nanoparticles into forming layered structures, known as the nanolayer (Figure 21(b)). These layered structures are considered as a thermal bridge between the bulk liquid and the nanoparticles and hence increase the thermal conductivity of the nanofluid [56]. In addition, the heat in the crystalline solids is carried by phonons that are formed randomly, propagate in random direction, and are scattered via defects or by colliding each other [226-228]. Moreover, clustering of particles was found to influence the effective thermal conductivity [228]. This is due to the creation of localized particle-rich zones, 


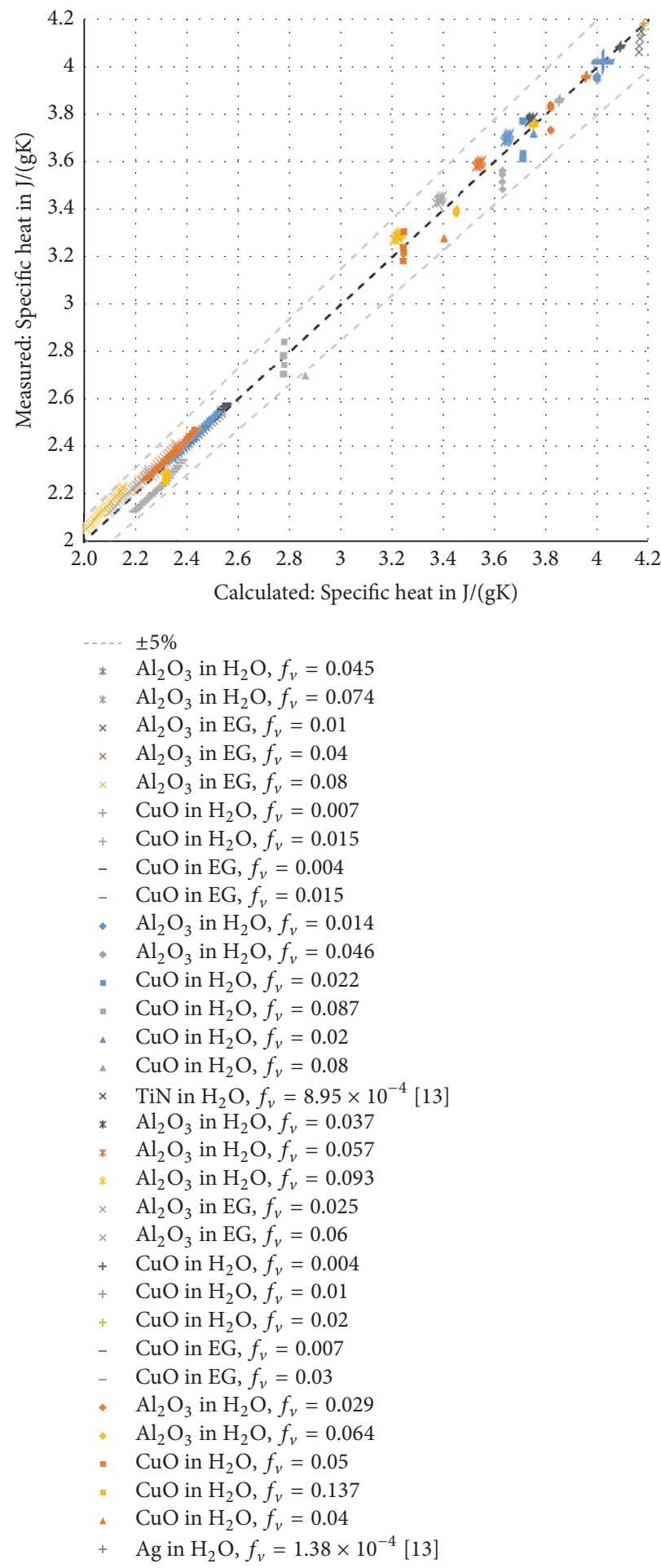

Figure 20: Comparison between theoretically calculated effective specific heat (4) and measured data [13]. The dashed line refers to the margin of error $( \pm 5 \%$ margin of error).

caused from particles agglomerations settling, which have less thermal resistance to heat flow. It was also reported that thermophoresis (also called thermodiffusion, thermomigration, the Ludwig-Soret effect, or the Sort effect), which is a phenomenon exhibited in a mixture of particles that tends to response differently to the force of a temperature gradient, can influence the effective thermal conductivity of nanofluids at high temperatures, but such theory was never proven by any of the published literature up to now $[229,230]$. 


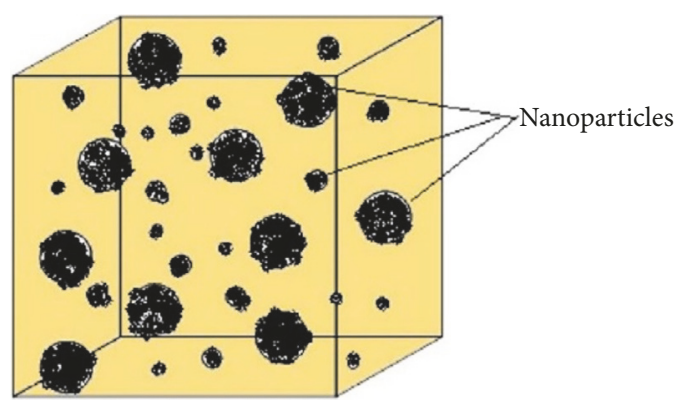

(a)

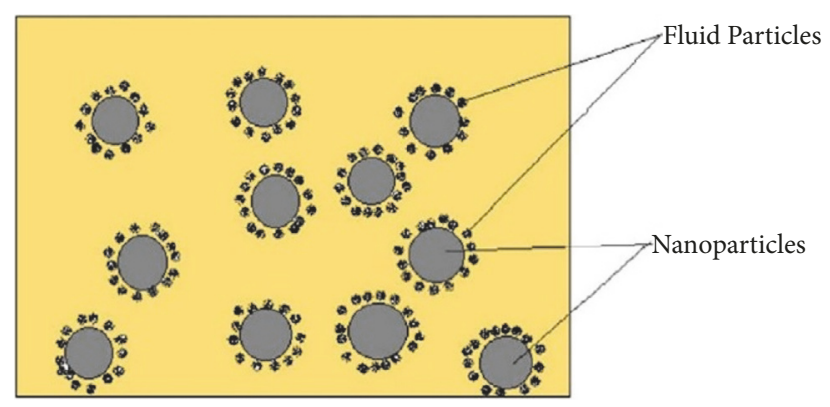

(b)

Figure 21: (a) Nanoparticles Brownian motion and (b) nanofluid structure containing bulk fluid, nanoparticles, and nanolayers at the liquid/solid interface [82].

Many experimental and theoretical work have been carried out to investigate the changes in nanofluids thermal conductivity. Maxwell model (5), which was developed in 1881, was the first correlation used to predict the effective thermal conductivity $\left(K_{\mathrm{nf}}\right)$ of solid-liquid dispersion, using the thermal conductivities of both nanoparticles $\left(K_{\mathrm{np}}\right)$ and basefluid $\left(K_{\mathrm{bf}}\right)$ [231].

$$
K_{\mathrm{nf}}=K_{\mathrm{bf}} \cdot \frac{K_{\mathrm{np}}+2 \cdot K_{\mathrm{bf}}+2 \cdot\left(K_{\mathrm{np}}-K_{\mathrm{bf}}\right) \cdot f_{V}}{K_{\mathrm{np}}+2 \cdot K_{\mathrm{bf}}-\left(K_{\mathrm{np}}-K_{\mathrm{bf}}\right) \cdot f_{V}} .
$$

The model considers the two phases (solid and liquid) of the nanofluid and satisfactorily predicts the effective thermal conductivity of nanofluids when the added particles are of spherical shape, low vol\%, and the suspension is at ambient conditions. Bruggeman [232] afterwards proposed, in 1935, an implicit model (6) of the effective thermal conductivity which can analyse the interactions between randomly distributed particles.

$$
\left[\left(\frac{K_{\mathrm{np}}-K_{\mathrm{nf}}}{K_{\mathrm{np}}+2 K_{\mathrm{nf}}}\right) \cdot f_{V}+\left(1-f_{V}\right)\left(\frac{K_{\mathrm{bf}}-2 K_{\mathrm{nf}}}{K_{\mathrm{bf}}+2 K_{\mathrm{nf}}}\right)\right]=0
$$

Bruggeman model can be applied to suspensions fabricated from particles of spherical shape at any concentration, where, for low vol\%, (6) gave almost the same results as (5).

Equation (5) was modified several times in an attempt to improve the accuracy of the predicted results by taking into consideration different effects such as the Brownian motion, surface charge, liquid-particle interface layer, particle clustering, and ballistic phonon transport. However, factors such as convection induced by electrophoresis, particle driven natural convection, thermophoresis, and others are still not considered but need to be encountered for better estimation of the effective thermal conductivity. Examples of some of the developed correlations with their remarks can be seen in Table 6 and additional models can be found at the following published literatures [230, 233-251].

Experimental measurements of nanofluids effective thermal conductivity were performed by several researchers using transient hot-wire method (low cost and easy to use, where the measurements are based on Fourier's law and the effective thermal conductivity reported to be of $5 \%$ uncertainty) [252-254], $3 \omega$ method (which uses frequency dependence of temperature oscillation to measure the thermal conductivity) $[76,255,256]$, temperature oscillation method (based on the oscillation method and requiring the measurement of the temperature response of the sample) $[59,257]$, thermal constants analyser (easy to perform, very fast, and able to measure thermal conductivity in the range of $0.02-200 \mathrm{~W} / \mathrm{m} \cdot \mathrm{K})$ [258], steady-state parallel-plate technique (which uses the one-dimensional heat conduction equation in its calculation), micro-hot strip method (significantly low measurement time and much accurate than the hot-wire method), and optical beam deflection technique (self-built device which requires long measurement time and can only predict the thermal conductivity at $\sim 100$ vol $\%$ accurately) $[114,259,260]$. Among all the aforementioned techniques, the thermal constant analyser has been the most favourable method used by many researchers.

5.4. Thermal Diffusivity. Very few published papers have considered the effective thermal diffusivity of nanofluids $\left(\alpha_{\mathrm{nf}}\right)$ [13], which can be theoretically calculated using the following equation.

$$
\alpha_{\mathrm{nf}}=\frac{K_{\mathrm{nf}}}{\rho_{\mathrm{nf}} \cdot C_{p_{\mathrm{nf}}}} .
$$

Experimental measurement of the effective thermal diffusivity can be achieved using the transient hot disk system, which is a robust and rapid thermal characterisation system [261], Laser Flash method [262], a temperature controlled photoacoustic device developed by Agresti et al. [263], thermalwave cavity technique, hot-wire method, and temperature oscillation method [264-266]. The thermal lens method is a sensitive technique used to measure the absolute thermal diffusivity value of liquids. This method is favourable due to its ultrahigh sensitivity, small volume of sample requirement, and its dependence on solvent thermo-optical properties [267, 268]. Murshed et al. [269] reported the enhancement in effective thermal diffusivity of nanofluids experimentally and found that they exceeded those calculated by (7). It should be pointed out that they used measured values in calculating the effective thermal diffusivity. Zhang et al. [270] have reported a $5 \%$ error in the effective thermal diffusivity measurement using the hot-wire technique. Agresti et al. 


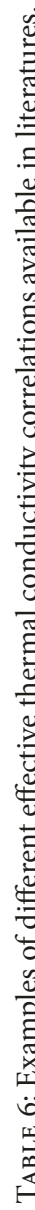
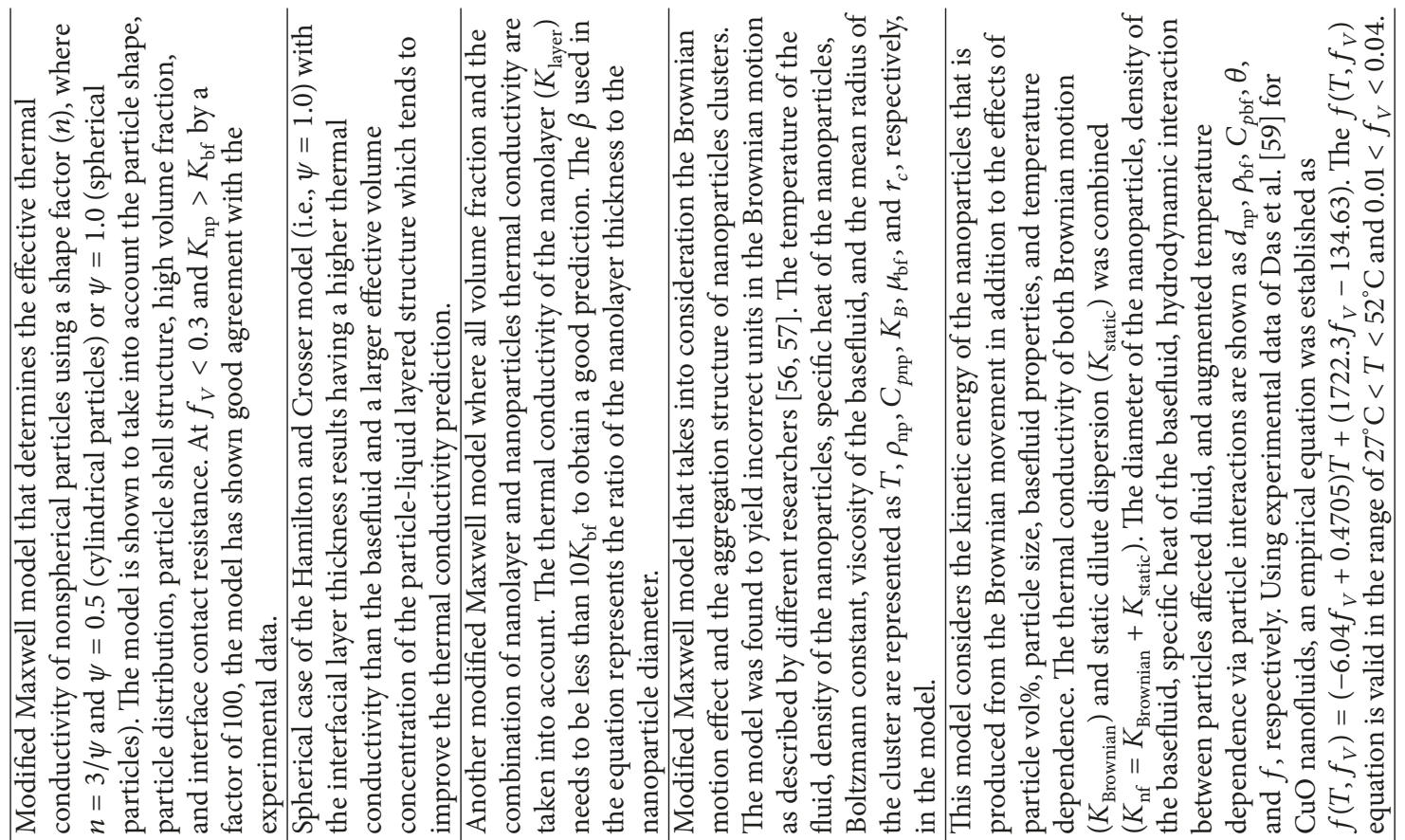

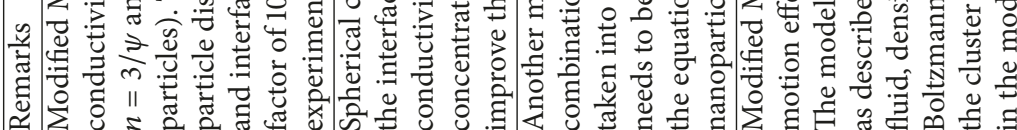

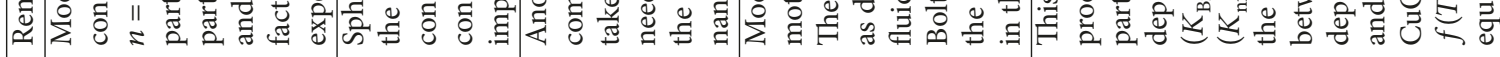

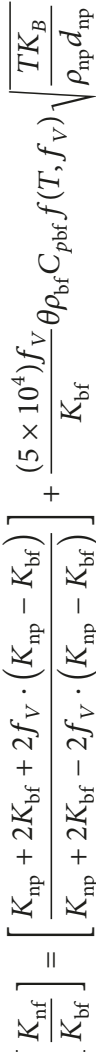

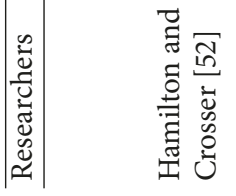

|

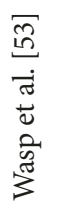

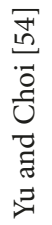

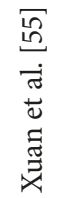

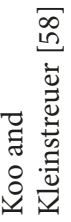




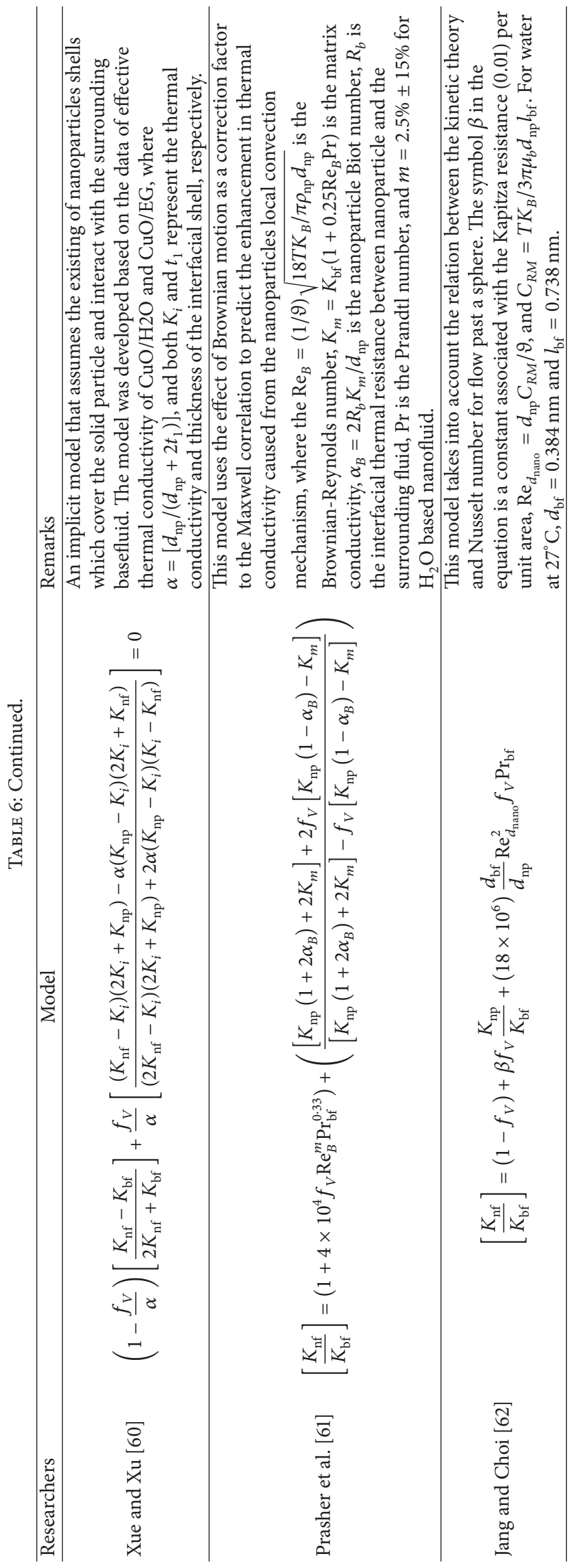


[263] pointed in their article that measuring techniques such as the laser flash and hot disk methods are more suitable for solids and powders and that the implementation of these two techniques are very complicated in comparison to the photoacustic approach. To the best of our knowledge and from reviewing many literature, there exists only one effective thermal diffusivity theoretical model (Eq. (7)), which is currently being used. This gap of knowledge needs to be encountered for in order to gain better prediction of the theoretical values with the experimental results.

5.5. Effective Viscosity. Nanofluid viscosity is a measure of the tendency of the suspension to resist the flow. It can also be defined as the ratio of the shear stress to the shear rate. The benefit associated with nanofluids heat enhancement is counteracted by the rise in effective viscosity caused from the added nanoparticles in the basefluid. This increase in viscosity leads to higher pressure losses and hence elevates the pumping power demands. The main parameters that influence the effective viscosity are the basefluid viscosity, nanoparticles concentration, particle shape, particle diameter, particles type, temperature, pressure, $\mathrm{pH}$ value, and shear rate [13]. Phenomenological hydrodynamic equations were the first attempts used, by Einstein, to calculate the effective viscosity of suspensions of spherical solids [271, 272]. Driven from the basefluid viscosity $\left(\mu_{\mathrm{bf}}\right)$ and $f_{V}$, the Einstein effective viscosity $\left(\mu_{\mathrm{nf}}\right)$ equation is given as

$$
\mu_{\mathrm{nf}}=\mu_{\mathrm{bf}} \cdot\left(1+2.5 f_{V}\right) .
$$

The viscosity of $\mu_{\mathrm{nf}}$ is always greater than $\mu_{\mathrm{bf}}$ and depends only on $f_{V}$ of the particles dispersed. Comparison between (8) and experimental data has shown that the equation can be used to predict the effective viscosity of nanofluids with vol $\% \leq 10^{-2}$. At a particle concentration of $10-15 \mathrm{vol} \%$, the interaction between the particles becomes more influential. For such reason, (8) had been modified continuously in an attempt to develop a much accurate effective viscosity correlation. The effective viscosity was also modified to represent a linear relation [273] as seen in (9), where $a$ is a coefficient that varies, based on the nanofluid, from 4.3 to 22 .

$$
\mu_{\mathrm{nf}}=\mu_{\mathrm{bf}} \cdot\left(1+\mathrm{a} f_{V}\right) .
$$

The results of (9) were found to be several times higher than the ones predicted by (8). Many other correlations were then developed to determine the effective viscosity of nanofluids, which can be found published [274, 275]. Unlike the effective density and the effective specific heat correlations, which are widely accepted by researchers, effective viscosity is considered to be one of the intensely discussed fields of research [82]. This is because several parameters affect the nanofluid effective viscosity such as particle size, particle shape, particle concentration, basefluid type, and nanofluid temperature. The effect of the particle size was first found by molecular dynamic simulation [276]. It was discovered that nanofluids, of particle size $1-2 \mathrm{~nm}$, had a reduction in their effective viscosity with the increase in nanoparticle size, which was also confirmed experimentally by Namburu et al. [277].
Up to now, the Einstein equation can be assumed to be the only available universal correlation that can predict the effective viscosity of nanofluids of low concentration [273]. In addition, the best available model, based on a committee machine intelligent system (CMIS), is the one developed by Hemmati-Sarapardeh et al. [275], which had approximately $4 \%$ relative error. Instruments used to determine the effective viscosity of nanofluids are capillary viscometer, piston type rheometer, and rotational rheometer.

\section{Challenges of Nanofluids and Future Direction}

Nanofluids have been shown to be superior, as a HTF, to conventional known fluids available in the market. In order to commercialise such type of advanced fluids, some factors are required to be improved and better understood by researchers. Examples of these factors are listed below $[13,26,82,99,106,213]$ :

(i) Experimental investigations of nanofluids need to be optimised with respect to stability, preparation technique, temperature, particle size, particle shape, and particles type.

(ii) The right ratio of nanoparticles to basefluid should be found to obtain the highest effective thermal conductivity as well as the lowest possible effective viscosity from the fabricated nanofluid. This is important to meet the applications of heat transfer and overcome the pressure drop in the system.

(iii) Additional research inputs are needed to develop much precise correlations, which can predict the changes in nanofluids $\mathrm{pH}$ value caused by temperature, particle concentration, type of basefluid, and so forth, since this affects the stability and thermophysical properties of nanofluids.

(iv) Several studies have considered the fouling effect of nanofluids in a thermal aspect but, to the best of our knowledge, have ignored their influence on the dynamics of the fluid. Though, if fully deposited on the inner pipe surface, it can provide similar wettability properties as nanocoating.

The aforementioned challenges need to be focused on and tackled by researches so that commercialisation of nanofluids can be possible.

\section{Conclusion}

The types of nanofluids, preparation approaches, fluid stability, and stability enhancement have been reviewed. The article also extends to the thermophysical properties of nanofluids, covering both the theoretical and experimental aspects. According to literature, several studies have discussed the potential of enhancing heat transfer using nanofluids and how the stability of a nanofluid affects its thermophysical properties. It was also pointed out that the stability of a nanofluid gets affected by a range of factors, such as 
preparation technique, $\mathrm{pH}$ value, nanoparticle concentration, particles type, particle shape, particle size, and fluid temperature.

To the best of our knowledge, in all the literature related to using nanofluids, no existing work related to controlling the temperature of the fluid while fabricating the nanofluid using an ultrasonicator has been reported. This preparation approach is very important as it can result in a completely different $\mathrm{pH}$ values, settling behaviour, particles agglomeration, and thermophysical properties. Additionally, using an ultrasonic device, for fabricating nanofluids, will increase the temperature of the fluid gradually but is strongly affected by the ambient temperature where the sample is prepared, meaning that various locations or different weather conditions will most likely result in producing a diverse nanofluid.

In addition, one can conclude from the literature that the major drawback of using such type of fluids is the rise in pressure losses in piping systems caused from the increase in viscosity of nanofluids. This increase in viscosity leads to a higher shear stress between the fluid and the surrounding surface. Moreover, the nanoparticles hosted by the fluid are most likely to deposit on the inner surface of the pipe when used in elevated temperature applications, causing what is known as the fouling effect. The deposited layer or foul would act similarly as inner pipe coating with nanoparticles (i.e., nanocoating) since the foul is formed from nanoparticles that were hosted by the carrier fluid itself. It was reported, by a number of authors, that nanocoating has the advantage of reducing the surface roughness which strongly influences the shear stress between the surface and the fluid [278]. Therefore, examining the wettability effect of nanoparticles of similar material type to the inner pipes can be very promising in encountering the pressure losses problem, while maintaining the thermal performance of the system.

\section{Conflicts of Interest}

The authors of this work declare that there are no conflicts of interest regarding the publication of this paper.

\section{Acknowledgments}

The authors would like to acknowledge the support provided by the Nanotechnology and Advanced Materials Program (NAM) at the Kuwait Institute for Scientific Research (KISR), Kuwait, and the School of Water, Energy and Environment (SWEE) at Cranfield University, UK. They are also grateful to Professor M. Sherif El-Eskandarany, the program manager of Nanotechnology and Advanced Materials Program at KISR, for providing his knowledge in the field.

\section{References}

[1] L. Coco-Enríquez, J. Muñoz-Antón, and J. M. Martínez-Val, "New text comparison between $\mathrm{CO} 2$ and other supercritical working fluids (ethane, $\mathrm{Xe}, \mathrm{CH} 4$ and N2) in line- focusing solar power plants coupled to supercritical Brayton power cycles,"
International Journal of Hydrogen Energy, vol. 42, no. 28, pp. 17611-17631, 2017.

[2] A. G. Memon and R. A. Memon, "Thermodynamic analysis of a trigeneration system proposed for residential application," Energy Conversion and Management, vol. 145, pp. 182-203, 2017.

[3] C. Yue, D. Han, W. Pu, and W. He, "Parametric analysis of a vehicle power and cooling/heating cogeneration system," Energy, vol. 115, pp. 800-810, 2016.

[4] K. Uebel, P. Rossger, U. Prüfert, A. Richter, and B. Meyer, "A new CO conversion quench reactor design," Fuel Processing Technology, vol. 148, pp. 198-208, 2016.

[5] S. U. S. Choi and J. A. Eastman, Enhancing Thermal Conductivity of Fluids with Nanoparticles, Argonne National Lab., 1995.

[6] M. Hashemian, S. Jafarmadar, J. Nasiri, and H. Sadighi Dizaji, "Enhancement of heat transfer rate with structural modification of double pipe heat exchanger by changing cylindrical form of tubes into conical form," Applied Thermal Engineering, vol. 118, pp. 408-417, 2017.

[7] J. C. Maxwell, A Treatise on Electricity and Magnetism, Clarendon Press, Oxford, UK, 1891

[8] S. U. S. Choi, Y. I. Cho, and K. E. Kasza, "Degradation effects of dilute polymer solutions on turbulent friction and heat transfer behavior," Journal of Non-Newtonian Fluid Mechanics, vol. 41, no. 3, pp. 289-307, 1992.

[9] U. Choi, D. M. France, and B. D. Knodel, "Impact of advanced fluids on costs of district cooling systems," in Argonne National Lab, 1992.

[10] U. Choi and T. Tran, "Experimental studies of the effects of non-Newtonian surfactant solutions on the performance of a shell-and-tube heat exchanger," in Recent Developments in NonNewtonian Flows and Industrial Applications, The American Society of Mechanical Engineers, New York, NY, USA, 1991.

[11] K. Liu, U. Choi, and K. E. Kasza, Measurements of Pressure Drop And Heat Transfer in Turbulent Pipe Flows of Particulate Slurries, Argonne National Lab., 1988.

[12] Y. Xuan and Q. Li, "Heat transfer enhancement of nanofluids," International Journal of Heat and Fluid Flow, vol. 21, no. 1, pp. 58-64, 2000.

[13] J. R. Eggers and S. Kabelac, "Nanofluids revisited," Applied Thermal Engineering, vol. 106, pp. 1114-1126, 2016.

[14] Z.-Q. Liu, J. Ma, and Y.-H. Cui, "Carbon nanotube supported platinum catalysts for the ozonation of oxalic acid in aqueous solutions," Carbon, vol. 46, no. 6, pp. 890-897, 2008.

[15] L. Jiang, L. Gao, and J. Sun, "Production of aqueous colloidal dispersions of carbon nanotubes," Journal of Colloid and Interface Science, vol. 260, no. 1, pp. 89-94, 2003.

[16] H. Chang, Y. Wu, X. Chen, and M. Kao, "Fabrication of Cu based nanofluid with superior dispersion," National Taipei University of Technology Journal, vol. 5, pp. 201-208, 2000.

[17] M. Sato, Y. Abe, Y. Urita, R. Di Paola, A. Cecere, and R. Savino, "Thermal performance of self-rewetting fluid heat pipe containing dilute solutions of polymer-capped silver nanoparticles synthesized by microwave-polyol process," International Journal of Transport Phenomena, vol. 12, no. 3/4, pp. 339-345, 2011.

[18] Y. Hwang, J. K. Lee, C. H. Lee et al., "Stability and thermal conductivity characteristics of nanofluids," Thermochimica Acta, vol. 455, no. 1-2, pp. 70-74, 2007.

[19] M. N. Pantzali, A. A. Mouza, and S. V. Paras, "Investigating the efficacy of nanofluids as coolants in plate heat exchangers (PHE)," Chemical Engineering Science, vol. 64, no. 14, pp. 32903300, 2009. 
[20] M. Chandrasekar, S. Suresh, and A. C. Bose, "Experimental investigations and theoretical determination of thermal conductivity and viscosity of $\mathrm{Al}_{2} \mathrm{O}_{3}$ /water nanofluid," Experimental Thermal and Fluid Science, vol. 34, no. 2, pp. 210-216, 2010.

[21] Y. Hwang, J.-K. Lee, J.-K. Lee et al., "Production and dispersion stability of nanoparticles in nanofluids," Powder Technology, vol. 186, no. 2, pp. 145-153, 2008.

[22] W. Yu, H. Xie, L. Chen, and Y. Li, "Enhancement of thermal conductivity of kerosene-based $\mathrm{Fe}_{3} \mathrm{O}_{4}$ nanofluids prepared via phase-transfer method," Colloids and Surfaces A: Physicochemical and Engineering Aspects, vol. 355, no. 1-3, pp. 109-113, 2010.

[23] L. Kong, J. Sun, and Y. Bao, "Preparation, characterization and tribological mechanism of nanofluids," RSC Advances, vol. 7, no. 21, pp. 12599-12609, 2017.

[24] X. F. Li, D. S. Zhu, X. J. Wang, N. Wang, J. W. Gao, and H. $\mathrm{Li}$, "Thermal conductivity enhancement dependent $\mathrm{pH}$ and chemical surfactant for $\mathrm{Cu}-\mathrm{H}_{2} \mathrm{O}$ nanofluids," Thermochimica Acta, vol. 469, no. 1-2, pp. 98-103, 2008.

[25] I. Madni, C.-Y. Hwang, S.-D. Park, Y.-H. Choa, and H.-T. Kim, "Mixed surfactant system for stable suspension of multiwalled carbon nanotubes," Colloids and Surfaces A: Physicochemical and Engineering Aspects, vol. 358, no. 1-3, pp. 101-107, 2010.

[26] D. Dey, P. Kumar, and S. Samantaray, "A review of nanofluid preparation, stability, and thermo-physical properties," Heat Transfer - Asian Research, vol. 46, no. 8, pp. 1413-1442, 2017.

[27] X. Li, D. Zhu, and X. Wang, "Evaluation on dispersion behavior of the aqueous copper nano-suspensions," Journal of Colloid and Interface Science, vol. 310, no. 2, pp. 456-463, 2007.

[28] H. J. Kim, I. C. Bang, and J. Onoe, "Characteristic stability of bare $\mathrm{Au}$-water nanofluids fabricated by pulsed laser ablation in liquids," Optics and Lasers in Engineering, vol. 47, no. 5, pp. 532538, 2009.

[29] G. Paul, S. Sarkar, T. Pal, P. K. Das, and I. Manna, "Concentration and size dependence of nano-silver dispersed water based nanofluids," Journal of Colloid and Interface Science, vol. 371, no. 1, pp. 20-27, 2012.

[30] J. Qu, H.-Y. Wu, and P. Cheng, "Thermal performance of an oscillating heat pipe with $\mathrm{Al}_{2} \mathrm{O}_{3}$-water nanofluids," International Communications in Heat and Mass Transfer, vol. 37, no. 2, pp. 111-115, 2010.

[31] K. B. Anoop, T. Sundararajan, and S. K. Das, "Effect of particle size on the convective heat transfer in nanofluid in the developing region," International Journal of Heat and Mass Transfer, vol. 52, no. 9-10, pp. 2189-2195, 2009.

[32] K. Rohini Priya, K. S. Suganthi, and K. S. Rajan, “Transport properties of ultra-low concentration $\mathrm{CuO}$-water nanofluids containing non-spherical nanoparticles," International Journal of Heat and Mass Transfer, vol. 55, no. 17-18, pp. 4734-4743, 2012.

[33] M. H. Chang, H. S. Liu, and C. Y. Tai, "Preparation of copper oxide nanoparticles and its application in nanofluid," Powder Technology, vol. 207, no. 1-3, pp. 378-386, 2011.

[34] Z.-H. Liu, J.-G. Xiong, and R. Bao, "Boiling heat transfer characteristics of nanofluids in a flat heat pipe evaporator with micro-grooved heating surface," International Journal of Multiphase Flow, vol. 33, no. 12, pp. 1284-1295, 2007.

[35] X.-F. Yang and Z.-H. Liu, "Pool boiling heat transfer of functionalized nanofluid under sub-atmospheric pressures," International Journal of Thermal Sciences, vol. 50, no. 12, pp. 2402-2412, 2011.

[36] J. Qu and H. Wu, "Thermal performance comparison of oscillating heat pipes with $\mathrm{SiO}$ 2/water and $\mathrm{Al} 2 \mathrm{O} 3$ /water nanofluids,"
International Journal of Thermal Sciences, vol. 50, no. 10, pp. 1954-1962, 2011.

[37] K. S. Suganthi and K. S. Rajan, “Temperature induced changes in $\mathrm{ZnO}$-water nanofluid: Zeta potential, size distribution and viscosity profiles," International Journal of Heat and Mass Transfer, vol. 55, no. 25-26, pp. 7969-7980, 2012.

[38] W. Duangthongsuk and S. Wongwises, "An experimental study on the heat transfer performance and pressure drop of $\mathrm{TiO}_{2}$ water nanofluids flowing under a turbulent flow regime," International Journal of Heat and Mass Transfer, vol. 53, no. 1-3, pp. 334-344, 2010.

[39] M. Hari, S. A. Joseph, S. Mathew, B. Nithyaja, V. P. N. Nampoori, and P. Radhakrishnan, "Thermal diffusivity of nanofluids composed of rod-shaped silver nanoparticles," International Journal of Thermal Sciences, vol. 64, pp. 188-194, 2013.

[40] M. Kole and T. K. Dey, “Thermal performance of screen mesh wick heat pipes using water-based copper nanofluids," Applied Thermal Engineering, vol. 50, no. 1, pp. 763-770, 2013.

[41] R. Kathiravan, R. Kumar, A. Gupta, and R. Chandra, "Preparation and pool boiling characteristics of copper nanofluids over a flat plate heater," International Journal of Heat and Mass Transfer, vol. 53, no. 9-10, pp. 1673-1681, 2010.

[42] T. Yousefi, E. Shojaeizadeh, F. Veysi, and S. Zinadini, "An experimental investigation on the effect of $\mathrm{pH}$ variation of MWCNT- $\mathrm{H}_{2} \mathrm{O}$ nanofluid on the efficiency of a flat-plate solar collector," Solar Energy, vol. 86, no. 2, pp. 771-779, 2012.

[43] P. Garg, J. L. Alvarado, C. Marsh, T. A. Carlson, D. A. Kessler, and K. Annamalai, "An experimental study on the effect of ultrasonication on viscosity and heat transfer performance of multiwall carbon nanotube-based aqueous nanofluids," International Journal of Heat and Mass Transfer, vol. 52, no. 21-22, pp. 50905101, 2009.

[44] Y. Ding, H. Alias, D. Wen, and R. A. Williams, "Heat transfer of aqueous suspensions of carbon nanotubes (CNT nanofluids)," International Journal of Heat and Mass Transfer, vol. 49, no. 1-2, pp. 240-250, 2006.

[45] M. Abareshi, E. K. Goharshadi, S. Mojtaba Zebarjad, H. Khandan Fadafan, and A. Youssefi, "Fabrication, characterization and measurement of thermal conductivity of $\mathrm{Fe} 3 \mathrm{O} 4$ nanofluids," Journal of Magnetism and Magnetic Materials, vol. 322, no. 24, pp. 3895-3901, 2010.

[46] T. X. Phuoc, Y. Soong, and M. K. Chyu, "Synthesis of Agdeionized water nanofluids using multi-beam laser ablation in liquids," Optics and Lasers in Engineering, vol. 45, no. 12, pp. 1099-1106, 2007.

[47] T. Parametthanuwat, S. Rittidech, and A. Pattiya, "A correlation to predict heat-transfer rates of a two-phase closed thermosyphon (TPCT) using silver nanofluid at normal operating conditions," International Journal of Heat and Mass Transfer, vol. 53, no. 21-22, pp. 4960-4965, 2010.

[48] T. Yousefi, F. Veysi, E. Shojaeizadeh, and S. Zinadini, "An experimental investigation on the effect of $\mathrm{Al}_{2} \mathrm{O}_{3}-\mathrm{H}_{2} \mathrm{O}$ nanofluid on the efficiency of flat-plate solar collectors," Journal of Renewable Energy, vol. 39, no. 1, pp. 293-298, 2012.

[49] Y.-H. Hung, T.-P. Teng, and B.-G. Lin, "Evaluation of the thermal performance of a heat pipe using alumina nanofluids," Experimental Thermal and Fluid Science, vol. 44, pp. 504-511, 2013.

[50] M. M. Heyhat, F. Kowsary, A. M. Rashidi, M. H. Momenpour, and A. Amrollahi, "Experimental investigation of laminar convective heat transfer and pressure drop of water-based 
$\mathrm{Al}_{2} \mathrm{O}_{3}$ nanofluids in fully developed flow regime," Experimental Thermal and Fluid Science, vol. 44, pp. 483-489, 2013.

[51] M. M. Tawfik, "Experimental studies of nanofluid thermal conductivity enhancement and applications: A review," Renewable \& Sustainable Energy Reviews, vol. 75, pp. 1239-1253, 2017.

[52] R. L. Hamilton and O. K. Crosser, "Thermal conductivity of heterogeneous two-component systems," Industrial \& Engineering Chemistry Fundamentals, vol. 1, no. 3, pp. 187-191, 1962.

[53] E. J. Wasp, J. P. Kenny, and R. L. Gandhi, Solid-Liquid Flow: Slurry Pipeline Transportation, Pumps, valves, mechanical equipment, economics, 1977.

[54] W. Yu and S. U. S. Choi, "The role of interfacial layers in the enhanced thermal conductivity of nanofluids: A renovated Maxwell model," Journal of Nanoparticle Research, vol. 5, no. 1-2, pp. 167-171, 2003.

[55] Y. Xuan, Q. Li, and W. Hu, "Aggregation structure and thermal conductivity of nanofluids," AIChE Journal, vol. 49, no. 4, pp. 1038-1043, 2003.

[56] P. Keblinski, J. A. Eastman, and D. G. Cahill, "Nanofluids for thermal transport," Materials Today, vol. 8, no. 6, pp. 36-44, 2005.

[57] R. S. Vajjha and D. K. Das, "Experimental determination of thermal conductivity of three nanofluids and development of new correlations," International Journal of Heat and Mass Transfer, vol. 52, no. 21-22, pp. 4675-4682, 2009.

[58] J. Koo and C. Kleinstreuer, "A new thermal conductivity model for nanofluids," Journal of Nanoparticle Research, vol. 6, no. 6, pp. 577-588, 2004.

[59] S. K. Das, N. Putra, P. Thiesen, and W. Roetzel, “Temperature dependence of thermal conductivity enhancement for nanofluids," Journal of Heat Transfer, vol. 125, no. 4, pp. 567-574, 2003.

[60] Q. Xue and W.-M. Xu, "A model of thermal conductivity of nanofluids with interfacial shells," Materials Chemistry and Physics, vol. 90, no. 2-3, pp. 298-301, 2005.

[61] R. Prasher, P. Bhattacharya, and P. E. Phelan, "Brownianmotion-based convective-conductive model for the effective thermal conductivity of nanofluids," Journal of Heat Transfer, vol. 128, no. 6, pp. 588-595, 2006.

[62] S. P. Jang and S. U. S. Choi, "Role of Brownian motion in the enhanced thermal conductivity of nanofluids," Applied Physics Letters, vol. 84, no. 21, pp. 4316-4318, 2004.

[63] K. S. Suganthi and K. S. Rajan, "Metal oxide nanofluids: Review of formulation, thermo-physical properties, mechanisms, and heat transfer performance," Renewable \& Sustainable Energy Reviews, vol. 76, pp. 226-255, 2017.

[64] D. Wen, G. Lin, S. Vafaei, and K. Zhang, "Review of nanofluids for heat transfer applications," Particuology, vol. 7, no. 2, pp. 141150, 2009.

[65] N. Ali, J. A. Teixeira, A. Addali, F. Al-Zubi, E. Shaban, and I. Behbehani, "The effect of aluminium nanocoating and water $\mathrm{pH}$ value on the wettability behavior of an aluminium surface," Applied Surface Science, vol. 443, pp. 24-30, 2018.

[66] M. Kang, J. W. Lee, and Y. T. Kang, "Reduction of liquid pumping power by nanoscale surface coating," International Journal of Refrigeration, vol. 71, pp. 8-17, 2016.

[67] P. Ganesan, S. M. Vanaki, K. K. Thoo, and W. M. Chin, "Airside heat transfer characteristics of hydrophobic and superhydrophobic fin surfaces in heat exchangers: A review," International Communications in Heat and Mass Transfer, vol. 74, pp. 27-35, 2016.
[68] W. Yu and H. Xie, "A review on nanofluids: preparation, stability mechanisms, and applications," Journal of Nanomaterials, vol. 2012, Article ID 435873, 17 pages, 2012.

[69] S. Mukherjee, "Preparation and Stability of Nanofluids-A Review," IOSR Journal of Mechanical and Civil Engineering, vol. 9, no. 2, pp. 63-69, 2013.

[70] R. Mondragon, J. E. Julia, A. Barba, and J. C. Jarque, "Characterization of silica-water nanofluids dispersed with an ultrasound probe: A study of their physical properties and stability," Powder Technology, vol. 224, pp. 138-146, 2012.

[71] D. Wen and Y. Ding, "Formulation of nanofluids for natural convective heat transfer applications," International Journal of Heat and Fluid Flow, vol. 26, no. 6, pp. 855-864, 2005.

[72] M. J. Pastoriza-Gallego, C. Casanova, R. Páramo, B. Barbés, J. L. Legido, and M. M. Piñeiro, "A study on stability and thermophysical properties (density and viscosity) of Al2 O3 in water nanofluid," Journal of Applied Physics, vol. 106, no. 6, Article ID 064301, 2009.

[73] L. Chen and H. Xie, "Properties of carbon nanotube nanofluids stabilized by cationic gemini surfactant," Thermochimica Acta, vol. 506, no. 1-2, pp. 62-66, 2010.

[74] S. U. Ilyas, R. Pendyala, and N. Marneni, "Settling characteristics of alumina nanoparticles in ethanol-water mixtures," Applied Mechanics and Materials, vol. 372, pp. 143-148, 2013.

[75] S. Witharana, C. Hodges, D. Xu, X. Lai, and Y. Ding, "Aggregation and settling in aqueous polydisperse alumina nanoparticle suspensions," Journal of Nanoparticle Research, vol. 14, article 851, 2012.

[76] D.-W. Oh, A. Jain, J. K. Eaton, K. E. Goodson, and J. S. Lee, "Thermal conductivity measurement and sedimentation detection of aluminum oxide nanofluids by using the $3 \omega$ method," International Journal of Heat and Fluid Flow, vol. 29, no. 5, pp. 1456-1461, 2008.

[77] S. Nallusamy, "Thermal conductivity analysis and characterization of copper oxide nanofluids through different techniques," Journal of Nano Research, vol. 40, pp. 102-112, 2015.

[78] P. Razi, M. A. Akhavan-Behabadi, and M. Saeedinia, "Pressure drop and thermal characteristics of CuO-base oil nanofluid laminar flow in flattened tubes under constant heat flux," International Communications in Heat and Mass Transfer, vol. 38, no. 7, pp. 964-971, 2011.

[79] M.-A. Neouze and U. Schubert, "Surface modification and functionalization of metal and metal oxide nanoparticles by organic ligands," Monatshefte für Chemie, vol. 139, no. 3, pp. 183195, 2008.

[80] Q500 Sonicator-Qsonica, QSONICA SONICATORS, 2017.

[81] "Digital Bench-Top Ultrasonic Cleaners - Soniclean — So Easy - So Fast - So Clean," Soniclean, 2017.

[82] M. Gupta, V. Singh, R. Kumar, and Z. Said, "A review on thermophysical properties of nanofluids and heat transfer applications," Renewable \& Sustainable Energy Reviews, vol. 74, pp. 638-670, 2017.

[83] M. M. Sarafraz, V. Nikkhah, M. Nakhjavani, and A. Arya, "Fouling formation and thermal performance of aqueous carbon nanotube nanofluid in a heat sink with rectangular parallel microchannel," Applied Thermal Engineering, vol. 123, pp. 2939, 2017.

[84] M. M. Sarafraz, F. Hormozi, and S. M. Peyghambarzadeh, "Role of nanofluid fouling on thermal performance of a thermosyphon: Are nanofluids reliable working fluid?" Applied Thermal Engineering, vol. 82, pp. 212-224, 2015. 
[85] M. M. Sarafraz and F. Hormozi, "Convective boiling and particulate fouling of stabilized $\mathrm{CuO}$-ethylene glycol nanofluids inside the annular heat exchanger," International Communications in Heat and Mass Transfer, vol. 53, pp. 116-123, 2014.

[86] V. Nikkhah, M. M. Sarafraz, F. Hormozi, and S. M. Peyghambarzadeh, "Particulate fouling of $\mathrm{CuO}$-water nanofluid at isothermal diffusive condition inside the conventional heat exchanger-experimental and modeling," Experimental Thermal and Fluid Science, vol. 60, pp. 83-95, 2014.

[87] M. M. Sarafraz, V. Nikkhah, S. A. Madani, M. Jafarian, and F. Hormozi, "Low-frequency vibration for fouling mitigation and intensification of thermal performance of a plate heat exchanger working with $\mathrm{CuO}$ /water nanofluid," Applied Thermal Engineering, vol. 121, pp. 388-399, 2017.

[88] K. H. Teng, A. Amiri, S. N. Kazi et al., "Retardation of heat exchanger surfaces mineral fouling by water-based diethylenetriamine pentaacetate-treated CNT nanofluids," Applied Thermal Engineering, vol. 110, pp. 495-503, 2017.

[89] K. Kouloulias, A. Sergis, and Y. Hardalupas, "Sedimentation in nanofluids during a natural convection experiment," International Journal of Heat and Mass Transfer, vol. 101, pp. 1193-1203, 2016.

[90] H. T. Phan, N. Caney, P. Marty, S. Colasson, and J. Gavillet, "Surface wettability control by nanocoating: the effects on pool boiling heat transfer and nucleation mechanism," International Journal of Heat and Mass Transfer, vol. 52, no. 23-24, pp. 54595471, 2009.

[91] M. E. Burnett and S. Q. Wang, "Current sunscreen controversies: A critical review," Photodermatology, Photoimmunology \& Photomedicine, vol. 27, no. 2, pp. 58-67, 2011.

[92] D. Lapotko, "Erratum: Plasmonic nanoparticle-generated photothermal bubbles and their biomedical applications (Nanomedicine (Nanomedicine [Lond.]) (2009) 4:7 (813-845))," Nanomedicine, vol. 11, no. 5, p. 566, 2016.

[93] K. Maier-Hauff, R. Rothe, and R. Scholz, "Intracranial thermotherapy using magnetic nanoparticles combined with external beam radiotherapy: results of a feasibility study on patients with glioblastoma multiforme," Journal of Neuro-Oncology, vol. 81, no. 1, pp. 53-60, 2007.

[94] D. P. Kulkarni, D. K. Das, and R. S. Vajjha, "Application of nanofluids in heating buildings and reducing pollution," Applied Energy, vol. 86, no. 12, pp. 2566-2573, 2009.

[95] L. Vékás, D. Bica, and M. V. Avdeev, "Magnetic nanoparticles and concentrated magnetic nanofluids: synthesis, properties and some applications," China Particuology, vol. 5, no. 1-2, pp. 43-49, 2007.

[96] T. Sharma, A. L. M. Reddy, T. S. Chandra, and S. Ramaprabhu, "Development of carbon nanotubes and nanofluids based microbial fuel cell," International Journal of Hydrogen Energy, vol. 33, no. 22, pp. 6749-6754, 2008.

[97] R. Taylor, S. Coulombe, T. Otanicar et al., "Small particles, big impacts: a review of the diverse applications of nanofluids," Journal of Applied Physics, vol. 113, no. 1, Article ID 011301, 2013.

[98] Scopus-Database, Nanofluids analyze search results from 2015 to 2018, Elsevier, 2018.

[99] N. K. Gupta, A. K. Tiwari, and S. K. Ghosh, "Heat transfer mechanisms in heat pipes using nanofluids - A review," Experimental Thermal and Fluid Science, vol. 90, pp. 84-100, 2018.

[100] L. S. Sundar, K. V. Sharma, M. K. Singh, and A. C. M. Sousa, "Hybrid nanofluids preparation, thermal properties, heat transfer and friction factor - A review," Renewable \& Sustainable Energy Reviews, vol. 68, pp. 185-198, 2017.
[101] M. Modak, S. S. Chougule, and S. K. Sahu, "An Experimental Investigation on Heat Transfer Characteristics of Hot Surface by Using CuO-Water Nanofluids in Circular Jet Impingement Cooling," Journal of Heat Transfer, vol. 140, no. 1, Article ID 012401, 2018.

[102] L. Yang and K. Du, "A comprehensive review on heat transfer characteristics of $\mathrm{TiO} 2$ nanofluids," International Journal of Heat and Mass Transfer, vol. 108, pp. 11-31, 2017.

[103] W. H. Azmi, M. Z. Sharif, T. M. Yusof, R. Mamat, and A. A. M. Redhwan, "Potential of nanorefrigerant and nanolubricant on energy saving in refrigeration system - A review," Renewable \& Sustainable Energy Reviews, vol. 69, pp. 415-428, 2017.

[104] K. S. Reddy, N. R. Kamnapure, and S. Srivastava, "Nanofluid and nanocomposite applications in solar energy conversion systems for performance enhancement: A review," International Journal of Low-Carbon Technologies, vol. 12, no. 1, pp. 1-23, 2017.

[105] S. Jana, A. Salehi-Khojin, and W.-H. Zhong, "Enhancement of fluid thermal conductivity by the addition of single and hybrid nano-additives," Thermochimica Acta, vol. 462, no. 1-2, pp. 4555, 2007.

[106] W. Chamsa-ard, S. Brundavanam, C. C. Fung, D. Fawcett, and G. Poinern, "Nanofluid types, their synthesis, properties and incorporation in direct solar thermal collectors: A review," Nanomaterials, vol. 7, no. 6, article no. 131, 2017.

[107] H. Akoh, Y. Tsukasaki, S. Yatsuya, and A. Tasaki, "Magnetic properties of ferromagnetic ultrafine particles prepared by vacuum evaporation on running oil substrate," Journal of Crystal Growth, vol. 45, no. C, pp. 495-500, 1978.

[108] M. Wagener, B. S. Murty, and B. Günther, "Preparation of metal nanosuspensions by high-pressure dc-sputtering on running liquids," in Proceedings of the 1996 MRS Fall Symposium, E. P. George, R. Gotthardt, K. Otsuka, S. Trolier-McKinstry, and M. Wun-Fogle, Eds., pp. 149-154, Materials Research Society, Pittsburgh, PA, USA, 1997.

[109] J. A. Eastman, S. U. Choi, S. Li, L. J. Thompson, and S. Lee, "Enhanced thermal conductivity through the development of nanofluids," in Proceedings of the 1996 MRS Fall Symposium, E. P. George, R. Gotthardt, K. Otsuka, S. Trolier-McKinstry, and M. Wun-Fogle, Eds., vol. 457, pp. 3-11, Materials Research Society, Pittsburgh, PA, USA, 1997.

[110] H.-T. Zhu, Y.-S. Lin, and Y.-S. Yin, "A novel one-step chemical method for preparation of copper nanofluids," Journal of Colloid and Interface Science, vol. 277, no. 1, pp. 100-103, 2004.

[111] P. X. Tran and Y. Soong, Preparation of nanofluids using laser ablation in liquid technique, United States, Not published presentation only, 2007.

[112] C.-H. Lo, T.-T. Tsung, and L.-C. Chen, "Shape-controlled synthesis of Cu-based nanofluid using submerged arc nanoparticle synthesis system (SANSS)," Journal of Crystal Growth, vol. 277, no. 1-4, pp. 636-642, 2005.

[113] C.-H. Lo, T.-T. Tsung, and L.-C. Chen, "Ni nano-magnetic fluid prepared by submerged arc nano synthesis system (SANSS)," JSME International Journal Series B Fluids and Thermal Engineering, vol. 48, no. 4, pp. 750-755, 2006.

[114] X. Wang and X. Xu, "Thermal conductivity of nanoparticle-fluid mixture," Journal of Thermophysics and Heat Transfer, vol. 13, no. 4, pp. 474-480, 1999.

[115] S. Lee, S. U. Choi, S. Li, and J. A. Eastman, "Measuring thermal conductivity of fluids containing oxide nanoparticles," Journal of Heat Transfer, vol. 121, no. 2, pp. 280-289, 1999. 
[116] S. M. S. Murshed, K. C. Leong, and C. Yang, "Enhanced thermal conductivity of $\mathrm{TiO}_{2}$ water based nanofluids," International Journal of Thermal Sciences, vol. 44, no. 4, pp. 367-373, 2005.

[117] Q. Yu, Y. J. Kim, and H. Ma, "Nanofluids with plasma treated diamond nanoparticles," Applied Physics Letters, vol. 92, no. 10, Article ID 103111, 2008.

[118] M. S. Liu, M. Ching-Cheng Lin, I. T. Huang, and C. C. Wang, "Enhancement of thermal conductivity with carbon nanotube for nanofluids," International Communications in Heat and Mass Transfer, vol. 32, no. 9, pp. 1202-1210, 2005.

[119] S. Boncel, A. Zniszczoł, M. Pawlyta, K. Labisz, and G. Dzido, "Heat transfer nanofluid based on curly ultra-long multi-wall carbon nanotubes," Heat and Mass Transfer, pp. 333-339, 2017.

[120] A. Arya, M. M. Sarafraz, S. Shahmiri, S. A. H. Madani, V. Nikkhah, and S. M. Nakhjavani, "Thermal performance analysis of a flat heat pipe working with carbon nanotube-water nanofluid for cooling of a high heat flux heater," Heat and Mass Transfer, pp. 1-13, 2017.

[121] J. A. Eastman, S. U. S. Choi, S. Li, W. Yu, and L. J. Thompson, "Anomalously increased effective thermal conductivities of ethylene glycol-based nanofluids containing copper nanoparticles," Applied Physics Letters, vol. 78, no. 6, pp. 718-720, 2001.

[122] M. K. Bushehri, A. Mohebbi, and H. H. Rafsanjani, "Prediction of thermal conductivity and viscosity of nanofluids by molecular dynamics simulation," Journal of Engineering Thermophysics, vol. 25, no. 3, pp. 389-400, 2016.

[123] J. Hong and D. Kim, "Effects of aggregation on the thermal conductivity of alumina/water nanofluids," Thermochimica Acta, vol. 542, pp. 28-32, 2012.

[124] O. Arthur and M. A. Karim, "An investigation into the thermophysical and rheological properties of nanofluids for solar thermal applications," Renewable \& Sustainable Energy Reviews, vol. 55, pp. 739-755, 2016.

[125] H. Setia, R. Gupta, and R. K. Wanchoo, "Stability of nanofluids," Materials Science Forum, vol. 757, pp. 139-149, 2013.

[126] J. M. Wu and J. Zhao, "A review of nanofluid heat transfer and critical heat flux enhancement-research gap to engineering application," Progress in Nuclear Energy, vol. 66, pp. 13-24, 2013.

[127] A. Ghadimi, R. Saidur, and H. S. C. Metselaar, "A review of nanofluid stability properties and characterization in stationary conditions," International Journal of Heat and Mass Transfer, vol. 54, no. 17-18, pp. 4051-4068, 2011.

[128] H. Chang, C. S. Jwo, P. S. Fan, and S. H. Pai, "Process optimization and material properties for nanofluid manufacturing," The International Journal of Advanced Manufacturing Technology, vol. 34, no. 3-4, pp. 300-306, 2007.

[129] X.-J. Wang, D.-S. Zhu, and S. yang, "Investigation of $\mathrm{pH}$ and SDBS on enhancement of thermal conductivity in nanofluids," Chemical Physics Letters, vol. 470, no. 1-3, pp. 107-111, 2009.

[130] X. Wei and L. Wang, "Synthesis and thermal conductivity of microfluidic copper nanofluids," Particuology, vol. 8, no. 3, pp. 262-271, 2010.

[131] X. Wei, H. Zhu, T. Kong, and L. Wang, "Synthesis and thermal conductivity of $\mathrm{Cu} 2 \mathrm{O}$ nanofluids," International Journal of Heat and Mass Transfer, vol. 52, no. 19-20, pp. 4371-4374, 2009.

[132] S. U. Ilyas, R. Pendyala, and N. Marneni, "Preparation, sedimentation, and agglomeration of nanofluids," Chemical Engineering \& Technology, vol. 37, no. 12, pp. 2011-2021, 2014.

[133] W. Xian-Ju and L. Xin-Fang, "Influence of pH on Nanofluids' Viscosity and Thermal Conductivity," Chinese Physics Letters, vol. 26, no. 5, p. 056601, 2009.
[134] S. A. Angayarkanni and J. Philip, "Effect of nanoparticles aggregation on thermal and electrical conductivities of nanofluids," Journal of Nanofluids, vol. 3, no. 1, pp. 17-25, 2014.

[135] S. U. Ilyas, R. Pendyala, and N. Marneni, "Stability and Agglomeration of Alumina Nanoparticles in Ethanol-Water Mixtures," in Proceedings of the 4th International Conference on Process Engineering and Advanced Materials, ICPEAM 2016, M. A. Bustam, L. K. Keong, Z. Man, A. A. Hassankiadeh, and Y. Y. Fong, Eds., pp. 290-297, August 2016.

[136] M. A. Lemes, D. Rabelo, and A. E. De Oliveira, "A novel method to evaluate nanofluid stability using multivariate image analysis," Analytical Methods, vol. 9, no. 39, pp. 5826-5833, 2017.

[137] A. K. Singh and V. S. Raykar, "Microwave synthesis of silver nanofluids with polyvinylpyrrolidone (PVP) and their transport properties," Colloid and Polymer Science, vol. 286, no. 14-15, pp. 1667-1673, 2008.

[138] D. Li and R. B. Kaner, "Processable stabilizer-free polyaniline nanofiber aqueous colloids," Chemical Communications, no. 26, pp. 3286-3288, 2005.

[139] M. Mehrali, E. Sadeghinezhad, M. A. Rosen et al., "Heat transfer and entropy generation for laminar forced convection flow of graphene nanoplatelets nanofluids in a horizontal tube," International Communications in Heat and Mass Transfer, vol. 66, pp. 23-31, 2015.

[140] D. G. Souza, B. Bellaver, G. S. Raupp, D. O. Souza, and A. Quincozes-Santos, "Astrocytes from adult Wistar rats aged in vitro show changes in glial functions," Neurochemistry International, vol. 90, pp. 93-97, 2015.

[141] V. A. Martínez, D. A. Vasco, and C. M. García-Herrera, "Transient measurement of the thermal conductivity as a tool for the evaluation of the stability of nanofluids subjected to a pressure treatment," International Communications in Heat and Mass Transfer, vol. 91, pp. 234-238, 2018.

[142] N. R. Karthikeyan, J. Philip, and B. Raj, "Effect of clustering on the thermal conductivity of nanofluids," Materials Chemistry and Physics, vol. 109, no. 1, pp. 50-55, 2008.

[143] P. K. Das, N. Islam, A. K. Santra, and R. Ganguly, "Experimental investigation of thermophysical properties of Al2O3-water nanofluid: Role of surfactants," Journal of Molecular Liquids, vol. 237, pp. 304-312, 2017.

[144] H.-S. Kim, F. Yilmaz, P. Dharmaiah, D.-J. Lee, T.-H. Lee, and S.-J. Hong, "Characterization of $\mathrm{Cu}$ and Ni Nano-Fluids Synthesized by Pulsed Wire Evaporation Method," Archives of Metallurgy and Materials, vol. 62, no. 2, pp. 999-1004, 2017.

[145] S. Rubalya Valantina, K. Arockia Jayalatha, D. Phebee Angeline, S. Uma, and B. Ashvanth, "Synthesis and characterisation of electro-rheological property of novel eco-friendly rice bran oil and nanofluid," Journal of Molecular Liquids, vol. 256, pp. 256266, 2018.

[146] D. Wu, H. Zhu, L. Wang, and L. Liu, "Critical issues in nanofluids preparation, characterization and thermal conductivity," Current Molecular Pharmacology, vol. 5, no. 1, pp. 103-112, 2009.

[147] A. M. Tiara, S. Chakraborty, I. Sarkar, A. Ashok, S. K. Pal, and S. Chakraborty, "Heat transfer enhancement using surfactant based alumina nanofluid jet from a hot steel plate," Experimental Thermal and Fluid Science, vol. 89, pp. 295-303, 2017.

[148] L. Chen, H. Xie, Y. Li, and W. Yu, "Nanofluids containing carbon nanotubes treated by mechanochemical reaction," Thermochimica Acta, vol. 477, no. 1-2, pp. 21-24, 2008.

[149] Z. Mingzheng, X. Guodong, L. Jian, C. Lei, and Z. Lijun, "Analysis of factors influencing thermal conductivity and viscosity in 
different kinds of surfactant solutions," Experimental Thermal and Fluid Science, vol. 36, pp. 22-29, 2012.

[150] E. V. Timofeeva, M. R. Moravek, and D. Singh, "Improving the heat transfer efficiency of synthetic oil with silica nanoparticles," Journal of Colloid and Interface Science, vol. 364, no. 1, pp. 71-79, 2011.

[151] M. D. Byrne, R. A. Hart, and A. K. da Silva, "Experimental thermal-hydraulic evaluation of $\mathrm{CuO}$ nanofluids in microchannels at various concentrations with and without suspension enhancers," International Journal of Heat and Mass Transfer, vol. 55, no. 9-10, pp. 2684-2691, 2012.

[152] M. H. Kayhani, H. Soltanzadeh, M. M. Heyhat, M. Nazari, and F. Kowsary, "Experimental study of convective heat transfer and pressure drop of $\mathrm{TiO}_{2}$ /water nanofluid," International Communications in Heat and Mass Transfer, vol. 39, no. 3, pp. 456-462, 2012.

[153] H. Han, Y. Zhang, N. Wang et al., "Functionalization mediates heat transport in graphene nanoflakes," Nature Communications, vol. 7, Article ID 11281, 2016.

[154] I. M. Mahbubul, E. B. Elcioglu, R. Saidur, and M. A. Amalina, "Optimization of ultrasonication period for better dispersion and stability of TiO2-water nanofluid," Ultrasonics Sonochemistry, vol. 37, pp. 360-367, 2017.

[155] S. J. Chung, J. P. Leonard, I. Nettleship et al., "Characterization of $\mathrm{ZnO}$ nanoparticle suspension in water: effectiveness of ultrasonic dispersion," Powder Technology, vol. 194, no. 1-2, pp. 75-80, 2009.

[156] G. Petzold, R. Rojas-Reyna, M. Mende, and S. Schwarz, "Application relevant characterization of aqueous silica nanodispersions," Journal of Dispersion Science and Technology, vol. 30, no. 8, pp. 1216-1222, 2009.

[157] M. Kole and T. K. Dey, "Effect of prolonged ultrasonication on the thermal conductivity of $\mathrm{ZnO}$-ethylene glycol nanofluids," Thermochimica Acta, vol. 535, pp. 58-65, 2012.

[158] X.-F. Peng, X.-L. Yu, L.-F. Xia, and X. Zhong, "Influence factors on suspension stability of nanofluids," Zhejiang Daxue Xuebao (Gongxue Ban)/Journal of Zhejiang University (Engineering Science), vol. 41, no. 4, pp. 577-580, 2007.

[159] R. Choudhary, D. Khurana, A. Kumar, and S. Subudhi, "Stability analysis of Al2O3/water nanofluids," Journal of Experimental Nanoscience, pp. 1-12, 2017.

[160] R. Azizian, E. Doroodchi, and B. Moghtaderi, "Influence of controlled aggregation on thermal conductivity of nanofluids," Journal of Heat Transfer, vol. 138, no. 2, Article ID 021301, 2016.

[161] S. Askari, H. Koolivand, M. Pourkhalil, R. Lotfi, and A. Rashidi, "Investigation of Fe3O4/Graphene nanohybrid heat transfer properties: Experimental approach," International Communications in Heat and Mass Transfer, vol. 87, pp. 30-39, 2017.

[162] M. Mohammadi, M. Dadvar, and B. Dabir, “TiO2/SiO2 nanofluids as novel inhibitors for the stability of asphaltene particles in crude oil: Mechanistic understanding, screening, modeling, and optimization," Journal of Molecular Liquids, vol. 238, pp. 326-340, 2017.

[163] K. Y. Leong, Z. A. Najwa, K. Z. Ku Ahmad, and H. C. Ong, "Investigation on Stability and Optical Properties of Titanium Dioxide and Aluminum Oxide Water-Based Nanofluids," International Journal of Thermophysics, vol. 38, no. 5, article no. 77, 2017.

[164] P. C. M. Kumar and M. Muruganandam, "Stability analysis of heat transfer MWCNT with different base fluids," Journal of Applied Fluid Mechanics, vol. 10, pp. 51-59, 2017.
[165] A. Menbari, A. A. Alemrajabi, and Y. Ghayeb, "Investigation on the stability, viscosity and extinction coefficient of $\mathrm{CuO}$ $\mathrm{Al} 2 \mathrm{O} 3 /$ Water binary mixture nanofluid," Experimental Thermal and Fluid Science, vol. 74, pp. 122-129, 2016.

[166] S. Witharana, I. Palabiyik, Z. Musina, and Y. Ding, "Stability of glycol nanofluids - The theory and experiment," Powder Technology, vol. 239, pp. 72-77, 2013.

[167] S. Manjula, S. M. Kumar, A. M. Raichur, G. M. Madhu, R. Suresh, and M. A. Raj, "A sedimentation study to optimize the dispersion of alumina nanoparticles in water," Cerâmica, vol. 51, no. 318, pp. 121-127, 2005.

[168] D. Zhu, X. Li, N. Wang, X. Wang, J. Gao, and H. Li, “Dispersion behavior and thermal conductivity characteristics of $\mathrm{Al}_{2} \mathrm{O}_{3}$ $\mathrm{H}_{2} \mathrm{O}$ nanofluids," Current Applied Physics, vol. 9, no. 1, pp. 131139, 2009.

[169] D. Lee, J.-W. Kim, and B. G. Kim, "A new parameter to control heat transport in nanofluids: Surface charge state of the particle in suspension," The Journal of Physical Chemistry B, vol. 110, no. 9, pp. 4323-4328, 2006.

[170] H. Chang, X.-Q. Chen, C.-S. Jwo, and S.-L. Chen, "Electrostatic and sterical stabilization of $\mathrm{CuO}$ nanofluid prepared by vacuum arc spray nanofluid synthesis system (ASNSS)," Materials Transactions, vol. 50, no. 8, pp. 2098-2103, 2009.

[171] Y. Y. Song, H. K. D. H. Bhadeshia, and D.-W. Suh, "Stability of stainless-steel nanoparticle and water mixtures," Powder Technology, vol. 272, pp. 34-44, 2015.

[172] B. C. Pak and Y. I. Cho, "Hydrodynamic and heat transfer study of dispersed fluids with submicron metallic oxide particles," Experimental Heat Transfer, vol. 11, no. 2, pp. 151-170, 1998.

[173] R. S. Vajjha, D. K. Das, and B. M. Mahagaonkar, "Density measurement of different nanofluids and their comparison with theory," Petroleum Science and Technology, vol. 27, no. 6, pp. 612624, 2009.

[174] I. Behroyan, S. M. Vanaki, P. Ganesan, and R. Saidur, "A comprehensive comparison of various CFD models for convective heat transfer of $\mathrm{Al} 2 \mathrm{O} 3$ nanofluid inside a heated tube," International Communications in Heat and Mass Transfer, vol. 70, pp. 27-37, 2016.

[175] S. M. Vanaki and H. A. Mohammed, "Numerical study of nanofluid forced convection flow in channels using different shaped transverse ribs," International Communications in Heat and Mass Transfer, vol. 67, pp. 176-188, 2015.

[176] F. Selimefendigil, H. F. Öztop, and N. Abu-Hamdeh, "Mixed convection due to rotating cylinder in an internally heated and flexible walled cavity filled with $\mathrm{SiO} 2$-water nanofluids: Effect of nanoparticle shape," International Communications in Heat and Mass Transfer, vol. 71, pp. 9-19, 2016.

[177] Y.-T. Yang, H.-W. Tang, B.-Y. Zeng, and C.-H. Wu, "Numerical simulation and optimization of turbulent nanofluids in a threedimensional rectangular rib-grooved channel," International Communications in Heat and Mass Transfer, vol. 66, pp. 71-79, 2015.

[178] B. Sun, W. Lei, and D. Yang, "Flow and convective heat transfer characteristics of Fe2O3-water nanofluids inside copper tubes," International Communications in Heat and Mass Transfer, vol. 64, pp. 21-28, 2015.

[179] B. H. Salman, H. A. Mohammed, and A. S. Kherbeet, "Numerical and experimental investigation of heat transfer enhancement in a microtube using nanofluids," International Communications in Heat and Mass Transfer, vol. 59, pp. 88-100, 2014. 
[180] X. Meng and Y. Li, "Numerical study of natural convection in a horizontal cylinder filled with water-based alumina nanofluid," Nanoscale Research Letters, vol. 10, no. 1, 2015.

[181] M. Mohammadpourfard, H. Aminfar, and M. Karimi, "Numerical investigation of non-uniform transverse magnetic field effects on the swirling flow boiling of magnetic nanofluid in annuli," International Communications in Heat and Mass Transfer, vol. 75, pp. 240-252, 2016.

[182] U. Akdag, S. Akcay, and D. Demiral, "Heat transfer enhancement with laminar pulsating nanofluid flow in a wavy channel," International Communications in Heat and Mass Transfer, vol. 59, pp. 17-23, 2014.

[183] N. A. Yacob, A. Ishak, I. Pop, and K. Vajravelu, "Boundary layer flow past a stretching/shrinking surface beneath an external uniform shear flow with a convective surface boundary condition in a nanofluid," Nanoscale Research Letters, vol. 6, no. 1, pp. 314-320, 2011.

[184] M. K. Moraveji and R. M. Ardehali, "CFD modeling (comparing single and two-phase approaches) on thermal performance of Al2o3/water nanofluid in mini-channel heat sink," International Communications in Heat and Mass Transfer, vol. 44, pp. 157-164, 2013.

[185] H. Xu, T. Fan, and I. Pop, "Analysis of mixed convection flow of a nanofluid in a vertical channel with the Buongiorno mathematical model," International Communications in Heat and Mass Transfer, vol. 44, pp. 15-22, 2013.

[186] M. Parsazadeh, H. A. Mohammed, and F. Fathinia, "Influence of nanofluid on turbulent forced convective flow in a channel with detached rib-arrays," International Communications in Heat and Mass Transfer, vol. 46, pp. 97-105, 2013.

[187] M. Sheikholeslami, M. Gorji-Bandpay, and D. D. Ganji, "Magnetic field effects on natural convection around a horizontal circular cylinder inside a square enclosure filled with nanofluid," International Communications in Heat and Mass Transfer, vol. 39, no. 7, pp. 978-986, 2012.

[188] A. M. Rashad, M. M. Rashidi, G. Lorenzini, S. E. Ahmed, and A. M. Aly, "Magnetic field and internal heat generation effects on the free convection in a rectangular cavity filled with a porous medium saturated with $\mathrm{Cu}$-water nanofluid," International Journal of Heat and Mass Transfer, vol. 104, pp. 878-889, 2017.

[189] K. Y. Leong, R. Saidur, M. Khairulmaini, Z. Michael, and A. Kamyar, "Heat transfer and entropy analysis of three different types of heat exchangers operated with nanofluids," International Communications in Heat and Mass Transfer, vol. 39, no. 6, pp. 838-843, 2012.

[190] M. Shahi, A. H. Mahmoudi, and F. Talebi, "Numerical simulation of steady natural convection heat transfer in a 3dimensional single-ended tube subjected to a nanofluid," International Communications in Heat and Mass Transfer, vol. 37, no. 10, pp. 1535-1545, 2010.

[191] O. Ghaffari, A. Behzadmehr, and H. Ajam, "Turbulent mixed convection of a nanofluid in a horizontal curved tube using a two-phase approach," International Communications in Heat and Mass Transfer, vol. 37, no. 10, pp. 1551-1558, 2010.

[192] O. Manca, P. Mesolella, S. Nardini, and D. Ricci, "Numerical study of a confined slot impinging jet with nanofluids," Nanoscale Research Letters, vol. 6, no. 1, pp. X1-16, 2011.

[193] M. Rostamani, S. F. Hosseinizadeh, M. Gorji, and J. M. Khodadadi, "Numerical study of turbulent forced convection flow of nanofluids in a long horizontal duct considering variable properties," International Communications in Heat and Mass Transfer, vol. 37, no. 10, pp. 1426-1431, 2010.

[194] E. Büyük Ögüt, "Natural convection of water-based nanofluids in an inclined enclosure with a heat source," International Journal of Thermal Sciences, vol. 48, no. 11, pp. 2063-2073, 2009.

[195] S. Kumar, S. K. Prasad, and J. Banerjee, "Analysis of flow and thermal field in nanofluid using a single phase thermal dispersion model," Applied Mathematical Modelling: Simulation and Computation for Engineering and Environmental Systems, vol. 34, no. 3, pp. 573-592, 2010.

[196] Z. Alloui, J. Guiet, P. Vasseur, and M. Reggio, "Natural convection of nanofluids in a shallow rectangular enclosure heated from the side," The Canadian Journal of Chemical Engineering, vol. 90, no. 1, pp. 69-78, 2012.

[197] I. I. Ryzhkov and A. V. Minakov, "The effect of nanoparticle diffusion and thermophoresis on convective heat transfer of nanofluid in a circular tube," International Journal of Heat and Mass Transfer, vol. 77, pp. 956-969, 2014.

[198] A. A. Minea, "Uncertainties in modeling thermal conductivity of laminar forced convection heat transfer with water alumina nanofluids," International Journal of Heat and Mass Transfer, vol. 68, pp. 78-84, 2014.

[199] O. Sadeghi, H. A. Mohammed, M. Bakhtiari-Nejad, and M. A. Wahid, "Heat transfer and nanofluid flow characteristics through a circular tube fitted with helical tape inserts," International Communications in Heat and Mass Transfer, vol. 71, pp. 234-244, 2016.

[200] S. S. Azimi and M. Kalbasi, "Numerical study of dynamic thermal conductivity of nanofluid in the forced convective heat transfer," Applied Mathematical Modelling: Simulation and Computation for Engineering and Environmental Systems, vol. 38, no. 4, pp. 1373-1384, 2014.

[201] A. V. Inakov, A. S. Lobasov, D. V. Guzei, M. I. Pryazhnikov, and V. Y. Rudyak, "The experimental and theoretical study of laminar forced convection of nanofluids in the round channel," Applied Thermal Engineering, vol. 88, pp. 140-148, 2015.

[202] H. Togun, H. I. Abu-Mulaweh, S. N. Kazi, and A. Badarudin, "Numerical simulation of heat transfer and separation Al2O3/ nanofluid flow in concentric annular pipe," International Communications in Heat and Mass Transfer, vol. 71, pp. 108-117, 2016.

[203] C. Cianfrini, M. Corcione, E. Habib, and A. Quintino, "Buoyancy-induced convection in $\mathrm{Al}_{2} \mathrm{O}_{3}$ /water nanofluids from an enclosed heater," European Journal of Mechanics - B/Fluids, vol. 48, pp. 123-134, 2014.

[204] M. Hemmat Esfe, S. Saedodin, and M. Mahmoodi, "Experimental studies on the convective heat transfer performance and thermophysical properties of $\mathrm{MgO}$-water nanofluid under turbulent flow," Experimental Thermal and Fluid Science, vol. 52, pp. 68-78, 2014.

[205] H. Ghodsinezhad, M. Sharifpur, and J. P. Meyer, "Experimental investigation on cavity flow natural convection of $\mathrm{Al} 2 \mathrm{O} 3$-water nanofluids," International Communications in Heat and Mass Transfer, vol. 76, pp. 316-324, 2016.

[206] W.-C. Chen and W.-T. Cheng, "Numerical simulation on forced convective heat transfer of titanium dioxide/water nanofluid in the cooling stave of blast furnace," International Communications in Heat and Mass Transfer, vol. 71, pp. 208-215, 2016.

[207] H. Maddah, M. Alizadeh, N. Ghasemi, and S. Rafidah Wan Alwi, "Experimental study of $\mathrm{Al}_{2} \mathrm{O}_{3}$ /water nanofluid turbulent heat transfer enhancement in the horizontal double pipes fitted with modified twisted tapes," International Journal of Heat and Mass Transfer, vol. 78, pp. 1042-1054, 2014. 
[208] A. M. Abed, M. A. Alghoul, K. Sopian, H. A. Mohammed, H. S. Majdi, and A. N. Al-Shamani, "Design characteristics of corrugated trapezoidal plate heat exchangers using nanofluids," Chemical Engineering and Processing: Process Intensification, vol. 87, pp. 88-103, 2015.

[209] G. Huminic and A. Huminic, "Heat transfer and entropy generation analyses of nanofluids in helically coiled tube-intube heat exchangers," International Communications in Heat and Mass Transfer, vol. 71, pp. 118-125, 2016.

[210] A. N. Al-Shamani, K. Sopian, H. A. Mohammed, S. Mat, M. H. Ruslan, and A. M. Abed, "Enhancement heat transfer characteristics in the channel with Trapezoidal rib-groove using nanofluids," Case Studies in Thermal Engineering, vol. 5, article no. 61, pp. 48-58, 2015.

[211] A. D. Sommers and K. L. Yerkes, "Experimental investigation into the convective heat transfer and system-level effects of $\mathrm{Al}_{2} \mathrm{O}_{3}$-propanol nanofluid," Journal of Nanoparticle Research, vol. 12, no. 3, pp. 1003-1014, 2010.

[212] C. J. Ho, W. K. Liu, Y. S. Chang, and C. C. Lin, "Natural convection heat transfer of alumina-water nanofluid in vertical square enclosures: an experimental study," International Journal of Thermal Sciences, vol. 49, no. 8, pp. 1345-1353, 2010.

[213] D. K. Devendiran and V. A. Amirtham, "A review on preparation, characterization, properties and applications of nanofluids," Renewable \& Sustainable Energy Reviews, vol. 60, pp. 21-40, 2016.

[214] M. Sharifpur, S. Yousefi, and J. P. Meyer, "A new model for density of nanofluids including nanolayer," International Communications in Heat and Mass Transfer, vol. 78, pp. 168-174, 2016.

[215] Y. Xuan and W. Roetzel, "Conceptions for heat transfer correlation of nanofluids," International Journal of Heat and Mass Transfer, vol. 43, no. 19, pp. 3701-3707, 2000.

[216] S.-Q. Zhou and R. Ni, "Measurement of the specific heat capacity of water-based $\mathrm{Al}_{2} \mathrm{O}_{3}$ nanofluid," Applied Physics Letters, vol. 92, no. 9, Article ID 093123, 2008.

[217] T. P. Teng and Y. H. Hung, "Estimation and experimental study of the density and specific heat for alumina nanofluid," Journal of Experimental Nanoscience, vol. 9, no. 7, pp. 707-718, 2014.

[218] D. P. Kulkarni, R. S. Vajjha, D. K. Das, and D. Oliva, "Application of aluminum oxide nanofluids in diesel electric generator as jacket water coolant," Applied Thermal Engineering, vol. 28, no. 14-15, pp. 1774-1781, 2008.

[219] Y. R. Sekhar and K. V. Sharma, "Study of viscosity and specific heat capacity characteristics of water-based $\mathrm{Al} 2 \mathrm{O} 3$ nanofluids at low particle concentrations," Journal of Experimental Nanoscience, vol. 10, no. 2, pp. 86-102, 2015.

[220] M. Ghazvini, M. A. Akhavan-Behabadi, E. Rasouli, and M. Raisee, "Heat transfer properties of nanodiamond-engine oil nanofluid in laminar flow," Heat Transfer Engineering, vol. 33, no. 6, pp. 525-532, 2012.

[221] R. S. Vajjha and D. K. Das, "A review and analysis on influence of temperature and concentration of nanofluids on thermophysical properties, heat transfer and pumping power," International Journal of Heat and Mass Transfer, vol. 55, no. 15-16, pp. 40634078, 2012.

[222] L.-P. Zhou, B.-X. Wang, X.-F. Peng, X.-Z. Du, and Y.-P. Yang, "On the specific heat capacity of $\mathrm{CuO}$ nanofluid," Advances in Mechanical Engineering, vol. 2, Article ID 172085, 2010.

[223] D. Shin and D. Banerjee, "Enhancement of specific heat capacity of high-temperature silica-nanofluids synthesized in alkali chloride salt eutectics for solar thermal-energy storage applications," International Journal of Heat and Mass Transfer, vol. 54, no. 5-6, pp. 1064-1070, 2011.

[224] D. Shin and D. Banerjee, "Specific heat of nanofluids synthesized by dispersing alumina nanoparticles in alkali salt eutectic," International Journal of Heat and Mass Transfer, vol. 74, pp. 210214, 2014.

[225] M. Fakoor Pakdaman, M. A. Akhavan-Behabadi, and P. Razi, "An experimental investigation on thermo-physical properties and overall performance of MWCNT/heat transfer oil nanofluid flow inside vertical helically coiled tubes," Experimental Thermal and Fluid Science, vol. 40, pp. 103-111, 2012.

[226] S. Volz, J. Ordonez-Miranda, A. Shchepetov et al., "Nanophononics: State of the art and perspectives," The European Physical Journal B, vol. 89, no. 1, article no. 15, 2016.

[227] H. Han, L. Feng, S. Xiong et al., "Effects of phonon interference through long range interatomic bonds on thermal interface conductance," Low Temperature Physics, vol. 42, no. 8, pp. 711716, 2016

[228] P. Keblinski, S. R. Phillpot, S. U. S. Choi, and J. A. Eastman, "Mechanisms of heat flow in suspensions of nano-sized particles (nanofluids)," International Journal of Heat and Mass Transfer, vol. 45 , no. 4 , pp. 855-863, 2001.

[229] J. Koo and C. Kleinstreuer, "Impact analysis of nanoparticle motion mechanisms on the thermal conductivity of nanofluids," International Communications in Heat and Mass Transfer, vol. 32, no. 9, pp. 1111-1118, 2005.

[230] J. Buongiorno, "Convective transport in nanofluids," Journal of Heat Transfer, vol. 128, no. 3, pp. 240-250, 2006.

[231] C.-W. Nan, R. Birringer, D. R. Clarke, and H. Gleiter, "Effective thermal conductivity of particulate composites with interfacial thermal resistance," Journal of Applied Physics, vol. 81, no. 10, pp. 6692-6699, 1997.

[232] D. A. G. Bruggeman, "Dielectric constant and conductivity of mixtures of isotropic materials," Annalen der Physik, vol. 24, pp. 636-679, 1935.

[233] D. H. Kumar, H. E. Patel, V. R. R. Kumar, T. Sundararajan, T. Pradeep, and S. K. Das, "Model for heat conduction in nanofluids," Physical Review Letters, vol. 93, no. 14, pp. 1-144301, 2004.

[234] K. C. Leong, C. Yang, and S. M. S. Murshed, "A model for the thermal conductivity of nanofluids - The effect of interfacial layer," Journal of Nanoparticle Research, vol. 8, no. 2, pp. 245254, 2006.

[235] H. Xie, M. Fujii, and X. Zhang, "Effect of interfacial nanolayer on the effective thermal conductivity of nanoparticle-fluid mixture," International Journal of Heat and Mass Transfer, vol. 48, no. 14, pp. 2926-2932, 2005.

[236] E. Yamada and T. Ota, "Effective thermal conductivity of dispersed materials," Wärme- und Stoffübertragung, vol. 13, no. 1-2, pp. 27-37, 1980.

[237] D. P. H. Hasselman and L. F. Johnson, "Effective thermal conductivity of composites with interfacial thermal barrier resistance," Journal of Composite Materials, vol. 21, no. 6, pp. 508-515, 1987.

[238] B.-X. Wang, L.-P. Zhou, and X.-F. Peng, "A fractal model for predicting the effective thermal conductivity of liquid with suspension of nanoparticles," International Journal of Heat and Mass Transfer, vol. 46, no. 14, pp. 2665-2672, 2003.

[239] R. H. Davis, "The effective thermal conductivity of a composite material with spherical inclusions," International Journal of Thermophysics, vol. 7, no. 3, pp. 609-620, 1986. 
[240] J. Xu, B. Yu, M. Zou, and P. Xu, "A new model for heat conduction of nanofluids based on fractal distributions of nanoparticles," Journal of Physics D: Applied Physics, vol. 39, no. 20, article no. 028, pp. 4486-4490, 2006.

[241] W. Evans, J. Fish, and P. Keblinski, "Role of Brownian motion hydrodynamics on nanofluid thermal conductivity," Applied Physics Letters, vol. 88, no. 9, Article ID 093116, 2006.

[242] M. Vladkov and J.-L. Barrat, "Modeling transient absorption and thermal conductivity in a simple nanofluid," Nano Letters, vol. 6, no. 6, pp. 1224-1229, 2006.

[243] P. D. Shima, J. Philip, and B. Raj, "Role of microconvection induced by Brownian motion of nanoparticles in the enhanced thermal conductivity of stable nanofluids," Applied Physics Letters, vol. 94, no. 22, Article ID 223101, 2009.

[244] S. M. S. Murshed, K. C. Leong, and C. Yang, "A combined model for the effective thermal conductivity of nanofluids," Applied Thermal Engineering, vol. 29, no. 11-12, pp. 2477-2483, 2009.

[245] C. H. Chon, K. D. Kihm, S. P. Lee, and S. U. S. Choi, "Empirical correlation finding the role of temperature and particle size for nanofluid $\left(\mathrm{Al}_{2} \mathrm{O}_{3}\right)$ thermal conductivity enhancement," Applied Physics Letters, vol. 87, Article ID 153107, pp. 1-3, 2005.

[246] H. E. Patel, T. Sundararajan, T. Pradeep, A. Dasgupta, N. Dasgupta, and S. K. Das, "A micro-convection model for thermal conductivity of nanofluids," Pramana-Journal of Physics, vol. 65, no. 5, pp. 863-869, 2005.

[247] S. E. B. Maïga, C. T. Nguyen, N. Galanis, and G. Roy, "Heat transfer behaviours of nanofluids in a uniformly heated tube," Superlattices and Microstructures, vol. 35, no. 3-6, pp. 543-557, 2004.

[248] E. V. Timofeeva, A. N. Gavrilov, J. M. McCloskey et al., “Thermal conductivity and particle agglomeration in alumina nanofluids: Experiment and theory," Physical Review E: Statistical, Nonlinear, and Soft Matter Physics, vol. 76, no. 6, Article ID 061203, 2007.

[249] W. H. Azmi, K. V. Sharma, R. Mamat, A. B. S. Alias, and I. Izwan Misnon, "Correlations for thermal conductivity and viscosity of water based nanofluids," IOP Conference Series: Materials Science and Engineering, vol. 36, no. 1, 2012.

[250] C. H. Li and G. P. Peterson, "Experimental investigation of temperature and volume fraction variations on the effective thermal conductivity of nanoparticle suspensions (nanofluids)," Journal of Applied Physics, vol. 99, no. 8, Article ID 084314, 2006.

[251] M. Corcione, "Empirical correlating equations for predicting the effective thermal conductivity and dynamic viscosity of nanofluids," Energy Conversion and Management, vol. 52, no. 1, pp. 789-793, 2011.

[252] H. Xie, J. Wang, T. Xi, and Y. Liu, "Thermal conductivity of suspensions containing nanosized $\mathrm{SiC}$ particles," International Journal of Thermophysics, vol. 23, no. 2, pp. 571-580, 2002.

[253] M. J. Assael, I. N. Metaxa, J. Arvanitidis, D. Christofilos, and C. Lioutas, "Thermal conductivity enhancement in aqueous suspensions of carbon multi-walled and double-walled nanotubes in the presence of two different dispersants," International Journal of Thermophysics, vol. 26, no. 3, pp. 647-664, 2005.

[254] T.-P. Teng, Y.-H. Hung, T.-C. Teng, H.-E. Mo, and H.-G. Hsu, "The effect of alumina/water nanofluid particle size on thermal conductivity," Applied Thermal Engineering, vol. 30, no. 14-15, pp. 2213-2218, 2010.

[255] T. Y. Choi, M. H. Maneshian, B. Kang, W. S. Chang, C. S. Han, and D. Poulikakos, "Measurement of the thermal conductivity of a water-based single-wall carbon nanotube colloidal suspension with a modified 3- $\omega$ method," Nanotechnology, vol. 20, no. 31, Article ID 315706, 2009.

[256] G. Paul, M. Chopkar, I. Manna, and P. K. Das, "Techniques for measuring the thermal conductivity of nanofluids: a review," Renewable \& Sustainable Energy Reviews, vol. 14, no. 7, pp. 19131924, 2010.

[257] W. Czarnetzki and W. Roetzel, “Temperature oscillation techniques for simultaneous measurement of thermal diffusivity and conductivity," International Journal of Thermophysics, vol. 16, no. 2, pp. 413-422, 1995.

[258] W. Jiang, G. Ding, and H. Peng, "Measurement and model on thermal conductivities of carbon nanotube nanorefrigerants," International Journal of Thermal Sciences, vol. 48, no. 6, pp. 1108-1115, 2009.

[259] S. M. S. Murshed, K. C. Leong, and C. Yang, "Thermal conductivity of nanoparticle suspensions (nanofluids)," in Proceedings of the 2006 IEEE Conference on Emerging Technologies - Nanoelectronics, pp. 155-158, Singapore, Singapore, January 2006.

[260] Y. S. Ju, J. Kim, and M.-T. Hung, "Experimental study of heat conduction in aqueous suspensions of aluminum oxide nanoparticles," Journal of Heat Transfer, vol. 130, no. 9, Article ID 092403, 2008.

[261] R. J. Warzoha and A. S. Fleischer, "Determining the thermal conductivity of liquids using the transient hot disk method. Part I: Establishing transient thermal-fluid constraints," International Journal of Heat and Mass Transfer, vol. 71, pp. 779-789, 2014.

[262] F. Agresti, S. Barison, S. Battiston et al., "Influence of molecular weight of PVP on aggregation and thermal diffusivity of silverbased nanofluids," in Nanotechnology 2013: Electronics, Devices, Fabrication, MEMS, Fluidics and Computational - 2013 NSTI Nanotechnology Conference and Expo, NSTI-Nanotech 2013, pp. 366-369, 2013.

[263] F. Agresti, A. Ferrario, S. Boldrini et al., "Temperature controlled photoacoustic device for thermal diffusivity measurements of liquids and nanofluids," Thermochimica Acta, vol. 619, pp. 48-52, 2015.

[264] N. G. C. Astrath, A. N. Medina, A. C. Bento et al., "Time resolved thermal lens measurements of the thermo-optical properties of $\mathrm{Nd} 2 \mathrm{O} 3$-doped low silica calcium aluminosilicate glasses down to $4.3 \mathrm{~K}$,' Journal of Non-Crystalline Solids, vol. 354, no. 2-9, pp. 574-579, 2008.

[265] J. L. Jiménez Pérez, R. Gutierrez Fuentes, J. F. Sanchez Ramirez, and A. Cruz-Orea, "Study of gold nanoparticles effect on thermal diffusivity of nanofluids based on various solvents by using thermal lens spectroscopy," The European Physical Journal Special Topics, vol. 153, no. 1, pp. 159-161, 2008.

[266] L. G. Rodriguez, P. Iza, and J. L. Paz, "Study of dependence between thermal diffusivity and sample concentration measured by means of frequency-resolved thermal lens experiment," Journal of Nonlinear Optical Physics Materials, vol. 25, no. 02, Article ID 1650022, 2016.

[267] S. A. Joseph, M. Hari, S. Mathew et al., "Thermal diffusivity of rhodamine $6 \mathrm{G}$ incorporated in silver nanofluid measured using mode-matched thermal lens technique," Optics Communications, vol. 283, no. 2, pp. 313-317, 2010.

[268] M. L. Baesso, J. R. D. Pereira, A. C. Bento, A. J. Palangana, A. M. Mansanares, and L. R. Evangelista, "Thermal lens spectrometry to study complex fluids," Brazilian Journal of Physics, vol. 28, no. 4, pp. 359-368, 1998. 
[269] S. M. S. Murshed, K. C. Leong, and C. Yang, "Determination of the effective thermal diffusivity of nanofluids by the double hot-wire technique," Journal of Physics D: Applied Physics, vol. 39, no. 24, pp. 5316-5322, 2006.

[270] X. Zhang, H. Gu, and M. Fujii, "Effective thermal conductivity and thermal diffusivity of nanofluids containing spherical and cylindrical nanoparticles," Experimental Thermal and Fluid Science, vol. 31, no. 6, pp. 593-599, 2007.

[271] A. Einstein, Investigation on the Theory of the Brownian Movement, Dover, New York, NY, USA, 1956.

[272] A. Einstein, "Eine neue Bestimmung der Moleküldimensionen," Annalen der Physik, vol. 324, no. 2, pp. 289-306, 1906.

[273] V. Y. Rudyak and A. V. Minakov, "Thermophysical properties of nanofluids," The European Physical Journal E, vol. 41, no. 1, 2018.

[274] S. U. Ilyas, R. Pendyala, A. S. Shuib, and N. Marneni, "A review on the viscous and thermal transport properties of nanofluids," Advanced Materials Research, vol. 917, pp. 18-27, 2014.

[275] A. Hemmati-Sarapardeh, A. Varamesh, M. M. Husein, and K. Karan, "On the evaluation of the viscosity of nanofluid systems: Modeling and data assessment," Renewable \& Sustainable Energy Reviews, vol. 81, pp. 313-329, 2018.

[276] V. Y. Rudyak, A. A. Belkin, and V. V. Egorov, "On the effective viscosity of nanosuspensions," Technical Physics, vol. 54, no. 8, pp. 1102-1109, 2009.

[277] P. K. Namburu, D. P. Kulkarni, A. Dandekar, and D. K. Das, "Experimental investigation of viscosity and specific heat of silicon dioxide nanofluids," IET Micro \& Nano Letters, vol. 2, no. 3, pp. 67-71, 2007.

[278] L. L. Vasiliev, L. P. Grakovich, M. I. Rabetskii, and Vasiliev Jr., "Heat transfer enhancement in heat pipes and thermosyphons using nanotechnologies (nanofluids, nanocoatings, and nanocomposites) as an hp envelope," Heat Pipe Science and Technology, An International Journal, vol. 4, no. 4, pp. 251-275, 2013. 


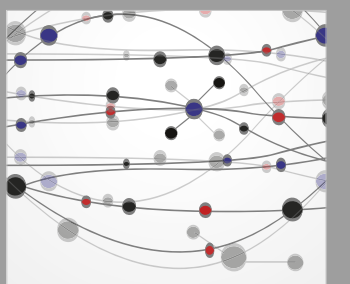

The Scientific World Journal
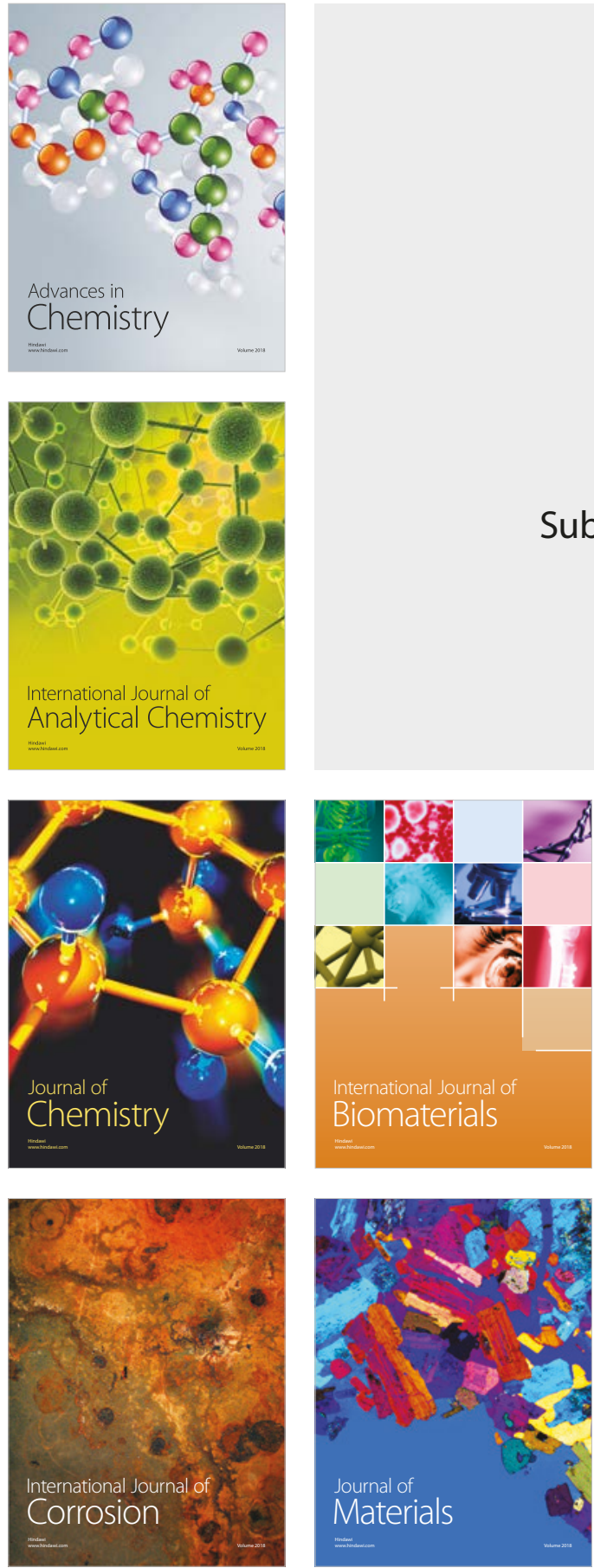

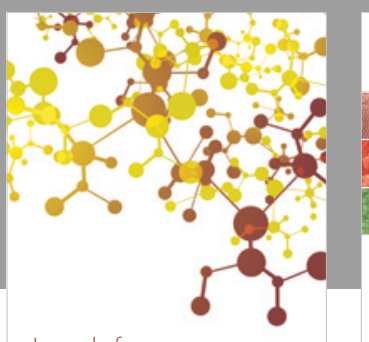

Journal of

Applied Chemistry
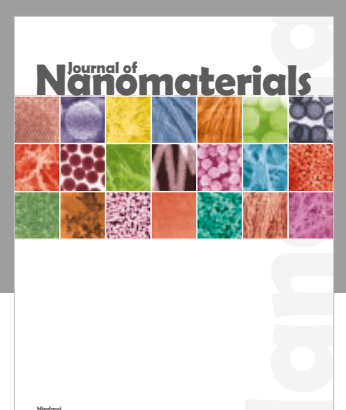

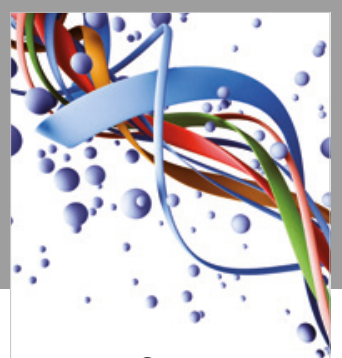

Scientifica

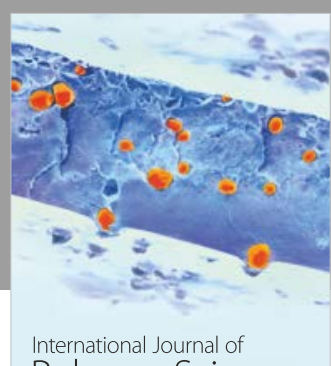

Polymer Science

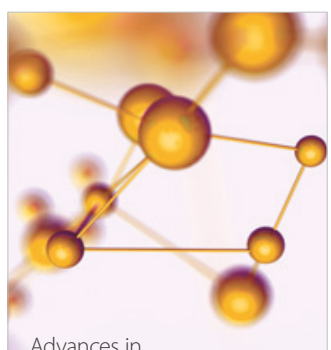

Physical Chemistry
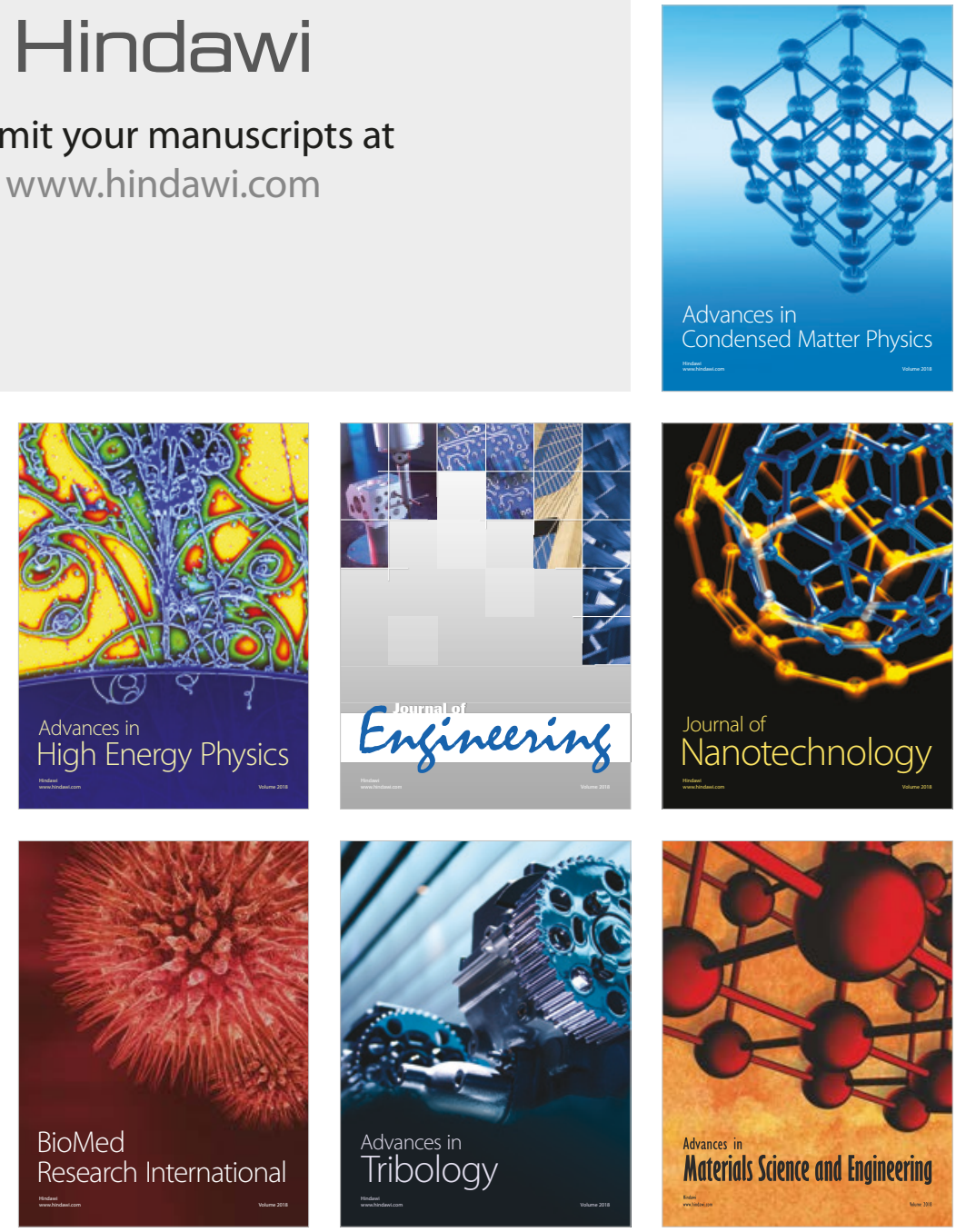